San Jose State University

SJSU ScholarWorks

Mineta Transportation Institute Publications

2-2021

\title{
Do Equity and Accountability Get Lost in LOSTs? An Analysis of Local Return Funding Provisions in California's Local Option Sales Tax Measures for Transportation
}

\author{
Jaimee Lederman \\ University of California, Los Angeles \\ Peter Haas \\ San Jose State University \\ Stephanie Kellogg \\ University of California, Los Angeles \\ Martin Wachs \\ University of California, Los Angeles \\ Asha Weinstein Agrawal \\ San Jose State University, asha.weinstein.agrawal@sjsu.edu
}

Follow this and additional works at: https://scholarworks.sjsu.edu/mti_publications

Part of the Taxation Commons, and the Transportation Commons

\begin{abstract}
Recommended Citation
Jaimee Lederman, Peter Haas, Stephanie Kellogg, Martin Wachs, and Asha Weinstein Agrawal. "Do Equity and Accountability Get Lost in LOSTs? An Analysis of Local Return Funding Provisions in California's Local Option Sales Tax Measures for Transportation" Mineta Transportation Institute Publications (2021). https://doi.org/10.31979/mti.2021.1811
\end{abstract}

This Report is brought to you for free and open access by SJSU ScholarWorks. It has been accepted for inclusion in Mineta Transportation Institute Publications by an authorized administrator of SJSU ScholarWorks. For more information, please contact scholarworks@sjsu.edu. 


\section{SJSU}

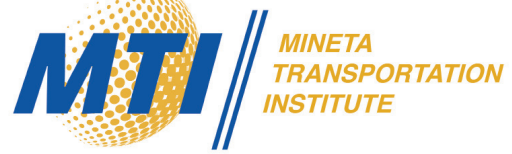

Do Equity and Accountability Get Lost in LOSTs?

An Analysis of Local Return Funding Provisions in California's Local Option Sales Tax Measures for Transportation

Jaimee Lederman, $\mathrm{PhD}$

Stephanie Kellogg, MURP

Peter Haas, $\mathrm{PhD}$

Martin Wachs, $\mathrm{PhD}$

Asha Weinstein Agrawal, PhD

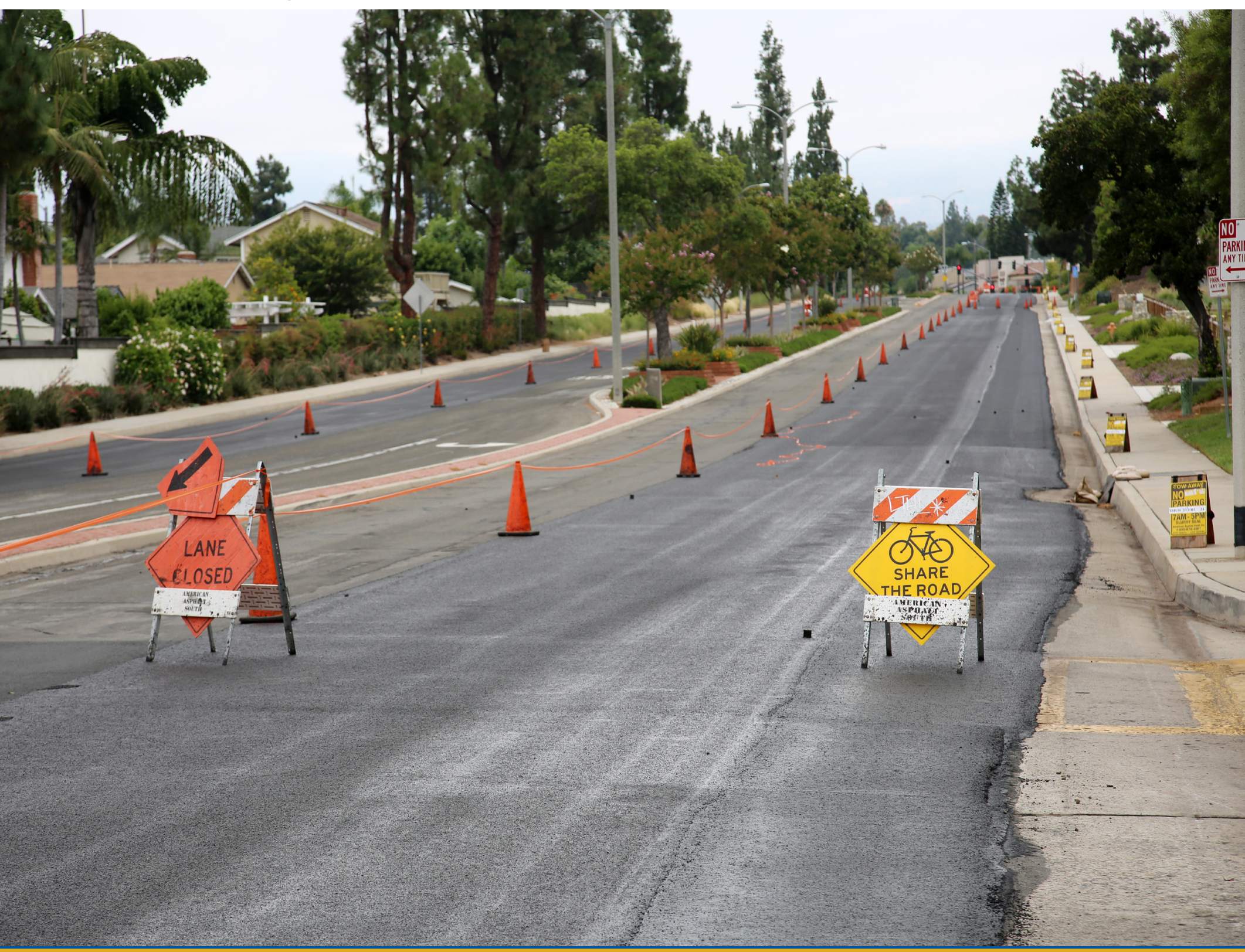




\section{Mineta Transportation Institute}

Founded in 1991, the Mineta Transportation Institute (MTI), an organized research and training unit in partnership with the Lucas College and Graduate School of Business at San José State University (SJSU), increases mobility for all by improving the safety, efficiency, accessibility, and convenience of our nation's transportation system. Through research, education, workforce development, and technology transfer, we help create a connected world. MTI leads the Mineta Consortium for Transportation Mobility (MCTM) funded by the U.S. Department of Transportation and the California State University Transportation Consortium (CSUTC) funded by the State of California through Senate Bill 1. MTI focuses on three primary responsibilities:

\section{Research}

MTI conducts multi-disciplinary research focused on surface transportation that contributes to effective decision making. Research areas include: active transportation; planning and policy; security and counterterrorism; sustainable transportation and land use; transit and passenger rail; transportation engineering; transportation finance; transportation technology; and workforce and labor. MTI research publications undergo expert peer review to ensure the quality of the research.

\section{Education and Workforce}

To ensure the efficient movement of people and products, we must prepare a new cohort of transportation professionals who are ready to lead a more diverse, inclusive, and equitable transportation industry. To help achieve this, MTI sponsors a suite of workforce development and education opportunities. The Institute supports educational programs offered by the Lucas Graduate School of Business: a Master of
Science in Transportation Management, plus graduate certificates that include High-Speed and Intercity Rail Management and Transportation Security Management. These flexible programs offer live online classes so that working transportation professionals can pursue an advanced degree regardless of their location.

\section{Information and Technology Transfer}

MTI utilizes a diverse array of dissemination methods and media to ensure research results reach those responsible for managing change. These methods include publication, seminars, workshops, websites, social media, webinars, and other technology transfer mechanisms. Additionally, MTI promotes the availability of completed research to professional organizations and works to integrate the research findings into the graduate education program. MTI's extensive collection of transportation-related publications is integrated into San José State University's world-class Martin Luther King, Jr. Library.

\section{Disclaimer}

The contents of this report reflect the views of the authors, who are responsible for the facts and accuracy of the information presented herein. This document is disseminated in the interest of information exchange. MTI's research is funded, partially or entirely, by grants from the California Department of Transportation, the California State University Office of the Chancellor, the U.S. Department of Homeland Security, and the U.S. Department of Transportation, who assume no liability for the contents or use thereof. This report does not constitute a standard specification, design standard, or regulation. 
Report 20-36

\title{
Do Equity and Accountability Get Lost in LOSTs?
}

\section{An Analysis of Local Return Funding Provisions in California's Local Option Sales Tax Measures for Transportation}

\author{
Jaimee Lederman \\ Stephanie Kellogg \\ Peter Haas \\ Martin Wachs \\ Asha Weinstein Agrawal
}

February 2021

\author{
A publication of the \\ Mineta Transportation Institute \\ Created by Congress in 1991 \\ College of Business \\ San José State University \\ San José, CA 95192-0219
}




\section{TECHNICAL REPORT DOCUMENTATION PAGE}

\begin{tabular}{|c|c|c|c|}
\hline & 2. Government Accession No. & \multicolumn{2}{|c|}{ 3. Recipient's Catalog No. } \\
\hline \multicolumn{2}{|l|}{ 4. Title and Subtitle } & \multicolumn{2}{|l|}{ 5. Report Date } \\
\hline \multirow{2}{*}{\multicolumn{2}{|c|}{$\begin{array}{l}\text { Do Equity and Accountability Get Lost in LOSTs? An Analysis of Local } \\
\text { Return Funding Provisions in California's Local Option Sales Tax Measures for } \\
\text { Transportation }\end{array}$}} & \multicolumn{2}{|c|}{ February 2021} \\
\hline & & \multicolumn{2}{|c|}{ 6. Performing Organization Code } \\
\hline \multicolumn{2}{|c|}{$\begin{array}{l}\text { 7. Authors } \\
\text { Jaimee Lederman: 0000-0002-7335-4294 } \\
\text { Peter Haas: 0000-0001-9429-0608 } \\
\text { Stephanie Kellogg: 0000-0003-0365-8425 } \\
\text { Martin Wachs: 0000-0002-6739-1654 } \\
\text { Asha Weinstein Agrawal: 0000-0003-2328-0263 }\end{array}$} & \multicolumn{2}{|c|}{$\begin{array}{l}\text { 8. Performing Organization } \\
\text { Report } \\
\quad \text { CA-MTI-1811 }\end{array}$} \\
\hline \multicolumn{2}{|c|}{ 9. Performing Organization Name and Address } & \multicolumn{2}{|c|}{ 10. Work Unit No. } \\
\hline \multirow{2}{*}{\multicolumn{2}{|c|}{$\begin{array}{l}\text { Mineta Transportation Institute } \\
\text { College of Business } \\
\text { San José State University } \\
\text { San José, CA 95192-0219 }\end{array}$}} & & \\
\hline & & \multicolumn{2}{|c|}{$\begin{array}{l}\text { 11. Contract or Grant No. } \\
\text { 69A } 3551747127\end{array}$} \\
\hline \multirow{2}{*}{\multicolumn{2}{|c|}{$\begin{array}{l}\text { 12. Sponsoring Agency Name and Address } \\
\text { U.S. Department of Transportation } \\
\text { Office of the Assistant Secretary for Research and Technology } \\
\text { University Transportation Centers Program } \\
1200 \text { New Jersey Avenue, SE } \\
\text { Washington, DC } 20590\end{array}$}} & \multicolumn{2}{|c|}{$\begin{array}{l}\text { 13. Type of Report and Period } \\
\text { Covered }\end{array}$} \\
\hline & & \multicolumn{2}{|c|}{ 14. Sponsoring Agency Code } \\
\hline \multicolumn{4}{|l|}{ 15. Supplemental Notes } \\
\hline \multicolumn{4}{|l|}{ 16. Abstract } \\
\hline \multicolumn{4}{|c|}{$\begin{array}{l}\text { This study explores how local return provisions of local option sales taxes (LOSTs) for transportation are allocated } \\
\text { and spent to meet local and regional transportation needs. Local return refers to the component of county LOST } \\
\text { measures that provides funding directly to municipalities in the county to be used to meet local needs. Local return } \\
\text { has become a fixture in LOSTs; } 58 \text { LOST measures placed on the ballot in California (as of 2019) that have included } \\
\text { local return in their expenditure plan have an average of } 35 \% \text { of revenues dedicated to local return. Local return } \\
\text { provisions in the ballot measures often contain guidelines on how a portion of the money should be spent. The } \\
\text { allocation of local return funds to localities has rarely been discussed in research, and spending decisions have to our } \\
\text { knowledge never been analyzed. This paper conducts a mixed-methods analysis of all LOSTs with local return, } \\
\text { relying on ordinances and other public documents related to local return expenditures, and supplemented with } \\
\text { interviews with officials in six counties. Findings indicate that local return provisions are crafted to balance the needs } \\
\text { of the county across different dimensions, including trying to achieve equity between urban and rural residents, } \\
\text { investment in different transportation modes, and meeting both local and regional policy needs. Moreover, } \\
\text { significant accountability mechanisms provide regulations to ensure that funds are distributed to and spent by } \\
\text { jurisdictions as promised by the measures. Overall, this research finds that local return is a vital part of LOST } \\
\text { measures in California, allowing cities to meet local needs ranging from maintenance of local streets to funding for } \\
\text { special programs, while simultaneously aligning local investment with regional priorities. }\end{array}$} \\
\hline 17. Key Words & \multicolumn{3}{|c|}{ 18. Distribution Statement } \\
\hline $\begin{array}{l}\text { Transportation, finance, local } \\
\text { government, sales tax, local return }\end{array}$ & \multicolumn{3}{|c|}{$\begin{array}{l}\text { No restrictions. This document is available to the public through } \\
\text { The National Technical Information Service, Springfield, VA } 22161 .\end{array}$} \\
\hline 19. Security Classif. (of this report) & 20. Security Classif. (of this page) & 21. No. of Pages & 22. Price \\
\hline Unclassified & Unclassified & 117 & \\
\hline
\end{tabular}


Copyright (C) 2021

\title{
by Mineta Transportation Institute
}

All rights reserved.

DOI: $10.31979 / \mathrm{mti} .2021 .1811$

\author{
Mineta Transportation Institute \\ College of Business \\ San José State University \\ San José, CA 95192-0219 \\ Tel: (408) 924-7560 \\ Email: mineta-institute@sjsu.edu
}

$\underline{\text { transweb.sjsu.edu/research/1811 }}$ 


\section{CONTENTS}

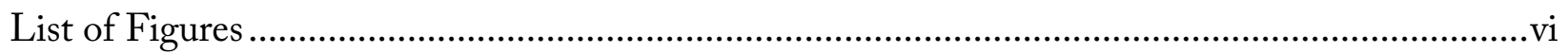

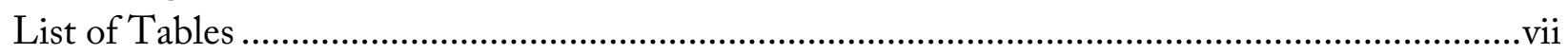

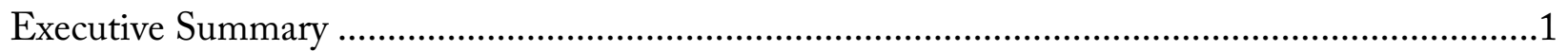

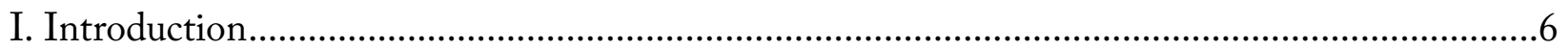

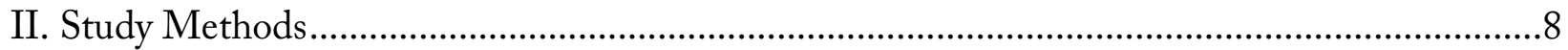

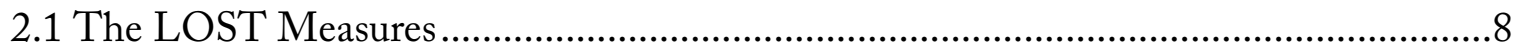

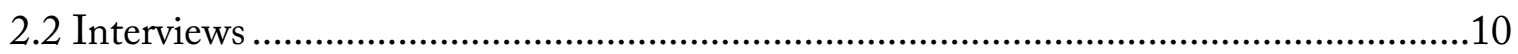

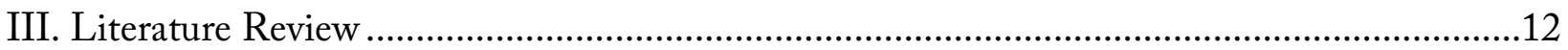

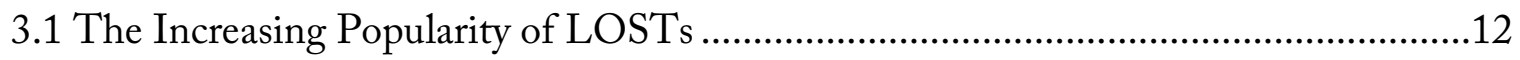

3.2 Passing LOST Measures …………………………...........................................13

3.3 Literature on Accountability ...............................................................................14

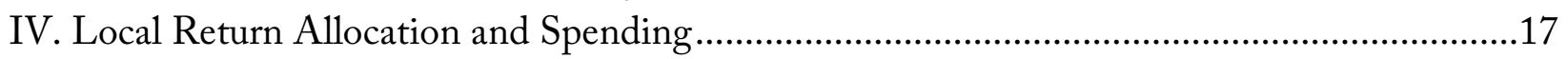

4.1 Rates of Local Return ........................................................................................17

4.2 Amount of Measure Revenues Dedicated to Local Return Funding..........................19

4.3 How Local Return Funding is Allocated among Municipalities ...............................20

4.4 Eligibility to Receive Local Return Funds.................................................................29

4.5 Requirements Placed on How Jurisdictions Spend Local Return Funding .................36

4.6 How Local Return Restrictions and Requirements Encourage Cities to Meet Complete Streets Goals .....................................................................................46

V. Accountability and Transparency in Local Return Programs ...............................................49

5.1 Maintenance of Effort ……………......................................................................49

5.2 Accountability Mechanisms and Reporting Requirements ..........................................51

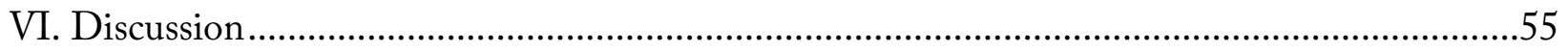

6.1 Local Return is Crucial Part of Measure Expenditure Plans .....................................55

6.2 Local Return Programs are Tailored to Meet Diverse Local Needs .............................56

6.3 Conditions on Local Return Funding can be Used to Meet Regional

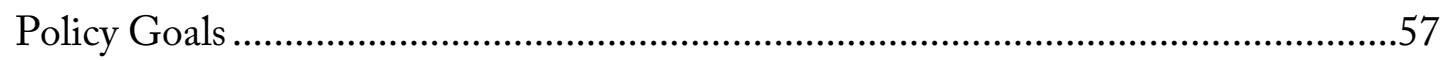

6.4 Local Return is a Tool to Address Equity Issues.......................................................58

6.5 Local Return Programs Have Successful Accountability Provisions.............................59

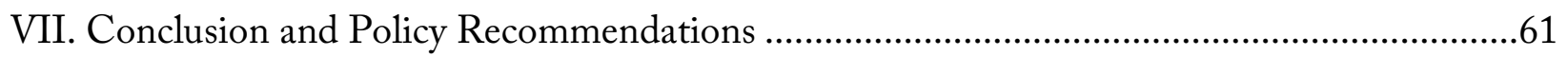

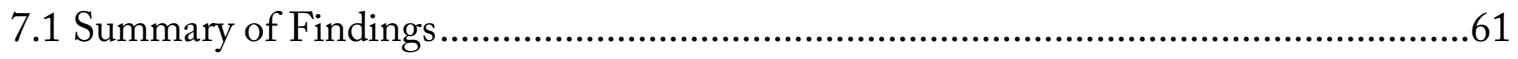

7.2 Policy Implications ...............................................................................................61

7.3 Study Limitations and Recommendations for Future Research....................................62

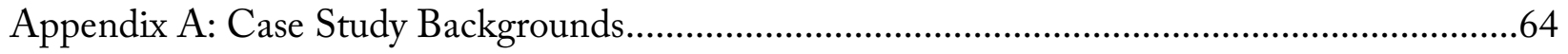

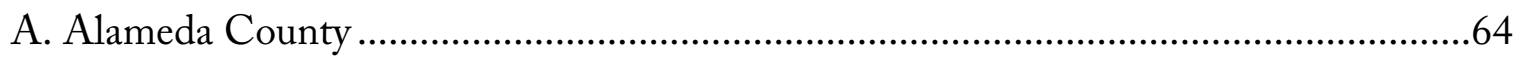

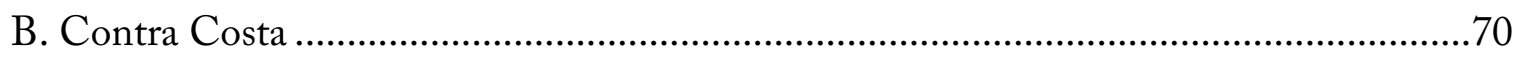

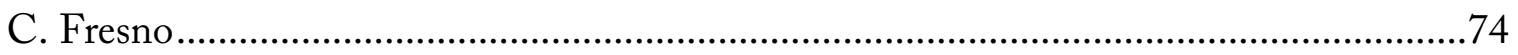

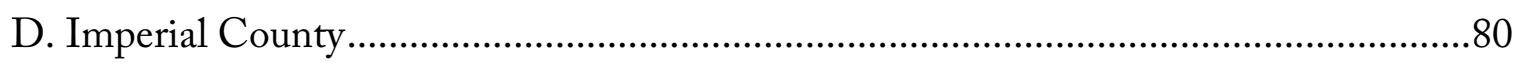

Mineta Transportation Institute iv 


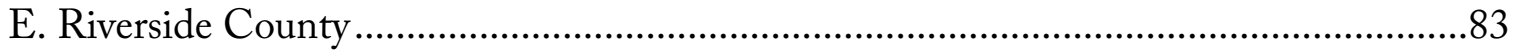

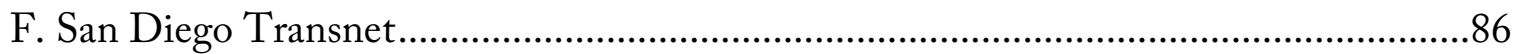

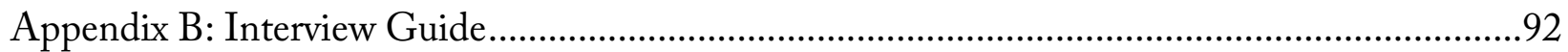

Appendix C: Measure Language Conditioning Local Return on Enacting Development

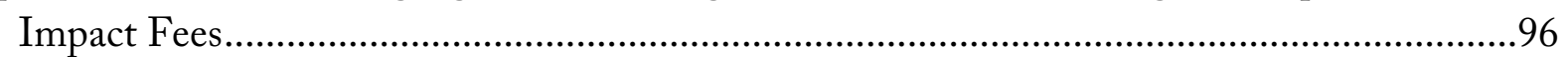

Appendix D: Text of Measures with Reporting Requirements ...................................................99

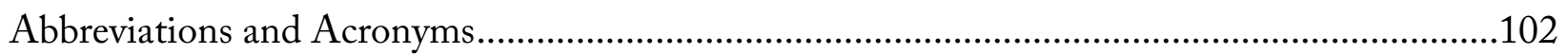

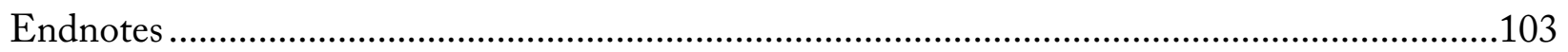

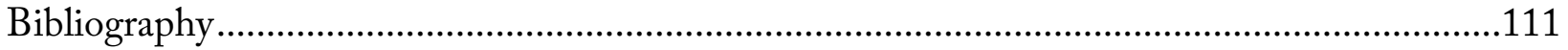

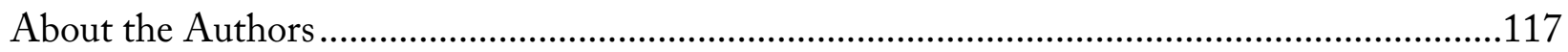




\section{LIST OF FIGURES}

Figure 1. Categorical Spending Requirements by Percentage of Local Return...............................

Figure 2. Percentage Point Difference between Percentages of Total and

Stated Local Return of Total Measure Funding ................................................................18

Figure 3. Percentage of LOST Revenues Dedicated to Local Return..........................................19

Figure 4. Average Local Return of All LOST Measures with Local Return by Year ...................20

Figure 5. Number of LOST Measures that Update Local Return Allocation at Different

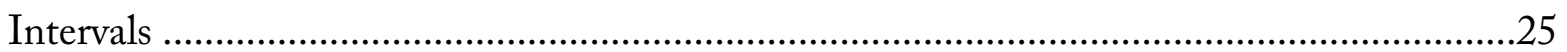

Figure 6. Comparison of RUCC Score and Percentage of Measure Dedicated to

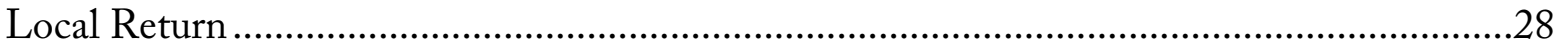

Figure 7. Categorical Spending Requirements by Percentage of Local Return.............................37

Figure 8. Percentage of Local Return Spending That is Flexible Compared to Total

Percentage of Measure Dedicated to Local Return .............................................................42

Figure 9. Funding Dedicated to Repair and Maintenance of Local Streets and Roads by

Local Return as a Percentage of Total Measure Expenditures

Figure 10. Funding Dedicated to Repair and Maintenance of Local Streets and Roads by

Local Return as a Percentage of Total Measure Expenditures

(Without Napa County, 2012).

Figure 11. Frequency of Complete Streets Requirements by Year

Figure 12. Jurisdictional Control of Maintained Roads for Counties with Complete

Streets Policies .48

Figure 13. Alameda County Regions and Transportation Projects (2016).................................64

Figure 14. Map of Contra Costa County, Including Transportation Subregions .........................70

Figure 15. Fresno County Transportation Network ................................................................75

Figure 16. Subregional Distribution of Local Return Funding in Riverside County .84 


\section{LIST OF TABLES}

Table 1. The Use of Population and Road Miles in Local Return Allocation Formulas ................2

Table 2. LOST Measures Studied (County, Measure Letter, and Date Passed) ...........................9

Table 3. The Use of Population and Road Miles in Local Return Allocation Formulas ..............22

Table 4. Number of Measures Using Different Definitions of Road Miles ..................................23

Table 5. Rural-Urban Continuum Code Definitions...............................................................27

Table 6. Inclusion of Road Miles as an Allocation Variable by RUCC Score................................29

Table 7. Measure or Expenditure Plan Text Describing Requirements Involving

Growth Management Plans or Nonmeasure Fund Contributions ............................................34

Table 8. Local Return (LR) Spending Requirements and Measure Characteristics

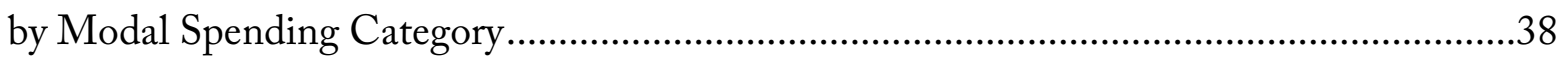

Table 9. Descriptions of Differing Modal Spending Restrictions ...............................................

Table 10. LOST Measure Text of Provisions Tying Funding Use to PCI .....................................43

Table 11. Projects Leveraged by LOST Funds in Alameda County .............................................56

Table 12. Largest Cities in Alameda County ........................................................................65

Table 13. Largest Cities in Contra Costa County …………....................................................

Table 14. Largest Cities in Fresno County ............................................................................75

Table 15. Largest Cities in Imperial County ...........................................................................81

Table 16. Largest Cities in Riverside County ...........................................................................

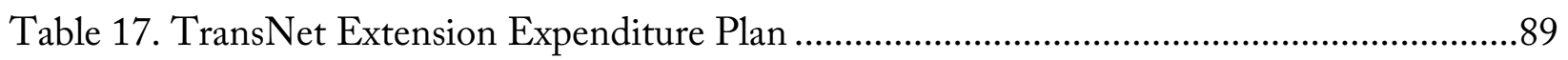

Table 18. Text of Measures Requiring Development Impact Fees................................................93

Table 19. Text of Measures with Reporting Requirements ......................................................96 


\section{Executive Summary}

\section{Introduction}

Since 1976, California residents have voted on 76 local option sales tax (LOST) measures for transportation in 30 of the most populated of the state's 58 counties. Such measures increasingly designate a portion of collected revenues to be returned directly to municipalities and the county to spend on local needs. This funding is commonly known as "local return," and it is considered important in gaining voter support for LOST measures. As of 2019, 58 of the LOST measures placed on the ballot in California have included local return in their expenditure plans, with an average of $35 \%$ of revenues dedicated to local return.

Local return provisions in the ballot measures often contain guidelines on how a portion of the money should be spent. This study explores how local return provisions are allocated and spent to meet local and regional transportation needs.

Despite LOSTs' increasing role in transportation finance and the growth of local return as a necessary component for passing transportation measures, no previous research has assessed either the requirements for and spending of local return funds, or the amount of flexibility built into these measures when it comes to keeping assurances made to taxpayers. This study explores these questions using a mixed-methods approach, including document analysis and interviews.

\section{Report Organization \& Findings}

This report presents the first study of the process of funding local government transportation programs via county transportation sales taxes in California. Sales tax revenue collected by counties but designated for local governments as part of their LOSTs are referred to as local return funds. The report relies on analysis of original measure documents for all LOST measures in California, supplemented by interviews with officials of six counties with LOSTs to understand their implementation. Chapter I thoroughly introduces the background and academic literature on LOSTs and local public finance. Chapter II discusses the methods used in this report to analyze local return. Because no literature has addressed the implementation of local return programs, Chapter III draws from the literature on LOSTs in general and on accountability for local projects and programs.

Chapter IV explores how much local return exists, who gets local return funding, and how cities spend local return. It first examines the percentage of LOST measures dedicated to local return. Then it turns to how local return revenues are allocated among jurisdictions in counties and what jurisdictions must do to receive local return funds. Last, it examines guidelines and requirements on how local return funds are spent. 
Of the 58 measures that include local return in the expenditure plan, the lowest percentage of total revenues allocated to local return programs was 10\%, the highest was $99 \%$, and the average allocation was 35\% (Figure 1). This is distinguished from stated local return, which is discussed in Chapter IV. The average allocation is heavily influenced by three measures that dedicated between $90 \%$ and $100 \%$ of revenues to local return. The first to third quartile range for local return allocated $20 \%$ to $44 \%$ of total measure revenues to local return.

Tax measures typically include equity provisions guiding how local return funds are allocated among jurisdictions. The vast majority of measures allocated local return funds based on population, road miles, or both. Population was the most common variable used to allocate local returns, with 52 local return measures considering population in their allocation formulas (90\%). 17 of the 52 measures allocated funds solely based on population (29\%). Some measure of road miles (such as lane miles, maintained road miles, arterial highway miles, etc.) was the second most common variable used to allocate local returns, and was included in 34 measures (59\%). The most common allocation formula, used by 17 measures (29\%), distributes funding according to 50\% population and $50 \%$ road miles. Ventura County Measure AA is the only measure to use greater than $50 \%$ road miles as an allocation variable, distributing local return funds solely based on road miles $(2 \%)$.

Table 1 details the use of these two most popular variables in measure allocation formulas. As previously described, the table demonstrates that population was used across many measures and tended to comprise a large portion of the overall distribution formula. Road miles was the second most common variable, but it was more likely to comprise a lower percentage of the total formula.

Table 1. The Use of Population and Road Miles in Local Return Allocation Formulas

\begin{tabular}{|c|c|c|}
\hline Variable & Percent Weight in Allocation Formula & $\mathrm{N}$ \\
\hline \multirow[t]{4}{*}{ Population $(n=52)^{a}$} & Between $0 \%$ and $50 \%$ (noninclusive) & 1 \\
\hline & $50 \%$ & 20 \\
\hline & Between $50 \%$ and $100 \%$ (noninclusive) & 11 \\
\hline & $100 \%$ & 17 \\
\hline \multirow{4}{*}{ Road Miles $(n=34)^{\mathrm{b}}$} & Between $0 \%$ and $50 \%$ (noninclusive) & 14 \\
\hline & $50 \%$ & 17 \\
\hline & Between $50 \%$ and $100 \%$ (noninclusive) & 0 \\
\hline & $100 \%$ & 1 \\
\hline $50 \%$ Population and 50\% Road Miles & & $17^{\mathrm{c}}$ \\
\hline \multicolumn{3}{|c|}{ a Includes three measures that included population, but the exact formula was unknown. } \\
\hline \multicolumn{3}{|c|}{ b Includes two measures that included road miles, but the exact formula was unknown. } \\
\hline \multicolumn{3}{|c|}{$\begin{array}{l}\text { Riverside County Measure A (1989) and its extension, Measure A (2002), both use a } 50 \% \text { population and } 50 \% \text { road } \\
\text { miles allocation for a portion of the county. Due to the elevated presence of private resorts with privately maintained } \\
\text { roads, and the high number of vacation residences, the Coachella Valley region uses dwelling units instead of population. }\end{array}$} \\
\hline
\end{tabular}


Some measure ordinances include county-specific requirements that cities must meet to receive their local return funds. These preconditions are defined as requirements that, if not fulfilled, will result in funding being suspended, withdrawn, or revoked. Such prerequisites generally do not dictate how cities spend local return funding, but they can place significant demands on localities and influence how localities plan their communities, such as by stipulating that the localities participate in a regional planning program or adopt a specified local policy. Other prerequisites include that cities implement a development impact fee, participate in regional growth management plans, invest in specific types of projects or programs before receiving local return funds, and develop a local pavement management plan. These prerequisites can be valuable policy tools for counties and are developed to address specific regional goals that appeal to voters and other stakeholders. In this way, local return funding is used to encourage local government participation in planning to meet regional goals.

Spending requirements can also strike a balance of funding among different modal purposes. Figure 1 shows the percentage of total local return funds that are subject to spending requirements. Of the 58 measures studied, 45 measures had at least some funding that was flexible and not limited or restricted to any category of spending. Of these measures, 29 included local return funds that did not specify funding restrictions (see Figure 1). Additionally, 20 measures prescribed at least some funds to be used strictly for road facility repair and maintenance. Of these, ten measures distributed $100 \%$ of their local return in this category. Only one measure, San Diego TransNet (2004), restricted a portion of local return to new capital and infrastructure. Of the measures studied, an average of $33.1 \%$ of all local return funding has some form of spending restriction.

Chapter $\mathrm{V}$ discusses accountability and transparency in local return distribution and spending. Under Proposition 13, LOST revenues are required to supplement, rather than replace, jurisdiction spending on transportation that was in place before the LOST was enacted, a provision known as "maintenance of effort" requirements. Chapter $\mathrm{V}$ then discusses the reporting and approval requirements found in individual measures. Combined, the authors found that these provisions support robust accountability protections for local return spending.

Many measures include explicit reporting requirements for how local jurisdictions spend their allocated funding, in some cases requiring reporting as a prerequisite to receiving measure funds. A total of 17 measures from 12 counties require that jurisdictions develop a short-range planning list of projects to be funded by measure revenues (such as a Program of Projects [POP] or Capital Improvement Plan [CIP]) before receiving funds. Of these, three measures specify that the list will be approved as long as it conforms to the measure ordinance and expenditure plan. The remaining 14 measures' ordinances require that cities and other localities develop a list of intended projects, but do not specify the conditions under which that that list would be approved. Reporting requirements rely on documentation more than active supervision. Reporting was one of the most frequent prerequisites to receiving funding. 


\title{
Figure 1. Categorical Spending Requirements by Percentage of Local Return
}

\author{
Flexible \\ Capital Investment Only \\ Local Street Repair and Maintenance \\ Bikes or Pedestrians \\ Paratransit/ADA
}

Alameda Measure B 1986 Alameda Measure B 1998

Alameda Measure B 2000

Alameda Measure B1 2012

Alameda Measure BB 2014

Contra Costa Measure C 1988

Contra Costa Measure J 2004

Contra Costa Measure X 2016

Fresno Measure C1 1986

Fresno Measure C 2002

Fresno Measure C 2006

Humboldt Measure U 2016

Imperial Measure D 2008

Los Angeles Proposition A 1980

Los Angeles Proposition C 1990

Los Angeles Measure R 2008

Los Angeles Measure J 2012

Los Angeles Measure M 2016 Madera T 2006 Marin A 2004 Marin AA 2018 Merced G 2006

Merced Measure V 2016

Monterey Z 2008

Monterey Measure X 2016 Napa T 2012

Orange M1 1990

Orange M2 2006

Placer Measure M 2016

Riverside A2 2002

Sacramento A1 1988

Sacramento A2 2004

Sacramento Measure B 2016

San Benito Measure P 2016

San Benito Measure G 2018

San Bernardino* Measure 122004

San Diego TransNet2 2004

San Diego Measure A 2016

San Joaquin K 1990

San Joaquin K 2006

San Luis Obispo Measure J 2016

San Mateo A1 1988

San Mateo A2 2004

San Mateo W 2018

Santa Barbara D 1989

Santa Barbara D 2006

Santa Barbara A 2008

Santa Clara B 2016

Santa Cruz J 2004

Santa Cruz Measure D 2016

Solano A 2004

Solano H 2006

Sonoma M 2004

Stanisalus K 2006

Stanisalus L 2016

Tulare R 2006

Ventura B 2004

Ventura AA 2016

Other
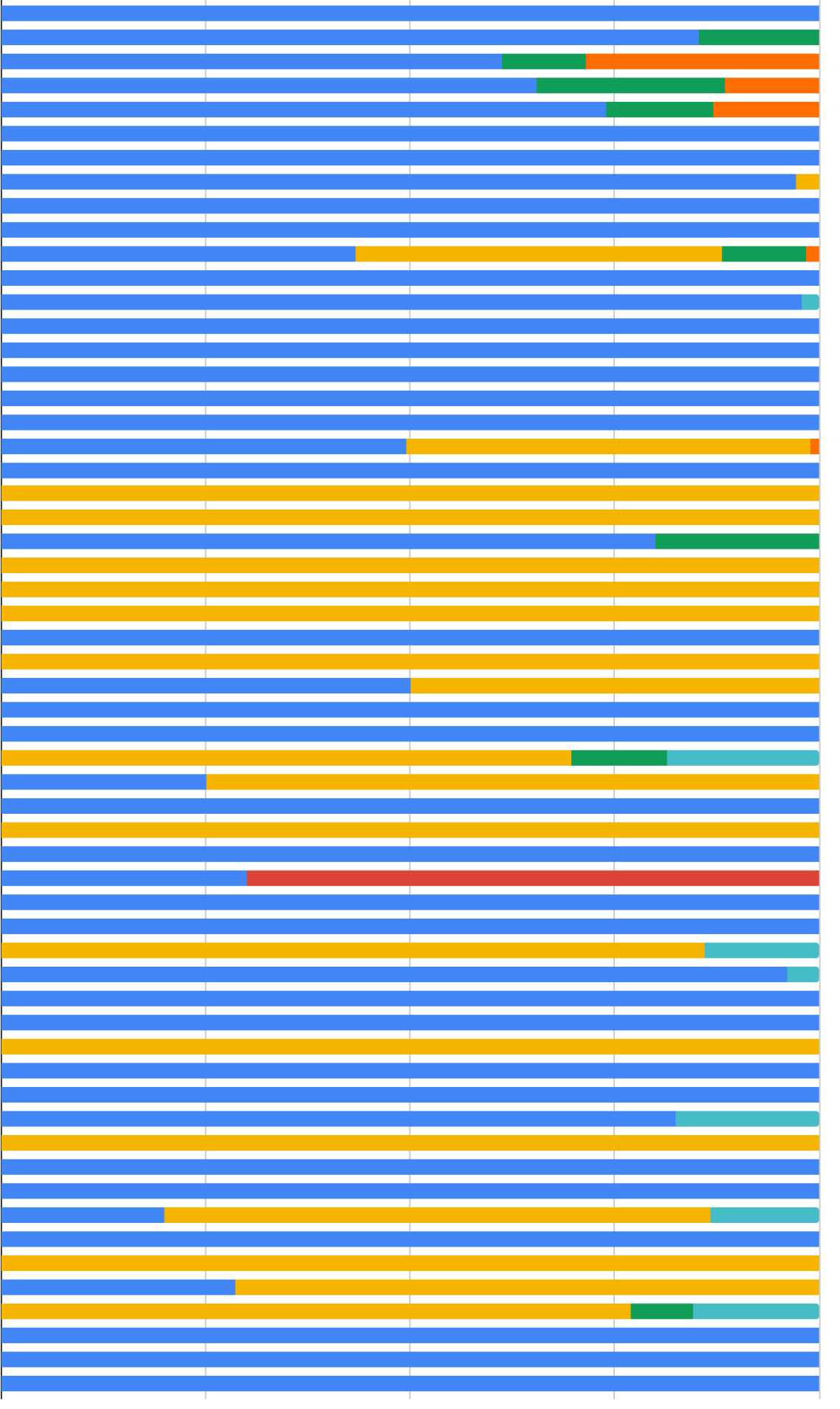


\section{Conclusion}

Local return provisions comprise a crucial part of transportation tax measure expenditure plans. Although they vary considerably in important ways, collectively, local return funds enable cities to address their transportation needs with relatively little conflict or implementation issues. City governments use LOST funds to fund a variety of needs and purposes, including maintenance and repair of local streets and roads, addressing policy goals such as congestion management and the mitigation of environmental impacts of growth and development, as well as leveraging additional funding in the form of locally-issued bonds and state and federal grant programs.

Tax measures typically include equity provisions guiding the geographic distribution of local return funds, and nearly always use variables such as population and road mileage in funding allocation formulae. Equity concerns are also visible in the spending requirements attached to the local return fund, which can be used to ensure spending on specific transportation modes and purposes. Our study found little or no discontent among city officials regarding these allocation schemes. Although counties vary considerably in how they attach both prerequisites for receiving funds and requirements for remaining eligible for them, we identified little evidence that such provisions create either significant conflict or unmanageable burdens for city governments. This is in part because counties develop measures in collaboration with local governments, and they tend to balance regional and local priorities with their return fund rules, smoothing their acceptability to city governments.

Return provisions examined in this study generally exhibit a great deal of transparency and accountability. Essentially, we found that concerning local return, counties provide funding to city governments as described in the measures' expenditure plans. Counties employ several accountability measures to ensure that local jurisdictions are spending funds as required, including mandatory reporting and auditing. However, some counties and cities do a significantly better job of making that clear to the public by making relevant data available in a readily digestible form. 


\section{Introduction}

Since 1976, California residents have voted on 76 local option sales tax (LOST) measures for transportation in 30 of the most populated of the state's 58 counties. Such measures increasingly designate a portion of collected revenues to be returned directly to municipalities and the county to spend on local needs. This funding is commonly known as local return and is considered important in gaining voter support for LOST measures. As of 2019, 58 of the LOST measures placed on the ballot in California have included local return in their expenditure plans.

This study explores how local return provisions are allocated and spent to meet local and regional transportation needs. Local return refers to provisions in county LOST measures that provide funding to municipalities in the county to be distributed to cities to meet local needs. Local return has become a fixture in LOSTs, with 35\% of revenues dedicated to local return on average across all measures placed on the ballot.

There is a rich literature on LOSTs that describes their growing role in transportation finance. One thread of the literature compares sales taxes to other transportation finance mechanisms, including potential equity concerns. Another thread in the literature explores factors that encourage their passage, including political and contextual factors. How local return funding is allocated, how it is spent, and how it works during measure implementation are questions that reflect gaps in the literature that this research addresses.

The rules governing the allocation and use of local return funding in LOST measures are complex, striving to strike a balance between giving local jurisdictions flexibility to meet local needs while promoting both geographic and modal funding equity. For example, Fresno County's Measure C (2006) dedicated $34.6 \%$ of total measure revenue to local return, but only $44.25 \%$ of local return funds are permitted to be used flexibly by local jurisdictions. The remaining funds are prescribed by the measure to be spent on specific transportation modes and needs. According to the measure ordinance, $50 \%$ of local return revenue must be spent on local street and road maintenance, $4 \%$ on bicycle and pedestrian infrastructure, and $1.75 \%$ for Americans with Disabilities Act (ADA) compliance. Local return provisions also seek to guide local planning decisions toward meeting regional goals. For example, in Contra Costa County Measures C (1988), J (2004), and X (2016), municipalities must adopt local growth management policies and coordinate growth and housing with regional agencies as a precondition for receiving local return LOST funding.

Despite LOSTs' increasing role in transportation finance and the growth of local return as a necessary component for passing transportation measures, no previous research has assessed requirements for and spending of local return funds, or the reliability of these measures when it comes to keeping the assurances made to taxpayers. This study explores these questions using a mixed-methods approach, including document analysis and interviews. 
This study collected and evaluated LOST expenditure plans to document the proposed spending guidelines for local return funds. As a first step, we reviewed how local return funding is regulated and distributed across the 76 LOSTs for which ordinances could be obtained. A review follows of the mechanisms allowed under the ordinances to adjust local return revenue distribution among jurisdictions. Apportionment can range from a simple formula based on population change to more complicated formulas that account for population, sales tax revenue raised in each jurisdiction, and miles of roadways to be maintained.

The remainder of the report is organized as follows. Chapter II describes document analysis of original measures for all LOST measures in California and how this analysis was supplemented with interviews with officials from both county transportation agencies and local governments in six counties with LOSTs to understand implementation. Next, Chapter III describes relevant literature. Because no literature has addressed the implementation of local return programs, this chapter draws from the literature on LOSTs in general and on accountability for local projects and programs. Chapter IV explores how much local return exists, who gets local return funding, and how cities spend it. Chapter $V$ evaluates accountability and transparency provisions in local return distribution and spending. Chapter VI discusses themes in local return distribution and usage found in this research. Finally, Chapter VII offers recommendations for policymakers and areas for further research.

Findings indicate that local return provisions are crafted to balance the needs of the county across different dimensions, including trying to achieve equity between urban and rural residents, investment in different transportation modes, and meeting both local and regional policy needs. Moreover, significant accountability mechanisms provide regulations to ensure that funds are distributed to and spent by jurisdictions as promised by the measures. Overall, this research finds that local return is a vital part of LOST measures in California, allowing cities to meet local needs ranging from maintenance of local streets to funding for special programs, while simultaneously aligning local investment with regional priorities. 


\section{Study Methods}

This chapter describes the analyzed set of LOST measures, plus the two key study methods: analysis of official documentation related to LOSTs and interviews with officials in six counties. The document analysis includes all LOST measures with local return and focuses on ordinances and expenditure plans that govern local return allocation and spending. The interviews supplement this analysis with qualitative findings about local return implementation during the life of the measure.

\subsection{The LOST Measures}

This study examines 58 LOST ballot measures in California (Table 2). The 58 measures examined in this chapter were placed on ballots across 29 counties, as some counties placed measures on the ballot in multiple years.

To analyze the local return funds of each measure included in this study, the authors started by identifying funds described in the measures as returned to localities. This part of the local return often consists of a minimum dollar allocation, a percentage allocation based on formula funding, or a percentage of funds for a specific purpose, such as bicycle infrastructure, distributed to cities by formula. This does not include funds provided to transit operators, which may include transit agencies run by a city or county government. Of the 76 measures studied, 58 dedicated a percentage of measure revenues to local return, and seven measures had no local return. An additional 11 measures did not specify the distribution of funding in the ballot measure text or accompanying ordinance and were excluded from the study. 
Table 2. LOST Measures Studied (County, Measure Letter, and Date Passed)

\begin{tabular}{|c|c|c|}
\hline Alameda, B, 1986 & Marin, AA, 2018 & San Mateo, A1, 1988 \\
\hline Alameda, B, 1998 & Merced, G, 2006 & San Mateo, A2, 2004 \\
\hline Alameda, B, 2000 & Merced, V, 2016 & San Mateo, W, 2018 \\
\hline Alameda, B1, 2012 & Monterey, X, 2016 & Santa Barbara, A, 2008 \\
\hline Alameda, BB, 2014 & Monterey, Z, 2008 & Santa Barbara, D, 1989 \\
\hline Contra Costa, C, 1988 & Napa, T, 2012 & Santa Barbara, D, 2006 \\
\hline Contra Costa, J, 2004 & Orange, M1, 1990 & Santa Clara, A/B, 1996 \\
\hline Contra Costa, X, 2016 & Orange, M2, 2006 & Santa Clara, B, 2016 \\
\hline Fresno, C, 2002 & Placer, M, 2016 & Santa Cruz, J, 2004 \\
\hline Fresno, C, 2006 & Riverside, A2, 2002 & Santa Cruz, D, 2016 \\
\hline Fresno, C1, 1986 & Sacramento, A1, 1988 & Solano, A, 2004 \\
\hline Humboldt, U, 2016 & Sacramento, A2, 2004 & Solano, H, 2006 \\
\hline Imperial, D, 2008 & Sacramento, B, 2016 & Sonoma, M, 2004 \\
\hline Los Angeles, A, 1980 & San Benito, G, 2018 & Stanislaus, K, 2006 \\
\hline Los Angeles, C, 1990 & San Benito, P, 2016 & Stanislaus, L, 2016 \\
\hline Los Angeles, J, 2012 & San Bernardino, I2, 2004 & Tulare, R, 2006 \\
\hline Los Angeles, M, 2016 & San Diego, A, 2004 & Ventura, AA, 2016 \\
\hline Los Angeles, R, 2008 & San Diego, A, 2016 & Ventura, B, 2004 \\
\hline Madera, T, 2006 & San Joaquin, K, 2006 & \\
\hline Marin, A, 2004 & San Luis Obispo, J, 2016 & \\
\hline
\end{tabular}

All 58 measures with verifiable, nonzero total local return were included in this analysis, regardless of the level of information available. Because measure passage is based on a multitude of factors, many of which cannot be attributed to specific local return provisions, the authors created a dataset that included both measures that passed and those that failed. The range of measures included in this study may cause some bias, however. For example, we generally found less documentation on the use of local return funds in older and/or failed measures. 
To analyze how local return funds are regulated before and after being distributed, the authors reviewed available ordinance language, ballot text, expenditure plans, annual reports, and information from county websites. Most measures used ordinance and expenditure plan text for descriptions of allocation and spending requirements. However, for some measures, the full text of the ordinance or expenditure plan was not available, and others used vague language. In cases where the original ordinance or expenditure plan for a measure provided little or no data, the authors used supplemental sources, including official documents and interviews with county officials.

\subsection{Interviews}

In addition to gathering information and data from primary and secondary documents, the authors conducted semistructured telephone interviews with local officials and transportation agency representatives in selected counties. The purpose of these interviews was to provide qualitative evidence and reasoning that complements the quantitative and documentary analysis used in this study. In particular, the interviews were designed to:

- Explore potential discrepancies between stated policies and practices and the actual implementation of LOST provisions,

- Obtain additional background information associated with the creation and implementation of LOST measures, and

- Obtain multiple stakeholder perspectives about the effectiveness and propriety of LOST implementation.

Interviews, for example, helped the study team gain detailed and nuanced insights into how cities choose to spend local return funding, what influences their investment decisions, how cities manage county prerequisites and requirements for LOST funds, and whether cities and counties clash on funding priorities for LOST revenues.

\section{Selecting Counties for the Interviews}

The authors pursued interviews in six counties with LOST measures: Alameda, Contra Costa, Fresno, Imperial, Riverside, and San Diego. Detailed descriptions of these measures can be found in Appendix A.

The following criteria were used to select appropriate counties for study: 
- The county's ordinances place unique regulations on receiving or spending local return funding.

- The county has at least one measure that has been in place for more than ten years and dedicates more than $10 \%$ of measure revenues to local return.

- The set of counties collectively reflect diversity with respect to region of the state, presence of economic centers, population demographics, and level of urbanization (urban, suburban, rural).

\section{Selecting the Interviewees}

For each county, the authors interviewed officials from both county transportation agencies and local governments. A member or members of the research team interviewed the Executive Director (or equivalent) of each county's transportation agency, and in some cases interviewed additional staff members from that agency with expertise in the county's LOST program. Additionally, in each county, the authors attempted to speak with an appropriate planning or finance official from both large cities and at least one smaller city. In a few instances, the authors also spoke with local officials from cities that earlier interviewees or news reports identified as potentially able to present an interesting example of local responses to LOST initiatives (for example, a conflict on spending requirements). Appendix A summarizes the information gained from the resulting 27 interviews and indicates which city representatives and agencies participated in the interviews in each county.

\section{The Interview Process}

The authors conducted interviews over the phone using a semistructured instrument that explored relevant aspects of each county's LOST program. Each interview lasted approximately 30 to 45 minutes. Appendix B presents the full text of the interview guide. 


\section{Literature Review}

The authors found very few research studies on the role of local return funding in LOST expenditure plans during their literature review. For this reason, this chapter reviews the literature on two topics closely related to the study: research on LOSTs and research into government accountability. The chapter first presents a review of the literature on LOSTs for transportation, including factors resulting in the growing popularity of using sales taxes for transportation and studies that examine what aspects of ballot measures influence voters. This chapter then explores the literature on government accountability, focusing on the delivery of transportation projects and programs, and accountability mechanisms for local spending.

\subsection{The Increasing Popularity of LOSTs}

Since the 1970s, the growing gap between transportation program needs and revenue has been narrowed in many places across the United States by LOST measures for transportation. LOSTs for transportation have proven to be popular among voters; 62 sales taxes for transportation were put before voters in the states and counties across the country in the November 2016 general election. ${ }^{1}$ Since 1976, California residents have voted on 76 LOSTs to fund transportation in 30 of the state's 58 counties. As of 2017, there are active LOST measures in 24 counties, home to $88 \%$ of the state's population, ${ }^{2}$ which produce more than $\$ 4$ billion per year for transportation construction and maintenance. ${ }^{3,4}$ Voters in some counties have approved LOST measures as many as five times. ${ }^{5}$

Counties turned toward LOSTs to cover gaps in funding for transportation investments. California's transportation revenue crisis has been well documented. ${ }^{6}$ Adjusted for inflation, federal transportation funding has decreased for decades. Per vehicle mile of travel, the funding fall has been even steeper. The federal tax of 18.4 cents per gallon and the statewide gasoline excise tax of 18 cents per gallon remained the same from 1993 to 2017 without adjustment for inflation or increased fuel efficiency. A statewide increase of 12 cents per gallon went into effect in November 2017, acknowledging in part that statewide bond measures and a fuel tax "swap" (for background and policy implications, see Wachs et al. ${ }^{7,8}$ implemented during the 24 years between state motor fuel tax increases did not meet the transportation investment needs of a growing population and economy.

LOST transportation measures are part of a small but growing collection of voter-approved, multiyear tax measures which include expenditure plans that dedicate their revenue to specific projects on a specific schedule - as opposed to revenue for general funds spent at the discretion of a legislative body. Specifying projects appeals to voters, as do taxes levied in small increments (often a half-cent or cent per dollar) over many transactions, which can raise a great deal of money despite their low rates. ${ }^{9}$ Specific expenditure plans engender voter trust, ${ }^{10,11}$ but they also tie the hands of 
public officials, who consider them to be rigid amid changing conditions. ${ }^{12}$ The presence of an expenditure list is often cited as one of the reasons for the increasing popularity of LOSTs as a local transportation finance measure, ${ }^{10,11,13}$ and these measures are sometimes referred to as "ballotbox planning" ${ }^{9,12,14,15}$ because the voter approval of expenditure plans dictates a significant portion of transportation investments during the life of the measure in a given region. The authors not aware of any previous studies exploring how well project delivery matches expenditure plans presented in the measures during the life of the sales taxes, or how administering agencies encourage accountability in local spending.

Although LOSTs are approved by voters by two-thirds majorities, distribution of funding to local agencies can raise equity concerns along income, modal, geographic, and temporal lines. Sales and fuel taxes support transportation investments, and both are regressive. How much people pay in fuel taxes rises with their fuel use, corresponding roughly to road use; however, fuel taxes are regressive as a portion of income. Transportation sales taxes, by contrast, are not directly tied to travel. Every consumer pays the tax when purchasing many goods. This means light users of transportation systems pay more in transportation sales taxes per mile traveled than heavy users. Thus, transportation sales taxes can be seen as "doubly regressive." ${ }^{16}$ Similar concerns can be raised if local returns are not allocated in proportion to system usage.

The authors reviewed relevant literature with regard to passing LOSTs and accountability via voter behavior, elected officials, governance, and transparency. The authors surveyed existing ballot measure ordinances to identify language that states requirements for local return of LOST revenue and control of the funds. The authors used interviews to explore implementation of local return funding through successful measures. To the authors' knowledge, no prior research has covered the spending implementation of the local return portion of LOST revenues.

\subsection{Passing LOST Measures}

Prior LOST studies tended to focus on factors influencing passage or failure of LOST ballot measures. Influential factors in passing measures that these studies point to include local return provisions and the development of the expenditure plan, ${ }^{5,10,11}$ public marketing campaigns, ${ }^{17}$ and contextual and socioeconomic factors. ${ }^{9}, 13$ For example, Hannay and Wachs ${ }^{9}$ and Haas et al. ${ }^{17}$ reported that measures are more likely to pass if they dedicate funding to a mix of highway and transit projects rather than a single mode.

Voters' perspectives and decision-making processes also affect transportation tax measure support. Voters, like all decision makers, make choices based on the information at hand. Unfortunately, the information needed to evaluate LOSTs, like many other transportation measures, is generally built on uncertainties. Costs, revenues, and timing must all be estimated based on future projections, and each projection introduces elements of uncertainty for decision makers at every 
level. Thus, voters look at the present state of transportation and assess LOST measures on projected futures, ${ }^{18}$ although even the most popular models of rational decision-making cannot account for the uncertainties of transportation measure estimates. ${ }^{19}$

Political ideology also matters when voters anticipate the potential impacts of proposals. In a study of voters' responses to a redistributive taxation ballot initiative (Washington State's Initiative 1098 of 2010), researchers found that although "framing the policy in terms of the economy was salient among members of both [Democrat and Republican] parties, ... each group reached different conclusions about the policy's economic effects, demonstrating the important role of partisan filtering in such debates." ${ }^{20}$ People's perception of the present state of affairs affects their perception of the government's ability to deliver on future promises. For example, a study of transportation sales tax measures in two Southern California counties found that survey respondents were less likely to support extending sales tax measures if they had a negative view of existing road maintenance. ${ }^{21}$ Green et al.'s ${ }^{21}$ study of Riverside and San Bernardino counties also found a strong link between political predisposition and voting against transportation taxes. People may vote against proposals to raise funds for poor services or systems, even if the funds are intended to fix the problems..$^{21,22}$

Stated expenditure plans, requirements, and provisions for local return are particularly important aspects of LOST measures on the ballot because they dedicate revenue to specific projects, programs, and local governments. They increase the popularity and passage rates of transportation taxes. ${ }^{5,10,11,13}$ Research has found that expenditure plans make the geographic distribution of funding explicit, and that provisions for guaranteed local revenue build voter trust, both of which are particularly important in areas where voters do not trust the discretion of their elected officials. ${ }^{10,11}$ The specificity of plans reassures voters that they will see the benefits of their $\operatorname{tax}$ dollars in projects near them, ${ }^{9}$ and counties with suburban voter bases can promise that their tax money will be distributed fairly. ${ }^{11}$ Importantly, failure to adhere to these provisions could erode voter support for future measures and endanger future transportation revenue. ${ }^{10}$ The concern for local benefits extends to the popularity of local return, the return of a portion of the tax revenues to local control for transportation projects and programs. ${ }^{5,11}$ Elements that guarantee a local focus increase the perception of fairness among voters. ${ }^{5}$

\subsection{Literature on Accountability}

Accountability is one of the basic tenets of democracy. ${ }^{23,24}$ Citizens must be able to hold their governments to promises and expectations. In relation to LOSTs, accountability generally refers to "whether a measure-sponsoring agency has delivered on past promises" or "safeguards in place to ensure that revenues are distributed as stated in the expenditure plan." The consequences of not delivering on promises may fall on local elected officials up for reelection. ${ }^{21,25,26,27}$ Regardless, 
partisanship and party loyalty affects voting behavior, ${ }^{20,21,28,29,30}$ and LOST measures must turn toward governance mechanisms for accountability once passed. ${ }^{5,31,32}$

\section{Accountability and Local Elected Officials}

Politicians act on the premise that voters could hold them accountable for delivering projects and programs, ${ }^{23}$ yet research on voter behavior provides conflicting evidence. On one hand, some research indicates that voters select candidates based on their ideology more than specific promises. ${ }^{30}$ Partisanship has been found to be "a critical determinant of support for specific policies in today's environment" ${ }^{20}$ and voter confidence in public officials. ${ }^{21}$ Contrary to some political theory, the political stance of either party's nominees does not shift in response to the electoral strength of one political party increasing in a district; thus, even a minority-party nominee would be unlikely to make project promises that seem unaligned with their associated political ideology in order to be elected..$^{28}$ For example, a minority-party nominee is unlikely to support increasing transit funding if that conflicts with party ideology, even if it might increase votes from independent or borderline majority-party voters. These studies align with literature that supports the theory that voters will not necessarily hold politicians accountable for programs and projects if it means straying from party-line voting. ${ }^{20,21}$ Voter party affiliation thus affects the extent to which voter behavior acts as an avenue of accountability.

On the other hand, several studies point to failing services or infrastructure as relevant to holding local elected representatives accountable via their reelectability. ${ }^{21,25,26}$ In Ohio, fiscally failing school districts saw higher school board and administrator turnover. ${ }^{27}$ In Florida, "voters dissatisfied with elected officials' infrastructure decisions have increasingly tossed them out of office," replacing incumbents with challengers to the offices of mayor and city councilor. ${ }^{26}$ Concern for local infrastructure issues outweighed concern for local services in both high- and low-growth cities, especially larger cities. ${ }^{26}$ In San Diego, California, local road quality as measured by pothole complaints—a specific issue voters generally understand as under local control—affected support for incumbent mayors and city councilmembers..$^{25}$ Thus, the state of local transportation infrastructure at the time of voting can act as an accountability measure that matters to incumbent politicians.

Furthermore, research shows that such elected representatives take credit for projects that finish during their terms and divert blame for unfinished or underperforming projects to nonelected bureaucratic leaders in institutions. ${ }^{29}$ Interest groups influence how officials use and portray performance information relative to their respective political ideologies. ${ }^{29}$ This aligns with prior research that suggests party affiliation and coinciding values matter to voting outcomes. ${ }^{20}$ Considering these factors, voter behavior may be a necessary but insufficient check on governments keeping LOST promises. 
Accountability, defined as holding people or agencies "answerable for decisions or actions," is a necessary part of good governance. ${ }^{33}$ As previously discussed, including accountability mechanisms increases the likelihood of passing measures. ${ }^{5}$ Some mechanisms precede any given measure. For example, all LOST measures must meet state-mandated requirements and restrictions for local sales taxes. ${ }^{31}$ These restrictions include what the sales tax can or cannot be earmarked to. ${ }^{31}$ Thus, literally accounting for revenues and expenditures to the state of California from LOSTs is one step of accountability. Further, "administrative accountability concerns the extent to which an administrative agency is answerable to its supervisory constituencies for the tasks assigned to it." ${ }^{2}$ In the case of LOSTs, the supervisory constituencies include not only the state but also the general public (particularly voters), organizational hierarchies, and any required oversight committees. In addition, each measure tends to include mechanisms of accountability to ensure that spending of the revenue raised by LOSTs matches the intent and promises in the measure. ${ }^{5}$ Yet a supervisory constituency needs information to hold an administrative agency accountable.

Public administrators and policy researchers hold transparency as a necessity for citizens to keep government accountable. ${ }^{24,33}$ Research often focuses on three types of government transparencyadministrative, political, and budget—having to do with three sets of activities: decision making, policymaking, and policy outcomes. ${ }^{34}$ Indeed, "access to information is an essential characteristic of accountability-virtually all accountability relies on the availability of relevant and timely information." ${ }^{33}$ To be transparent, government financial information also must be readily available and understandable. ${ }^{24}$ When information is relevant, timely, readily available, and understandable, transparency enables stakeholders such as voters to hold actors, such as elected officials, accountable.

Research on the effectiveness of transparency leading to specific governance outcomes is mixed, yet budget transparency appears to be one of the most actionable. ${ }^{34}$ For example, once Ohio introduced a public fiscal-stress labeling system for its school districts, voters often replaced incumbent board members when the state sanctioned fiscally-failing districts. ${ }^{27}$ Unlike elected representatives who must run for reelection, however, people vote once on a measure. That is why LOST measures include specific mechanisms such as citizens' oversight committees, limits on administrative costs, expenditure plan amendment processes, and annual audits. Accountability mechanisms vary from measure to measure, particularly regarding local return funds. 


\section{Local Return Allocation and Spending}

This chapter analyzes the diversity in provisions that regulate how local jurisdictions allocate and spend LOST revenues. The authors gathered the data for this analysis from the measure ordinances, expenditure plans, and guidance documents produced by transportation agencies administering 58 LOST measures. The chapter examines the variation in the proportion of measure revenue dedicated to local return and how it reflects county-specific demographics. The chapter then compares formulas used to allocate local return among jurisdictions and county unincorporated areas and discusses how different measurements used for allocation affect distributional equity. The authors then identify preconditions that municipalities must meet before they can receive local return funds. For example, some measures specify that municipalities must have a complete streets plan in place to receive their allocated measure revenues. Finally, this chapter explores requirements for how local return funding may be spent by jurisdictions after it is received. For example, some measures specify that a fixed percentage of the revenue returned to cities and unincorporated areas must be spent on bicycle or pedestrian infrastructure.

There is no statutory definition of local return, and for the purposes of this report, local return is defined as funding that the expenditure plan requires be distributed to local jurisdictions ${ }^{35}$, via a formula, for spending on transportation projects and services at the jurisdiction's discretion. This funding is then used to fund local projects at the city's discretion. The following are not considered local return for the purposes of this report: measure revenues spent on regional projects enumerated in the expenditure plan, revenues allocated to agencies other than general purpose governments, and funding allocated at the discretion of the administering agency, including funding allocated to local jurisdictions on a competitive basis (as opposed to by formula).

\subsection{Rates of Local Return}

One of the goals of this research is to determine how much of each measure is dedicated to local return. Findings indicate that there is sometimes inconsistency between local return as defined in this study and how local funding is used in LOST ballot measures. For example, some measures describe local funding programs as separate from funding that is returned to cities but dedicated to a specific purpose. For example, multiple measures in Alameda County both allocate funding for cities to use at their discretion and provide additional formula funding for ADA services through a distinct program. In such cases, the percentage of the measure revenue dedicated to local return under this report's definition is larger than appears on the face of the measure.

Other measures include revenue in their local funding portion either dedicated to specific named projects or required to be used on regional projects. Such funding is not considered here to be local return because it cannot be spent on local needs at the discretion of each jurisdiction. To calculate the local return as considered here, the authors subtracted funds that implied local return yet were 
not intended to be returned to localities. For example, Santa Cruz's Measure D (2016) included a category called "Neighborhood Projects" that receives 30\% of tax revenue. Most of that category is dedicated to local return, but an estimated $\$ 15$ million of the projected revenues are reserved for highway-related projects, making $26.5 \%$ of the measure the true percentage of revenues dedicated to local return.

The authors also added any other programs funded by the LOSTs that fit the definition of local return but were not categorized as such in the ordinances. These programs include funds required to be spent in certain ways and funds that are not distributed until certain requirements are met, as long as there is a set percentage to be distributed to the locality and under local control (subsequently discussed in detail). For example, Alameda's Measure B (1998) explicitly distributes 23.09\% of tax revenue to localities through its "Local Transportation" program. The measure also has a separate program ("Transportation Enhancements") that allocates $4 \%$ of measure funds to localities for bicycle projects, pedestrian projects, and open space procurement. This funding fits the definition of a local return with a modal requirement, and thus was included in the total calculated return. The following chapter analyzes the measures with a nonzero local return after this calculation has been completed and discusses the methods used to allocate those funds to local jurisdictions. Note that excluded from analysis were any funds provided directly to transit operators, which may include transit agencies that are run by a city or county government, and any funds allocated by competitive grant.

Figure 2. Percentage Point Difference between Percentages of Total and Stated Local Return of Total Measure Funding

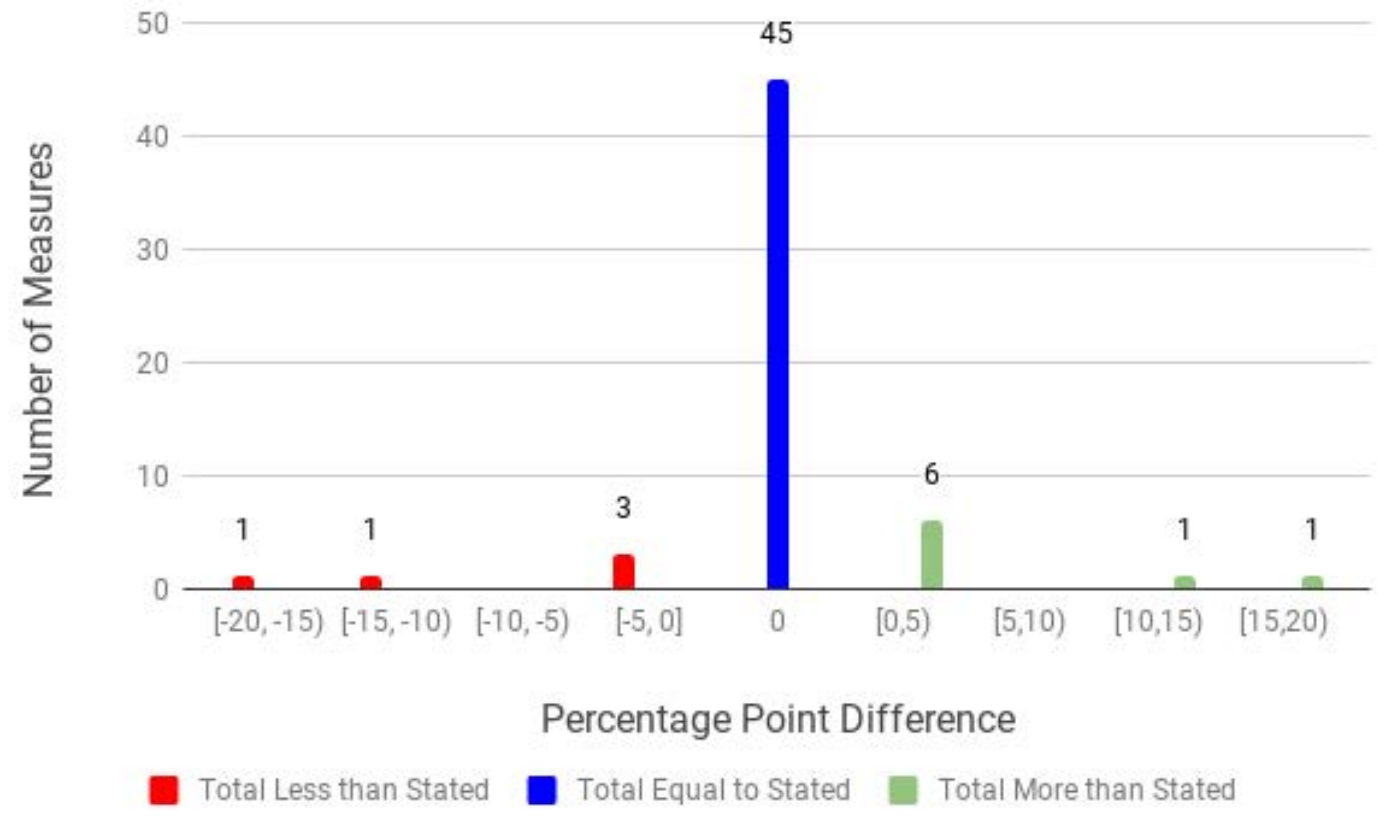


Figure 2 compares the percentage of funding as stated by the measure to be local funding (stated local return) with the percentage of the measure considered local return by the definition used by the authors (total local return). For example, Alameda Measure B1 (2012) allocates 20\% of measure funds to localities through its "local streets and roads" program, but it also allocates funds to localities through two separate programs that address mobility challenges and support complete streets programs. These programs add up to an additional $6 \%$ of measure revenue, bringing the final local return, as used in this report, to $26 \%$ of measure revenue. Red bars indicate measures for which the total local return was less than what was stated in the measure. Of the 58 measures, five measures had a lower total local return than stated, because some of the funds described as local in the measure text were not distributed to the cities but retained by the measure administering agency for use on predetermined regional projects. Eight measures had a larger total local return than stated because of by-right allocations to cities from multiple programs apart from the stated local return category, indicated by green bars in the figure. These measures included separate funding categories designated for bikes and pedestrians, and three also included allocations for paratransit.

\subsection{Amount of Measure Revenues Dedicated to Local Return Funding}

Of the 58 measures that include local return in the expenditure plan, the lowest percentage of total revenues allocated to local return programs was 10\%, the highest was $99 \%$, and the average allocation was 35\% (Figure 3). Three measures heavily influence the average allocation by dedicating between $90 \%$ and $100 \%$ of revenues to local return (Imperial's 2008 Measure D, Napa's 2012 Measure T, and Humboldt's 2016 Measure U). The 25\% to 75\% range for local return allocation allocated $20 \%$ to $44 \%$ of total measure revenues dedicated to local return.

Figure 3. Percentage of LOST Revenues Dedicated to Local Return

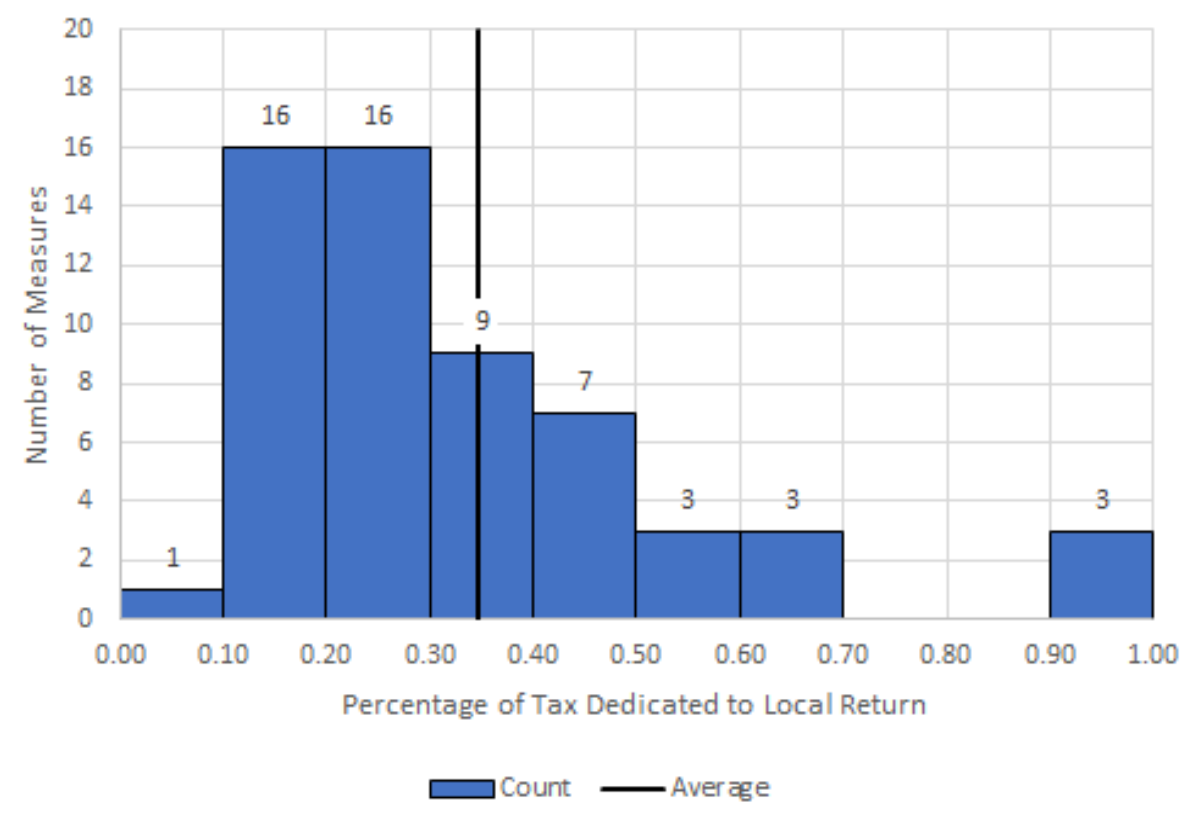


Figure 3 shows the average local return dedication across all measures on the ballot in a given year. The figure shows a slight increase in the proportion of measure revenues dedicated to local return over time. Again, outliers have a large effect on the small sample size for each year. For example, Santa Barbara's Measure D was the only measure passed in 1989, and it dedicated $70 \%$ of revenue to local return. Because of this, the upward trend in 1989 was the result of a single measure, rather than an average of multiple measures.

Figure 4. Average Local Return of All LOST Measures with Local Return by Year

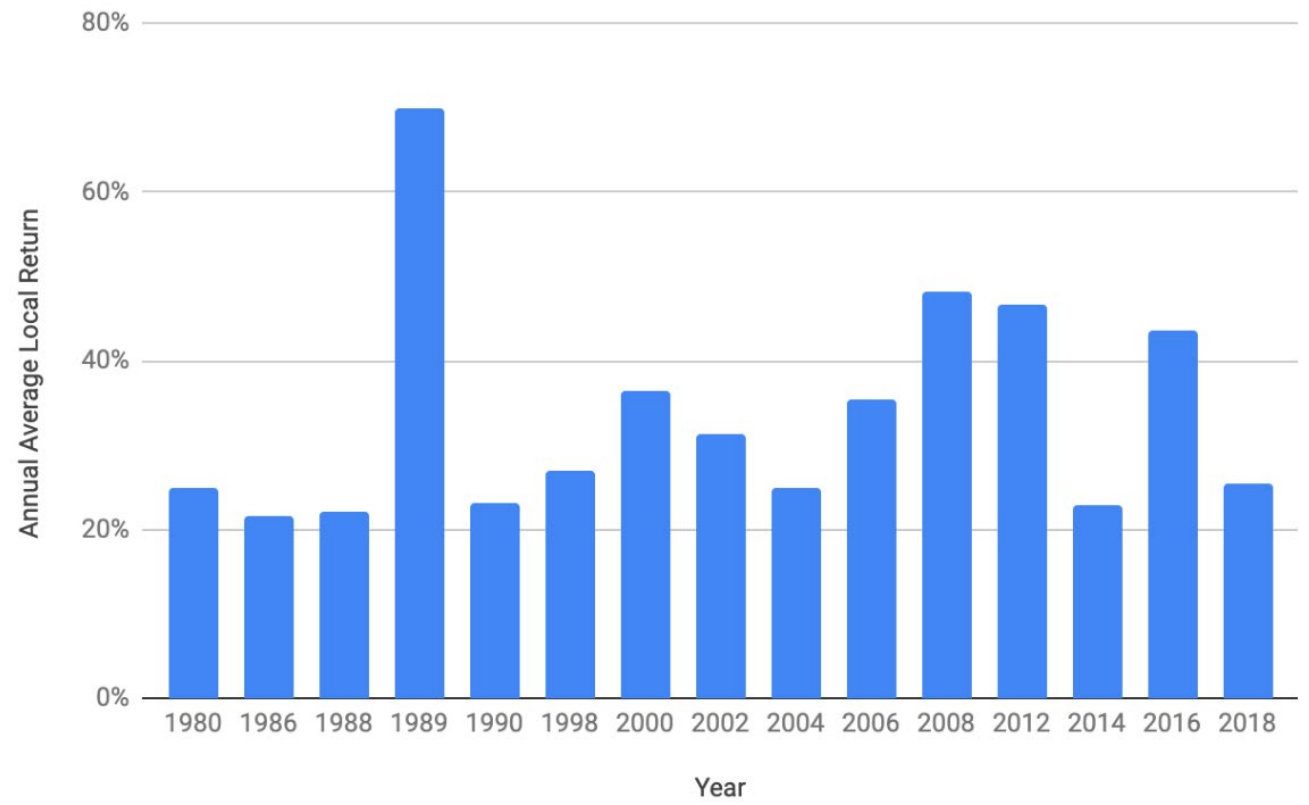

\subsection{How Local Return Funding is Allocated Among Municipalities}

Sales tax revenues generated by measures are collected by the transportation agency administering the measure. Revenues are then distributed to jurisdictions in the county, typically according to a formula. This chapter discusses the variations of allocation formulas among LOST measures and how the variables used in the formula reflect the unique transportation geography of each county. Note that for the analysis in this chapter, the authors only considered stated local return programs as previously described because some programs that account for a small percentage of local return funding have distinct allocation mechanisms.

\section{Common Variables Used in Allocation Formulas}

After allocating a percentage of the total tax to local return, most measures annually distribute the local return program funds to jurisdictions using a formula. Formulas typically involve a combination of population, road miles, ${ }^{36}$ and sales tax generation. Even in measures that only use 
one or more of these three variables, however, there are some important differences among measures in terms of which variables are considered, how they are defined, how often they are updated, and how often funds are distributed. Other measures use different variables, such as vehicle miles traveled, or added procedures such as allocating a percentage first to specified regions, which then is distributed (or suballocated) to localities based on a formula.

Of the 58 measures studied, 17 measures across 11 counties included a base allocation to ensure that no locality receives less than the specified amount, which is most beneficial to smaller cities in the county. The lowest base allocation is $\$ 50,000$ per year (Contra Costa 1988 , Humboldt 2016, San Diego 2004, Santa Barbara 1989, Santa Barbara 2006). Ventura's Measure AA (2016) had the highest base allocation of $\$ 500,000$ per year, double that of the next highest, Placer's Measure $\mathrm{M}$, at $\$ 250,000$ per year. ${ }^{37}$

The vast majority of measures allocated funds based on city population, road miles, or both. Allocation based on population ensures that all taxpayers receive some proportional benefit from their contribution to the tax, whereas a road miles variable can be used to ensure that funding is distributed to areas with infrastructure in need of repair. Only one measure (Stanislaus Measure $\mathrm{K}$, 2006) had a known allocation formula that did not use either population or road miles. Funds for this measure were returned based on sales tax generation. Population was the most common variable used to allocate local returns, with 52 local return measures considering population in their allocation formulas. Of these measures, 17 allocated funds solely based on population. Road miles was the second most common variable and was included in 34 measures; the exact measurement of road miles affected funding allocation, which is discussed in the following section. Only one measure (Ventura, Measure AA) distributed funds solely based on road miles, whereas 18 measures used road miles to determine at least $50 \%$ of their distribution. There were 17 measures used 50\% population and $50 \%$ road miles. For a further breakdown of how much population and road miles measures affected the local return formulas, see Table 3. As previously described, the table demonstrates that population was used across many measures and tended to comprise a large portion of the overall distribution formula. Road miles was also used often but was more likely to comprise a lower percentage of the total formula. 
Table 3. The Use of Population and Road Miles in Local Return Allocation Formulas

\begin{tabular}{|c|c|c|}
\hline Variable & Percent Weight in Allocation Formula & $\mathrm{N}$ \\
\hline \multirow[t]{4}{*}{ Population $(n=52)^{\mathrm{a}}$} & Between $0 \%$ and $50 \%$ (noninclusive) & 1 \\
\hline & $50 \%$ & 20 \\
\hline & Between $50 \%$ and $100 \%$ (noninclusive) & 11 \\
\hline & $100 \%$ & 17 \\
\hline \multirow[t]{4}{*}{ Road Miles $(n=34)^{\mathrm{b}}$} & Between $0 \%$ and $50 \%$ (noninclusive) & 14 \\
\hline & $50 \%$ & 17 \\
\hline & Between > 50\% and 100\% (noninclusive) & 0 \\
\hline & $100 \%$ & 1 \\
\hline 50\% Population and 50\% Road Miles & & $17^{\mathrm{c}}$ \\
\hline \multicolumn{3}{|c|}{ a Includes three measures that included population, but the exact formula was unknown. } \\
\hline \multicolumn{3}{|c|}{ b Includes two measures that included road miles, but the exact formula was unknown. } \\
\hline \multicolumn{3}{|l|}{$\begin{array}{lll}c & \mathrm{H}\end{array}$} \\
\hline \multicolumn{3}{|c|}{$\begin{array}{l}\text { miles allocation for a portion of the county. Due to the elevated presence of private resorts with privately maintained } \\
\text { roads and the high number of vacation residences, the Coachella Valley region uses dwelling units instead of population. } \\
\text { The distribution of local return revenues in Riverside County is discussed further below. }\end{array}$} \\
\hline
\end{tabular}

The third most common variable used for allocation was sales tax generation in the jurisdiction, returning more funding to jurisdictions with commercial districts. Whereas seven of the measures considered sales tax generation, most often in combination with population and road miles, only one county (Stanislaus) considered only sales tax generated. Finally, one measure, Tulare Measure $\mathrm{R}$ (2006), included daily vehicle miles traveled in the jurisdiction as a variable in the local return allocation formula.

\section{How Road Miles are Defined Changes How Funding is Allocated}

For measures that include a road miles variable, the unit of measurement used to define how many miles of road each locality has jurisdiction over varies considerably, and these differences affect the balance of allocation between urban and rural areas. If a measure specifies lane miles, for example, it is more likely to favor urban centers with wider roads. And in contrast, rural areas contain more miles of narrower roads and thus are favored when centerline miles are used. Table 4 shows the distribution of these different definitions.

Of the 34 expenditure plans that include road miles in their allocation formula, five define road miles as lane miles, whereas four specify centerline miles. Twenty-three measures do not specify wording beyond "road miles" in the ordinance text; this was categorized as "unspecified" but likely means centerline miles, because most measures use the same figures for road miles as reported to Caltrans every year, and this is how the term is used in the Public Road Data Report. ${ }^{38}$

Both measures in Orange County use the term arterial highway miles as defined by the regional Master Plan of Arterial Highways (MPAH), reflecting a concern that different localities contribute their "fair share" of investment in the regional transportation system. ${ }^{39}$ As the plan states, "Consistency with the MPAH is essential to the integrity of a functional regional highway 
network. It ensures that cities and the County implement their share of the regional transportation network using similar standards and assumptions ... Consistency with the MPAH is a prerequisite ... for local agencies to be eligible for all Measure M2 Net Revenues as well as programs."

Table 4. Number of Measures Using Different Definitions of Road Miles

\begin{tabular}{|l|c|}
\hline \multicolumn{1}{|c|}{ Definition of Road Miles } & $N$ \\
\hline Unspecified & 23 \\
\hline Centerline Miles & 4 \\
\hline Lane Miles & 5 \\
\hline Arterial Highway Miles & 2 \\
\hline
\end{tabular}

\section{Subregional Allocations}

A few counties, such as Santa Barbara and Riverside, allocated funds to specified regions in the county and distributed them to jurisdictions throughout each region based on a formula. Santa Barbara, for example, divides local return revenues between the North County and South Coast subareas, which are then allocated to jurisdictions based on population after a $\$ 100,000$ annual base allocation. San Benito gives a small percentage of funds to the city of San Juan Bautista and divides the rest equally between San Benito County and the city of Hollister. Similarly, both Alameda and Contra Costa counties use regional governments as vehicles for funneling aid to cities; although these mechanisms are largely similar to those used by counties that do not distribute subregionally, respondents from these counties indicate that they help tailor aid to the distinctive areas in their jurisdictions. 


\section{Riverside: Subregional Local Return Programs Managed by Councils of Governments (COGs)}

Riverside Measure A (2002) is unique in its distinction among subregional programs. Sales tax revenues raised in each subregion are returned to that subregion, which then allocates a different percentage of revenues to local return as determined by local needs. Riverside County refers to its local return program as return to source funding. The more densely populated western part of the county (governed by Western Riverside Council of Governments [COG]) and the Coachella Valley (governed by Coachella Valley Association of Governments) respectively dedicate 29\% and $35 \%$ of revenues to local return. Palo Verde Valley, located in the extreme eastern portion of the county on the border of Arizona, contains only one incorporated city (Blythe) and allocates all revenues to be returned to the city and this portion of the county through its local streets and road programs.

Each COG determines both the total amount of local return distributed to, and the allocation formula for distribution among, its member jurisdictions. Local return programs are frequently justified with the reason that local governments know local needs best. In Riverside, decisionmaking as to how to craft distribution and usage requirements for local return occurs at a governmental level that is larger than a city, and smaller than the county, via a subregional governance organization that represents the distinct needs of the area. In western Riverside, local return allocation is weighted $75 \%$ by population and $25 \%$ by taxable sales. In Coachella Valley, local return allocation is based $50 \%$ on dwelling units and $50 \%$ on taxable sales. Coachella Valley uses dwelling units instead of population due to the larger percentage of second homes and vacation properties in the region.

\section{Flexibility Built into the Allocation Process}

Local option sales taxes run for a long time-most last 10 to 40 years and five are permanent-so it is important to consider how stable these funding allocations are over time. This chapter describes how distribution formulas were designed to incorporate updated data over time, how often funds get distributed, and the process of amending the distribution formula. 
Because many of these measures extend over long periods, consideration must be given to how the variables used to distribute funds may change in value over time. For example, if a county uses population to determine how funding is allocated, yet there are no provisions for how often population figures are updated, the percentage allocation to each locality may continue to be disbursed based on outdated population figures indefinitely. Only 32 of the 58 measures specify how often the local return formula should be updated. As shown in Figure 5, most of these measures specify that the formula be updated annually, two biennially (Marin, 2018 and Sacramento, 2016), and two use the term "then current" (Madera, 2006 and Contra Costa, 1988). One measure states that the formula be updated in 2022 specifically (San Luis Obispo, 2016), whereas Solano's Measure H requires that the formula be updated halfway through the 20-year measure. One measure specifies that the formula never be updated (San Benito, 2018).

Figure 5. Number of LOST Measures that Update Local Return Allocation at Different Intervals

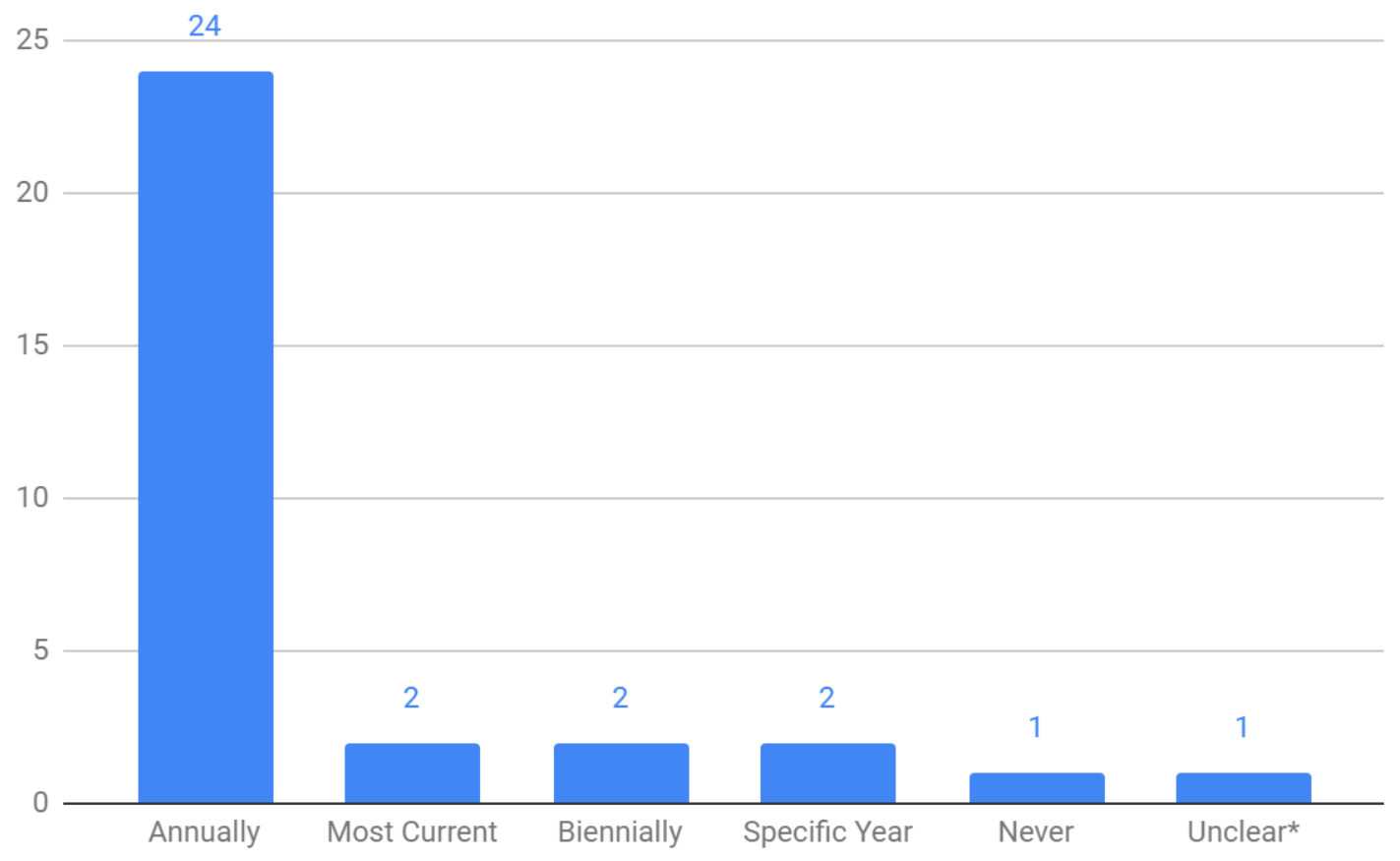

*Marin County's Measure A (2004) states that the allocation formula is balanced every 6 years, variables are updated annually, and percentages are reviewed every 2 years as part of the Strategic Plan

How Flexible is the Allocation Timing?

Funds are generally distributed yearly, but some measures build flexibility into the distribution of a locality's allocated local return funds during the life of the measure, usually to facilitate the 
implementation of larger projects that require a significant amount of capital investment. Seven measures in five counties specifically give jurisdictions the authority to lend or borrow local return funds from other local jurisdictions, and two give them the authority to lend or borrow funds from the county. Even more significant are provisions in four measures that include language that allows county agencies to distribute a jurisdiction's allocation of funds during the course of the measure, rather than guaranteeing a percentage in each distribution period. For example, Santa Cruz Measure J (2004) states:

The Auditor-Controller and Commission are authorized to make maximum use of available funds by temporarily shifting allocations between projects and programs which are included in the Plan, so long as no project included herein is deprived of needed funding. However, the proportionate shares for areas and purposes over the 30-year period may not be changed without an amendment of the Plan, as approved by the voters.

\section{How can Allocation Formulas be Amended?}

Another element of flexibility in fund allocation is how easy it is to amend the allocation procedure. Unlike the preceding chapter that analyzes how formulas are updated with new information over time, this refers to changes to the formula or method of distribution itself. Seven measures stipulate stricter amendment procedures for local return allocation formulas, compared to amendments to the rest of the expenditure plan or ordinance. For example, Imperial's 2008 measure states that the expenditure plan may be amended by a two-thirds vote of the transportation authority, but specifically exempts local return from that amendment procedure. The local return allocation formula instead requires a majority vote by the Imperial County Board of Supervisors and a majority of the incorporated cities representing a majority of the population to amend. Los Angeles' 2008 Measure R and 2016 Measure M specifically state that no amendment can alter the amount of funds going to local returns.

\section{The Relationship between Urbanization and Funding Allocation}

To analyze trends and patterns in how local return funds are distributed, the authors compared the distributions and allocation formulas of each measure to the county's level of urbanization. As an indicator of the level of degree of urbanization in the county, the authors used the U.S. Department of Agriculture's Rural-Urban Continuum Code (RUCC), which "distinguishes metropolitan counties by the population size of their metro area, and nonmetropolitan counties by degree of urbanization and adjacency to a metro area." ${ }^{40}$ The highest (and therefore most rural) value included in this study was a RUCC of 5, indicating that the population of the county is greater than 20,000, but it is not adjacent to an urban area. See Table 5 for definitions of included RUCC values. 


\section{Table 5. Rural-Urban Continuum Code Definitions}

\begin{tabular}{|c|c|}
\hline \multicolumn{2}{|r|}{2013 Rural-Urban Continuum Codes } \\
\hline Code & Description \\
\hline \multicolumn{2}{|r|}{ Metropolitan Counties } \\
\hline 1 & Counties in metro areas of 1 million population or more \\
\hline 2 & Counties in metro areas of 250,000 to 1 million population \\
\hline 3 & Counties in metro areas of fewer than 250,000 population \\
\hline \multicolumn{2}{|r|}{ Nonmetropolitan Counties } \\
\hline 4 & Urban population of 20,000 or more, adjacent to a metro area \\
\hline 5 & Urban population of 20,000 or more, not adjacent to a metro area \\
\hline
\end{tabular}

Local return allocations tend to increase when the county has a higher RUCC value (indicating that the county tends to be more rural). A clear example of this is Humboldt County, the only county with an RUCC score of 5, which had a local return of 99.5\% (Measure U, 2016). A possible explanation for the increase of local return percentage with a higher RUCC is that local returns are being used as a guarantee to rural voters that the benefits of the tax will not accrue disproportionately to dense urban areas. Additionally, rural counties would be less likely to use LOSTs to fund regional capital transit investment, as is common in urban counties in California. ${ }^{41}$ 
Figure 6. Comparison of RUCC Score and Percentage of Measure Dedicated to Local Return

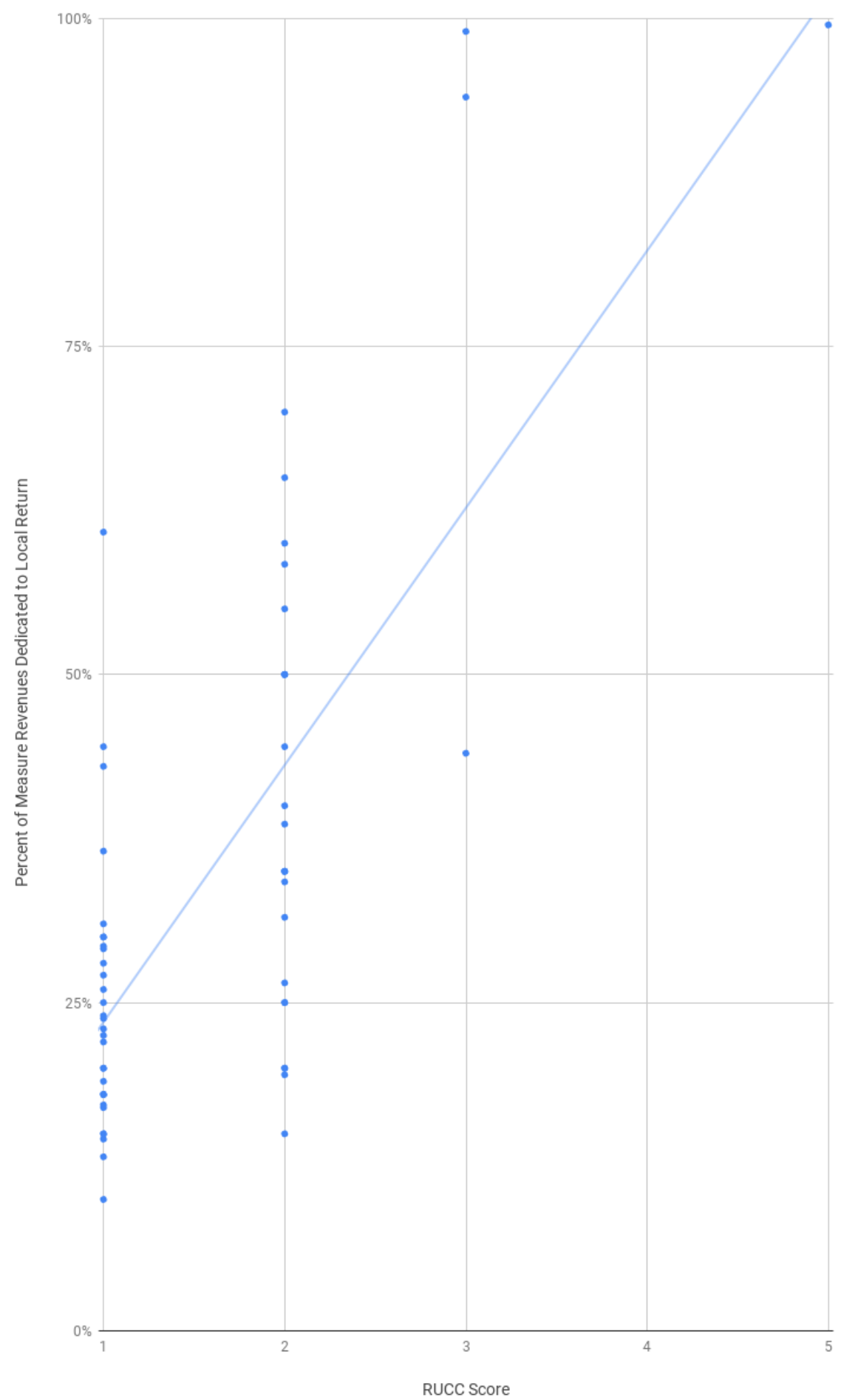

Table 6 compares measures that do and do not include road miles in their local return distribution calculation, sorted by their RUCC number. Although there are not enough data to discern any 
patterns regarding rural areas due to the low number of rural counties that have placed LOST measures on the ballot, the table shows that counties with high populations, i.e., those with an RUCC value of 1 , are more likely to include a road miles variable. Unless the measure specifies that these funds are distributed based on lane miles rather than general road miles, this method is more advantageous to more rural areas than a distribution by population, which is more beneficial to urban areas. This may suggest that officials in counties with a large proportion of their population in urban areas are concerned about rural populations receiving their "fair share" of measure revenues. For example, Fresno's Measure C (2006) uses road miles as part of the formula, giving a larger slice of the funding to rural areas, which have smaller populations but more road miles. $^{42}$

Table 6. Inclusion of Road Miles as an Allocation Variable by RUCC Score

\begin{tabular}{|c|c|c|c|}
\hline RUCC & Include Road Miles & $\begin{array}{c}\text { Do Not Include } \\
\text { Road Miles }\end{array}$ & Total \\
\hline 1 & 21 & 10 & 31 \\
\hline 2 & 12 & 11 & 23 \\
\hline 3 & 1 & 2 & 3 \\
\hline 4 & 0 & 0 & 0 \\
\hline 5 & 1 & 0 & 1 \\
\hline
\end{tabular}

\subsection{Eligibility to Receive Local Return Funds}

Some measure ordinances include county-specific requirements that cities must meet to receive their local return funds. These preconditions are defined as requirements that, if not fulfilled, will result in funding being suspended, withdrawn, or revoked. ${ }^{43}$ For example, some measures require cities to implement a development impact fee before they are eligible to receive funding. Such prerequisites generally do not dictate how cities spend local return funding, which is discussed later in this chapter, but they can place significant demands on localities and affect local planning decisions. They can be valuable policy tools for counties and are developed to address specific regional goals that appeal to voters and other stakeholders. In this way, local return funding is used to encourage local government participation in planning to meet regional goals.

The requirements discussed here influence how localities plan their communities by participating in a regional planning program or adopting a specified local policy. The most common of this type of prerequisite is a requirement that cities implement a development impact fee. Other measures condition funding on compliance with a regional planning document. Some measures require jurisdictions invest in specific types of projects or programs before receiving local return funds. Requiring a local pavement management plan is also common. Note that additional prerequisites to funding also act as accountability measures, requiring localities to certify that they comply with 
measure requirements and, in some cases, have projects approved by the measure authority. These are discussed in Chapter $\mathrm{V}$.

\section{Development Impact Fees}

The requirement of a development impact fee is the most common prerequisite for local jurisdictions to receive local return funding, which is included in 16 measures from 11 counties. This requirement involves either adopting a regional development impact fee locally or implementing some kind of local impact fee; it usually includes language ensuring that new development pays its "fair share" of the costs of development. For example, Merced County's Measure G (2006) states:

To receive funds from the Local Roads Maintenance and Improvements program of this plan, a jurisdiction must have a development mitigation program and be collecting transportation impact fees, including, but not limited to, the Regional Transportation Impact Fee, to ensure that new growth pays for its share of the transportation infrastructure costs associated with that growth.

Similarly, San Benito's Measure G (2018) states:

Each city and the county shall maintain participation in the Regional Traffic Impact Mitigation Fee program and shall impose the adopted fees on new development as applicable, to ensure new development pays for its impacts on the regional transportation system.

Contra Costa and Sacramento implemented the first development impact fee requirements with their first measures in 1988, and both included the requirement in subsequent measures. Appendix $\mathrm{C}$ shows the language that appears in measures that require jurisdictions to enact a development impact fee as a prerequisite for receiving local return funding.

Interviews with local officials in counties that require such fees reveal few, if any, concerns about them. Occasionally, however, cities have elected to forego local return funding by declining to collect development fees. This occurred in the city of La Quinta in Riverside County and as required by the measure, the city forfeited its LOST funds. More recently, in 2013, the city decided to opt back in and is in the process of becoming eligible for the funding again.

In Alameda County, officials from both Hayward and Berkeley explained that their cities are very supportive of the policy goals embodied by the development fees and related provision in the county's LOST measure. An official from Hayward added that the city (in his view) wants to be "as multimodal as possible," and thus supports more funds for pedestrian, cycling, and transit resources in a manner consistent with that priority. ${ }^{44}$ 
Interviews with city officials in counties selected for this study reveal no opposition to county requirements to collect development fees. It would seem that any objections that these city officials might harbor are outweighed by their need to access LOST revenues.

\section{Riverside County Development Impact Fees}

Riverside County requires that funded local governments participate in a Transportation Uniform Mitigation Fee (TUMF) program that the county commission or the Western Riverside Council of Governments develops and administers. The TUMF fees are essentially fees paid by developers that create new dwellings. The TUMF proceeds are used to fund the regional arterial system and the development of new corridors (through the Community Environmental Transportation Acceptability Process).

One city (La Quinta) opted out of the program for a time (circa 2013), foregoing local return funding from the LOST, apparently as a strategic decision. However, it is now participating and in the process of repaying the fees that it did not collect to qualify for full funding in the future. In the early 2000s, another city (Beaumont) collected fees but elected not to remit them to the county, which resulted in an indictment against local officials. Apparently, city officials felt that they were not legally required to remit the fees; ultimately, however, courts ruled that the city had to repay them. By 2017, the city was in compliance (i.e., collecting and remitting the fees) and receiving its local return funding.

\section{Growth Management Programs}

A total of five measures in three counties require cities to participate in regional growth management programs to receive local return funding. This includes Contra Costa's Urban Limit Line, Orange County's Growth Management Program, and Riverside's Multi Species Habitat Conservation Plan. These measures require localities to certify compliance with the county growth management plan before they are eligible to receive funds. 


\section{Contra Costa Growth Management Program}

Contra Costa County requires that to qualify for LOST funds, participating cities annually participate in a county-wide Growth Management Program. Specifically, the measure states that:

Each jurisdiction shall demonstrate its compliance with all of the components of the Growth Management Program in a completed compliance checklist. The jurisdiction shall submit, and the Authority shall review and make findings regarding the jurisdiction's compliance with the requirements of the Growth Management Program, consistent with the Authority's adopted policies and procedures ... If the Authority determines that the jurisdiction does not comply with the requirements of the Growth Management Program, the Authority shall withhold those funds and also make a finding that the jurisdiction shall not be eligible to receive Contra Costa Transportation for Livable Communities until the Authority determines the jurisdiction has achieved compliance. The Authority's findings of noncompliance may set deadlines and conditions for achieving compliance.

The plans are embodied in a checklist of items that each city must submit each year to quality for LOST revenues. A key component of the Growth Management Program is an Urban Limit Line (ULL) requirement, which limits urban development to certain areas of the county to preserve farmland and open space. Local officials generally support this requirement, although the ULL occasionally creates friction between cities and the county. For example, in recent years, two cities advanced proposals that would have extended beyond their limits. Eventually, they withdrew these proposals and remained in compliance. Cities may be ambivalent about the ULL provisions; on one hand, they want to remain in compliance and receive funding, but on the other hand, they are sometimes under pressure from developers to exceed the limits.

Additionally, existing law allows cities to bypass the ULL and seek annexations under state laws through a ruling by the county's Local Agency Formation Commission. However, to date, cities have not chosen this potentially more contentious approach. 
Jurisdictions in Western Riverside, in addition to collecting development impact fees, must also participate in the Western Riverside Multi-Species Habitat Conservation Plan to receive local return funding. The regional conservation plan was put in place to meet requirements under the federal and state Endangered Species Acts by directing growth away from endangered species habitat. Participating cities charge additional fees when issuing building permits, the revenues from which are used to support conservation purchases by a regional agency. ${ }^{45}$

Although potentially controversial, the approach of tying compliance to county growth management goals seems to result in outcomes that are consistent with county priorities without undue opposition from local authorities. In Alameda County, for example-one of the counties with more demanding restrictions on LOST funds-none of the interviewed local officials reported any problems complying with such restrictions. An official from the city of Alameda explained that "without this money, the city would be reduced to filling potholes; with it, the city can work towards more ambitious policy goals, such as lower vehicle miles traveled and reducing vehicle emissions." Officials from Oakland, Berkeley, and Hayward made similar comments, and each seemed quite comfortable with the county's funding requirements. The transportation division manager of the public works department of the city of Hayward explained:

[The city] does not feel constrained by the [Alameda County Transportation Commission] requirements for funding. The city wants to be as multimodal as possible, and it supports more transit/pedestrian/bike-and it uses funds in a manner consistent with that priority. ${ }^{44}$

In fact, none of the officials from any of the cities who were interviewed expressed objections or problems with compliance.

\section{Contribution of Nonmeasure Funding to Specific Funding Purposes}

Three counties included language that requires localities to fund projects supporting regional connectivity to be eligible for local return funding. For example, Los Angeles Measure M (2016) requires that localities make a $3 \%$ contribution to regional rail transit lines that cross their jurisdiction. In this case, localities have the option of using local return funds, but the requirement can also be satisfied using external funds. In contrast, Napa Measure T (2012) requires that localities dedicate funds specifically from nonmeasure revenues to bike lane projects to support a regional connectivity plan. These requirements further support the notion that requirements placed on local return funding can be used to support regional planning programs. Similarly, Sacramento Measure A1 (1988) and Measure A2 (2004) require that counties maintain previous levels of funding for paratransit services and that funding could come from either measure funds or other local monies. See Table 7 for relevant language in measure ordinances and expenditure plans. 
Table 7. Measure or Expenditure Plan Text Describing Requirements Involving Growth Management Plans or Nonmeasure Fund Contributions

\begin{tabular}{|c|c|c|c|}
\hline County & Measure & Year & Text \\
\hline Contra Costa & Measure C & 1988 & $\begin{array}{l}\text { In order to receive local street maintenance and improvement } \\
\text { funds from the Authority, each jurisdiction shall biennially submit } \\
\text { a statement of compliance with the Growth Management } \\
\text { Program. }\end{array}$ \\
\hline Contra Costa & Measure J & 2004 & $\begin{array}{l}\text { To receive its share of Local Transportation Maintenance and } \\
\text { Improvement funds and to be eligible for Contra Costa } \\
\text { Transportation for Livable Communities funds, each jurisdiction } \\
\text { must: Adopt a growth management element ... adopt an Urban } \\
\text { Limit Line (ULL) ... If the Authority determines that the } \\
\text { jurisdiction does not comply with the requirements of the Growth } \\
\text { Management Program, the Authority shall withhold those funds } \\
\text { and also make a finding that the jurisdiction shall not be eligible } \\
\text { to receive Contra Costa Transportation for Livable Communities } \\
\text { until the Authority determines the jurisdiction has achieved } \\
\text { compliance. }\end{array}$ \\
\hline Los Angeles & Measure M & 2016 & $\begin{array}{l}\text { The Measure M Ordinance includes a provision for 3\% local } \\
\text { contribution to major rail transit capital projects. } \\
\text { The Ordinance calculates the local contribution based on the } \\
\text { centerline track miles within a local jurisdiction with a new } \\
\text { station in those jurisdictions. } \\
\text { Eligible fund sources to satisfy } 3 \% \text { local contribution include any } \\
\text { funds controlled by the local agency or local agencies ... or any } \\
\text { funds awarded from non_Metro competitive grant process } \\
\text { funding. }\end{array}$ \\
\hline Napa & Measure T & 2012 & $\begin{array}{l}\text { Once this measure becomes operative, in order to receive annual } \\
\text { allocations under this measure, the Agencies (collectively) must } \\
\text { demonstrate that at least six and sixty-seven one-hundredths } \\
\text { percent ( } 6.67 \% \text { ) of the value of the allocations each year under } \\
\text { Section } 3(\mathrm{~A}) \text { has been committed to Class I Bike lane project(s) } \\
\text { identified in the adopted Countywide Bicycle Plan, as that Plan } \\
\text { may be amended from time to time, through funding not derived } \\
\text { from this Ordinance. }\end{array}$ \\
\hline Orange & Measure M1 & 1990 & $\begin{array}{l}\text { In order to receive Retail Tax Revenues from the Authority, local } \\
\text { jurisdictions must meet ... those requirements relating to growth } \\
\text { management which are described in the Growth Management } \\
\text { Program ... local jurisdictions ... shall adopt administrative } \\
\text { requirements to implement the Growth Management Program in } \\
\text { each local jurisdiction. } \\
\text { As a further prerequisite to receiving Retail Tax Revenues from } \\
\text { the Authority, within six months after approval of the Retail Tax } \\
\text { by the electors, local jurisdictions ... shall approve growth } \\
\text { management areas ("GMAs") to facilitate multi-jurisdictional } \\
\text { cooperation on traffic projects and improvements within GMAs } \\
\text { ("GMA Improvement Projects"). }\end{array}$ \\
\hline
\end{tabular}




\begin{tabular}{|c|c|c|c|}
\hline County & Measure & Year & Text \\
\hline Riverside & Measure A2 & 2002 & $\begin{array}{l}\text { The cities and the county in the Western County Area must } \\
\text { participate in the Multi Species Habitat Conservation Plan } \\
\text { (MSHCP) by endorsing the Permit Allocation and executing the } \\
\text { Implementation Agreement with the resources agencies in order } \\
\text { to be eligible to receive local streets and roads funds. }\end{array}$ \\
\hline Sacramento & Measure A1 & 1988 & $\begin{array}{l}\text {... the Authority shall not allocate any Sales Tax revenues for } \\
\text { expenditure by the County or Sacramento unless each such } \\
\text { recipient entity has, for the year for which the allocation is made, } \\
\text { paid to the consolidated Transportation Services Agency for } \\
\text { (Elderly and Handicap Transportation) Functions an amount at } \\
\text { least equal to that paid by the Entity for the 1986-87 fiscal years. }\end{array}$ \\
\hline Sacramento & Measure A2 & 2004 & $\begin{array}{l}\text {... the Authority ... shall not allocate any Sales Tax revenues for } \\
\text { expenditure by the County or Sacramento unless each such } \\
\text { recipient entity has, for the year for which the allocation is made, } \\
\text { paid to the consolidated Transportation Services Agency for } \\
\text { (Elderly and Handicap Transportation) Functions an amount at } \\
\text { least equal to that paid by the Entity for the 1986-87 fiscal years. }\end{array}$ \\
\hline
\end{tabular}

Note: Similar to the development impact fees described in the table, Orange County Measure M1 (1990) also requires cities to comply with the regional Growth Management Plan before receiving funds ${ }^{46}$ as discussed in Chapter V. ${ }^{47}$ The growth management program includes a requirement that cities implement a development impact fee. But the growth management plan is not established through the LOST measure expenditure plan and is subject to a separate amendment and implementation process. It therefore is not included as a development impact fee that is directly tied to the receipt of local return funding.

\section{Adopting a Local Pavement Management Plan}

In addition to certifying compliance with regional growth management plans, five measures in three counties require that localities develop a pavement management plan or program, incorporating the local Pavement Condition Index (PCI). Generally, this requires creating a report on the locality's PCI, but Alameda also requires that the locality describe a pavement improvement plan in the report if its PCI falls below 60 (indicating a "good" condition; Alameda Measure B [2000] and Measure B [2014]). Additional measures require cities to spend local return funds in particular ways based on their PCIs. This is discussed in Chapter V.

\section{Local Response to County Funding Requirements}

As described earlier, city officials generally do not have explicit disagreements with county policy priorities embodied in LOST provisions for collecting development fees. Similarly, they often are supportive, if not always proactively, of similar funding requirements, summarized in 0 . For example, Contra Costa County's requirement that cities establish ULLs is uncontroversial as a concept, even though minor skirmishes break out over annexation plans by individual cities. Interviews with city officials reveal that cities feel some pressure from developers to approve more growth, but to date, they ultimately stand by the policies. Apparently, doing little or nothing to appease developers is ultimately more desirable than losing local return funding. 
In some instances, however, cities have opted out of such policies-albeit usually for only a temporary, brief time. In Contra Costa County, the city of Pittsburg initially declined to participate in a subregional mitigation program requirement. Within a few years, it reversed that approach and returned to compliance. Also in Contra Costa County, the city of Danville was failing to meet a level-of-service requirement-not necessarily due to opposition to the provision. The issue was settled via negotiation and the funding was never curtailed. ${ }^{48}$

\subsection{Requirements Placed on How Jurisdictions Spend Local Return Funding}

Findings suggest that many measures include specific requirements regarding how local return funds are used, limiting the discretion of local jurisdictions. After localities have received their allocated measure funds, they are often constrained by the ordinance as to how those funds can be used. This chapter explores how these requirements reveal a nuanced portrait of local needs across different counties. For this section, the analysis considers the total local return funding distributed to cities (as opposed to stated local returns).

\section{Local Return is Often Required to be Spent on Specific Modes or Categories}

This chapter analyzes how local return funding is often required to be divided into different categories of spending - most often by mode of transit (such as bikes and pedestrians, streets and roads, public transit, etc.), but occasionally for other purposes (such as ADA compliance). These limitations frequently require a percentage of local return funding to be spent on a specific mode, for example, bicycle and pedestrian infrastructure. Other forms of modal split include a maximum (no more than a certain percentage of local return funds can be used for a category), a minimum (at least a certain percentage must be dedicated to a category), or a spending requirement that only applies to a subset of jurisdictions. Counties also constrain local use of funds by restricting expenditures to maintaining and repairing local streets and roads until the jurisdiction's PCI rises above a certain level.

Figure 7 shows a by-measure analysis of the percentage of local return funds that are subject to modal spending requirements and the percentage that can be spent flexibly and without restriction. Of the 58 measures studied, 29 restrict spending for at least some portion of local return. An average of $33.1 \%$ of all local return funding has some form of spending restriction. 


\section{Figure 7. Categorical Spending Requirements by Percentage of Local Return}

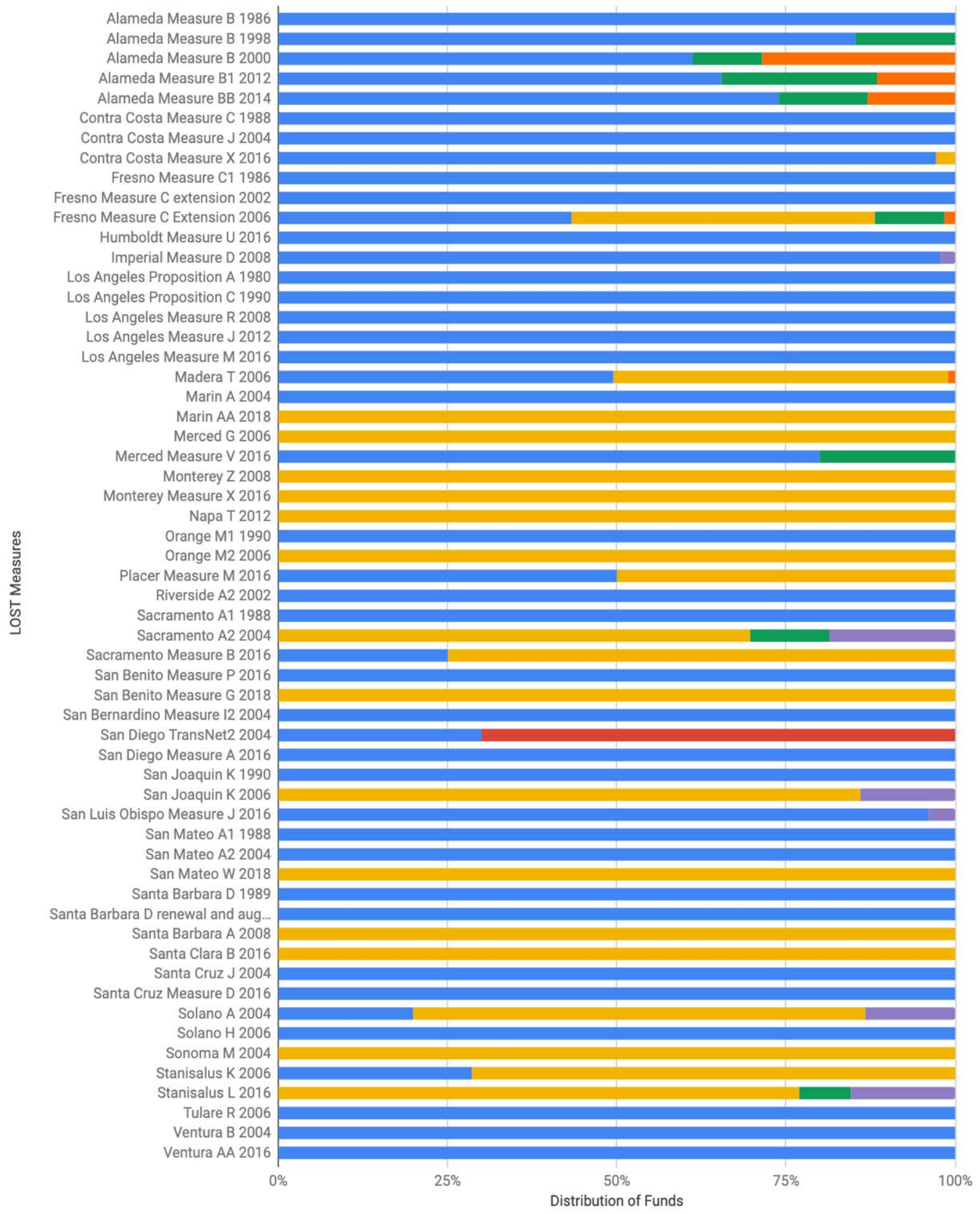


The most common spending restriction, present in 20 measures, prescribes at least some funds to be used strictly for road repair and maintenance. Of these, ten measures distribute $100 \%$ of their local returns to road repair and maintenance. Only one measure, San Diego TransNet (2004), restricts a portion of local returns to new capital and infrastructure.

\section{Restrictions on Local Return Spending}

As shown in Table 8, the most common restriction on local return spending is the requirement that revenues be spent on local street repair and maintenance. Local street repair and maintenance spending requirements also applied to a comparatively larger average share of local return (80\%) than other modal spending requirements. Measures that restrict some portion of local return funding to be spent on maintenance of local streets and roads have a slightly higher average local return compared to measures that designate all local return as flexible (38\% vs. 30\%, respectively).

Table 8. Local Return (LR) Spending Requirements and Measure Characteristics by Modal Spending Category

\begin{tabular}{|l|c|c|c|}
\hline \multicolumn{1}{|c|}{$\begin{array}{c}\text { Spending } \\
\text { Requirement }\end{array}$} & $\begin{array}{c}\text { Number of Measures } \\
\text { Including Spending } \\
\text { Requirement }\end{array}$ & $\begin{array}{c}\text { Average } \\
\text { Percent of LR } \\
\text { Subject to } \\
\text { Requirement }\end{array}$ & $\begin{array}{c}\text { 25-75 Percentile } \\
\text { Range of LR Subject } \\
\text { to Requirement } \\
\text { (Quartile) }\end{array}$ \\
\hline Capital Investment & 1 & $70 \%$ & n/a \\
\hline $\begin{array}{l}\text { Local Street Repair } \\
\text { and Maintenance }\end{array}$ & 20 & $80 \%$ & $69 \%-100 \%$ \\
\hline Bike and Pedestrian & 8 & $14 \%$ & $10 \%-16 \%$ \\
\hline Paratransit & 5 & $11 \%$ & $2 \%-13 \%$ \\
\hline Other & 7 & $12 \%$ & $9 \%-16 \%$ \\
\hline
\end{tabular}

Eight measures (four from Alameda, resulting in five originating counties) required a percentage of funds be spent on the development of infrastructure for bicycles and pedestrians, but this was generally a small part of local return. The measure with the largest percentage of local return dedicated to bike and pedestrian infrastructure was Alameda Measure B1 (2012), which required that $23 \%$ of local return funds be used for bikes and pedestrians. 


\section{Fresno County Bicycle and Pedestrian Programs}

Fresno County Measure C (2006) spending requirements for bike and pedestrian infrastructure and recreational trails reflect the specificity that can be attached to these requirements to best meet the needs of all cities in the county. The measure also includes two separate programs the distribute funding directly to jurisdictions: the Pedestrian/Trails Program (3.1\% of measure revenues) and the Bicycle Facilities Program (0.9\% of measure revenues). The Pedestrian/Trails program is further broken down so that $2.15 \%$ of measure revenues in this category are allocated to urban areas and $0.95 \%$ are allocated to rural areas, a funding split that does not reflect population.

According to an interviewee, the intent for these programs is for the pedestrian and trails program to provide safe recreation and walkability, and the bicycle facilities program to support bike commuting corridors and regional connectivity. One interviewee noted that during the development of the measure expenditure plan, spending transportation funding on bicycle and pedestrian infrastructure was not a popular idea and was considered more of an amenity than a transportation usage. In larger cities in the county, bike and pedestrian infrastructure was more common at the time the measure was placed on the ballot, and some constituents supported this investment as a way to increase property value.

Cities with populations under 25,000 are exempt from both programs and can use the funding flexibly instead. Cities with a population between 25,000 and 75,000 can combine the funding they receive for both programs to spend for any purpose qualified under either of the programs. Cities with a population above 75,000 must meet the requirements of both programs. ${ }^{49}$ If cities do not meet the percentage spending requirements, an equal amount of flexible funding is withheld the following year.

According to interviewees, the specificity of these two programs has at times been confusing and required a plan amendment to clarify and meet county needs. Although funding for the programs is distinct, in practice the lines have blurred, and implementation is discussed together in the ordinance. To receive funding under either of these programs, jurisdictions were required to adopt, by 2012, a "Master Plan for Trail, Bicycle and Pedestrian Facilities that promotes connectivity within all of Fresno County and its urban 
areas.” Funded projects were then required to be consistent with the developed and approved master plan. Most smaller rural cities did not have such a plan and used their measure funding to develop one, and additional funding under the program accumulated until the plan was approved. According to interviewees, all jurisdictions had approved plans within the first five years of the measure.

Overall, the bike and pedestrian programs have been mildly contentious, although all jurisdictions have complied. Smaller jurisdictions who had opposed the requirements used the funding to develop bike and pedestrian master plans. Fresno and Clovis, the largest cities in the county, had plans in place before the measure and were required to use the funding to build projects. An interviewee from the city of Fresno noted that they had pushed for bike, pedestrian, and transit programs to be included in the measures. Fresno completed significant bike infrastructure before the measure, and according to the interviewee, has already addressed all the "low-hanging fruit." As a result, it has faced significant local resistance to more significant projects such as road diets. ${ }^{50}$

The category "other" in Table 8 includes transit (Imperial Measure D, 2008), safety and traffic operations improvements (Sacramento Measure A2, 2004), roadway safety (San Joaquin Measure K, 2006 and Solano Measure A, 2004), safe routes to schools and colleges (San Luis Obispo Measure J, 2016), and traffic management (Stanislaus Measure L, 2016). Santa Barbara Measure $\mathrm{D}$ has complex and varied spending requirements and was included as "other" for this analysis. Each city and unincorporated areas in the southern portion of Santa Barbara must contribute 10\% of their respective local return to the Santa Barbara Metropolitan Transit District. Additionally, each jurisdiction must dedicate a specified amount of their revenue to "alternative transportation." In total, $17.6 \%$ of local return revenue is dedicated to these purposes.

Of the 58 measures studied, five measures had categorical requirements for local return that were not included in Table 8 . This is because the requirement: includes a maximum expenditure, rather than a minimum (for example, Los Angeles Measure M (2016) requires that no more than 33.33\% of local return funds be spent on Green Street projects); the requirement did not apply to all localities; or the required percentage modal split differed among localities. See Table 9 for more information. 
Table 9. Descriptions of Differing Modal Spending Restrictions

\begin{tabular}{|c|c|c|c|c|}
\hline County & Measure & Year & Measure Text & $\begin{array}{c}\text { Type of } \\
\text { Restriction }\end{array}$ \\
\hline $\begin{array}{l}\text { Los } \\
\text { Angeles }\end{array}$ & $\begin{array}{l}\text { Measure } \\
\mathrm{M}\end{array}$ & 2016 & $\begin{array}{l}\text { Notwithstanding any other provision of this Ordinance, no } \\
\text { recipient of Local Return program funds may expend more } \\
\text { than thirty-three and one-third percent }(331 / 3 \%) \text { of total } \\
\text { funds received in any fiscal year on Green Streets. }\end{array}$ & $\begin{array}{c}\text { Maximum } \\
\text { Spending Limit }\end{array}$ \\
\hline Madera & $\begin{array}{l}\text { Measure } \\
\mathrm{T}\end{array}$ & 2006 & $\begin{array}{l}\text { A maximum of } 69 \% \text { of the Measure proceeds can be } \\
\text { allocated to the reconstruction, rehabilitation and/or } \\
\text { maintenance of streets and roads, and ADA compliance } \\
\text { within the County and each of the cities. This maximum } \\
\text { allocation allows the local agencies to address the } \\
\text { improvement of streets and roads that provide access to } \\
\text { schools, jobs, farming activities and access to recreation areas. }\end{array}$ & $\begin{array}{c}\text { Maximum } \\
\text { Spending Limit }\end{array}$ \\
\hline Placer & $\begin{array}{c}\text { Measure } \\
\mathrm{M}\end{array}$ & 2016 & $\begin{array}{l}\text { The portion of funds under this Program designated to the } \\
\text { Non-Tahoe portion of Placer County shall include a } \\
\text { minimum of } 50 \% \text { into a "Placer County Rural Roads } \\
\text { Maintenance and Repair Fund." Expenditures from this } \\
\text { Fund shall be restricted to the repair, safety, and } \\
\text { maintenance of existing county roads, and not used for } \\
\text { capacity increasing transportation improvements, in the } \\
\text { areas represented by the following Municipal Advisory } \\
\text { Councils (MACs). }\end{array}$ & $\begin{array}{l}\text { Limited } \\
\text { Geographic } \\
\text { Area }\end{array}$ \\
\hline San Diego & Prop. A & 2004 & $\begin{array}{l}\text { No more than } 30 \% \text { of these funds should be used for local } \\
\text { street and road maintenance purposes. }\end{array}$ & $\begin{array}{c}\text { Maximum } \\
\text { Spending Limit }\end{array}$ \\
\hline Stanislaus & $\begin{array}{c}\text { Measure } \\
\mathrm{K}\end{array}$ & 2006 & $\begin{array}{l}\text { Up to } 25 \% \text { of each jurisdiction's share (of Local } \\
\text { Transportation Improvements funding) may be used for } \\
\text { pedestrian, bicycle, and transit capital projects. }\end{array}$ & $\begin{array}{c}\text { Maximum } \\
\text { Spending Limit }\end{array}$ \\
\hline
\end{tabular}

\section{Flexible Funding and Total Percentage of Local Return}

Of the 58 measures studied, 45 include at least some flexible funding. This category includes funding that is not explicitly described as flexible but is not limited or restricted to any category of spending. Of these measures, 29 do not specify funding restrictions. Of the 13 measures that do not include any flexible funding, the funding is most commonly restricted to local street repair and maintenance.

The authors considered whether any relationship existed between the total percentage of tax revenue dedicated to local return and the amount of that revenue that was flexible. As shown in Figure 8 , the percentage of local funding that is flexible decreases as the percentage of the tax dedicated to local return increases, although the relationship is weak. This provides some insight into how counties with different geographies may implement local return in different ways. As previously discussed, mostly rural counties tend to have larger local return. At the same time, 
counties with larger local return are more likely to have more restrictions on how those funds are used.

Figure 8. Percentage of Local Return Spending That is Flexible Compared to Total Percentage of Measure Dedicated to Local Return

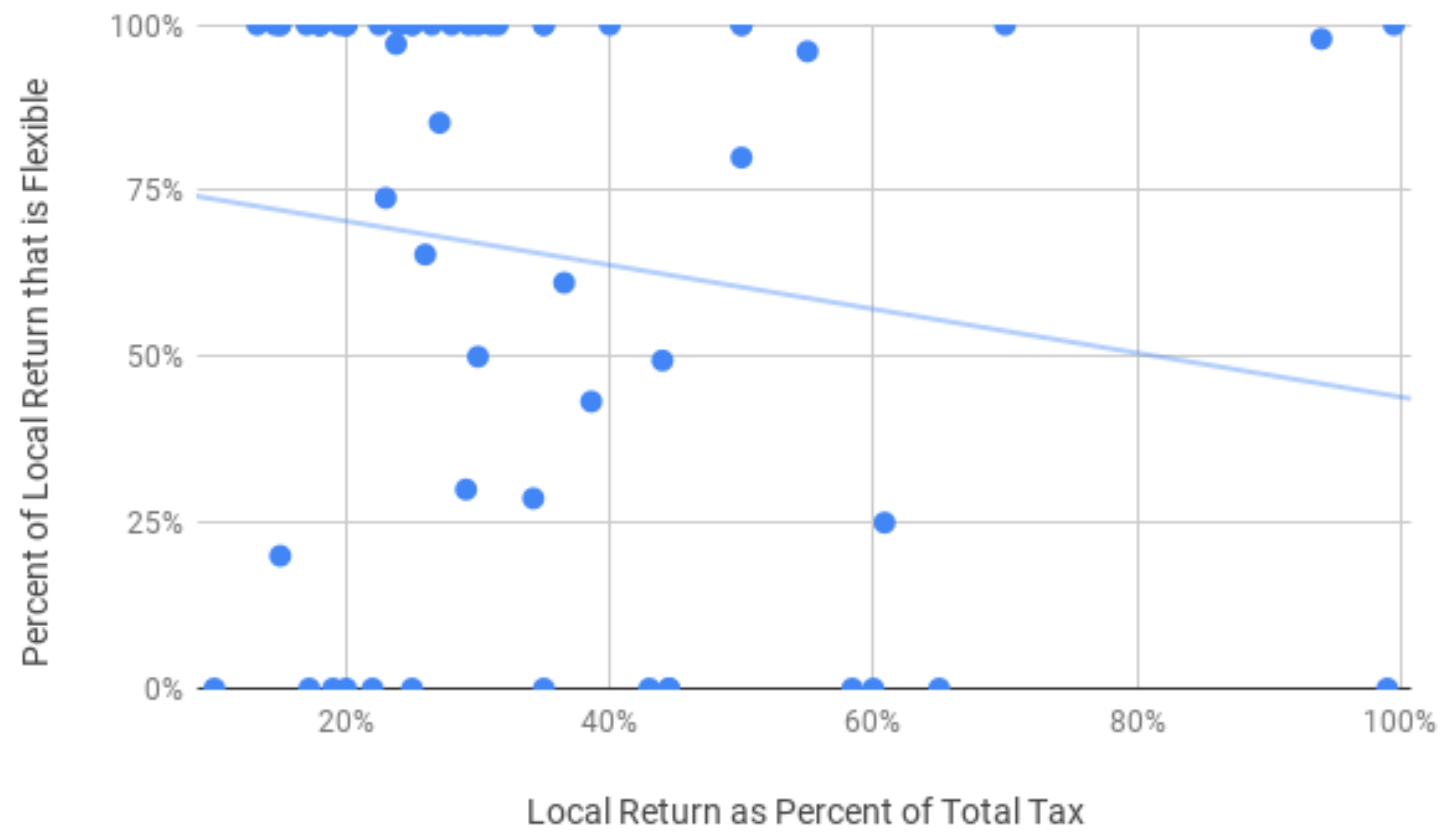

In Fresno, flexible funding helped the measure gain the support of environmental interest groups. According to interviewees, flexible funding provisions recognize that voters have increasingly embraced a multimodal vision of transportation systems, as opposed to the streets-and-roads approach of the original 1986 measure. Flexible funding has allowed cities to spend on modern mobility issues that meet their needs. Flexible funding also has advantages over categorical funding requirements because it reduces administrative burden in general and allows cities to change spending habits as transportation systems evolve without a formal amendment of the measure. 42

\section{Tying Spending to the Pavement Condition Index (PCI)}

As shown in Table 10, four measures in four counties require that some portion of local return funding be spent on local road maintenance if the jurisdiction's $\mathrm{PCI}^{51}$ is below a certain threshold. ${ }^{52}$ If the jurisdiction meets this minimum PCI, the funding can then be used flexibly. This is a way of ensuring that local funds are used to fix local roads when necessary, while allowing jurisdictions discretion otherwise. For example, Sacramento's Measure B (2016) states that:

For the 5 years following the date of implementation of the measure, not less than $75 \%$ of the funds identified in this Local Roadway \& Transit Capital, Operations \& Maintenance 
program shall be used exclusively by all Cities and the County of Sacramento for Fix it First street, road and bridge preventative maintenance and rehabilitation so as to bring up these facilities throughout Sacramento County to a Pavement Condition Index (PCI) of at least 70 at the soonest possible time.

All four measures with PCI requirements are from counties with a RUCC score of 1 , reflecting a preference toward including PCI requirements in urban counties. However, only four out of 58 measures have PCI requirements, and most counties with local return have RUCC scores of 1; this could be a result of this requirement only being present in a small number of measures. Table 10 presents the measure text relating to these provisions.

Table 10. LOST Measure Text of Provisions Tying Funding Use to PCI

\begin{tabular}{|l|l|l|l|}
\hline County & Measure & Year & \multicolumn{1}{|c|}{ Text } \\
\hline Orange & Measure M1 & 1990 & $\begin{array}{l}\text { In addition to Local Street and Roads Projects, jurisdictions may } \\
\text { use local return for any transportation purpose allowed for } \\
\text { expenditure of tax revenues under Article XIX of the California } \\
\text { Constitution if .. The jurisdiction makes a finding that streets } \\
\text { and roads within the jurisdiction are adequately maintained and } \\
\text { not in need of rehabilitation or reconstruction. }\end{array}$ \\
\hline Sacramento & Measure B & 2016 & $\begin{array}{l}\text { For the 5 years following the date of implementation of the } \\
\text { measure, not less than 75\% of the funds identified in this Local } \\
\text { Roadway \& Transit Capital, Operations \& Maintenance } \\
\text { program shall be used exclusively by all Cities and the County of } \\
\text { Sacramento for Fix it First street, road and bridge preventative } \\
\text { maintenance and rehabilitation so as to bring up these facilities } \\
\text { throughout Sacramento County to a Pavement Condition Index } \\
\text { (PCI) of at least 70 at the soonest possible time. }\end{array}$ \\
\hline San Mateo & Measure W & 2018 & $\begin{array}{l}\text { If a City or the County has a Pavement Condition Index score of } \\
\text { less than 70, it must use Tax Proceeds under this Category } \\
\text { exclusively for projects that will increase their PCI score until } \\
\text { such a time as they reach a PCI of 70 or greater. }\end{array}$ \\
\hline Santa Clara & Measure B & 2016 & $\begin{array}{l}\text { If an agency with a PCI of 70 or higher should have their PCI } \\
\text { fall below 70, the agency must redirect all funding to repair and } \\
\text { maintenance of the street system in the following cycle. }\end{array}$ \\
\hline
\end{tabular}

These four measures (Orange County Measure M1, 1990; San Mateo Measure W, 2018; Santa Clara Measure B, 2016; Sacramento Measure A, 2016) restrict most or all local return funds to projects that improve local streets and roads until the locality improves pavement condition to an acceptable level. All restrictions using PCI involve a target PCI score of at least 70, which indicates a "satisfactory" pavement condition, ${ }^{53}$ except for Orange County, which requires only that the jurisdiction determine that its streets and roads are "adequately maintained and not in need of rehabilitation or reconstruction." Orange County was the first to implement a PCI requirement (Orange Measure M1, 1990); the three other measures with PCI requirements were implemented in 2016 or later. 
Many specific spending categories are required by particular measures. Local street and road spending is the largest categorical requirement restricting how local return funds are spent. Requirements for local street and road spending are present in 21 measures and place limitations on an average of $81 \%$ of local return funds. But the term "local streets and roads" is very broad in application, and many measures attempt to limit this by further defining eligible uses in this category. This strategy frequently includes defining the use of local street and road funding as either maintenance spending or new capital investment.

Twenty-one measures in 18 counties limit expenditures to projects involving local streets and roads. Of these, five measures in five counties restrict expenditures to maintenance and repair of existing local streets and roads. One measure (Humboldt Measure U, 2016) restricts funds to maintenance and repair but specifies that this can be for local streets and roads or public transit.

The authors considered a possible relationship between the percentage of funding allocation to local return and the amount of that funding restricted to street maintenance. Figure 9 shows that funding restricted to repair and maintenance increases with the total percentage of local return, although the relationship is weak and influenced by outlier counties, including Napa (2012) because of the large percentage of the total measure dedicated to local return in this county. When excluding Napa (see Figure 10), the relationship remained the same, but was noticeably weakened. These figures show a weak relationship between local return as a percentage of measure expenditures and the requirement to spend local return funding on local street and road maintenance and repair. 
Figure 9. Funding Dedicated to Repair and Maintenance of Local Streets and Roads by Local Return as a Percentage of Total Measure Expenditures

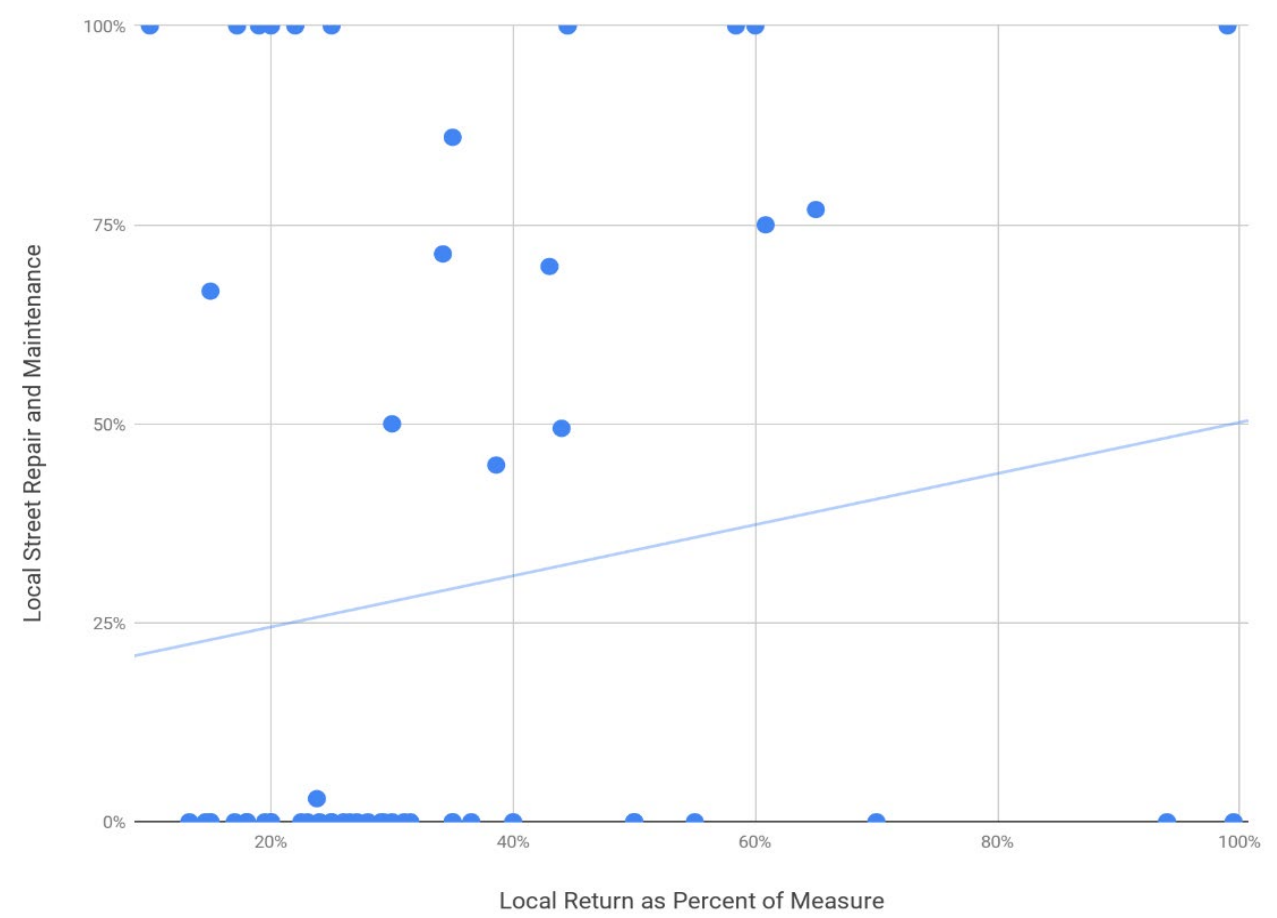

Figure 10. Funding Dedicated to Repair and Maintenance of Local Streets and Roads by Local Return as a Percentage of Total Measure Expenditures (Without Napa County, 2012)

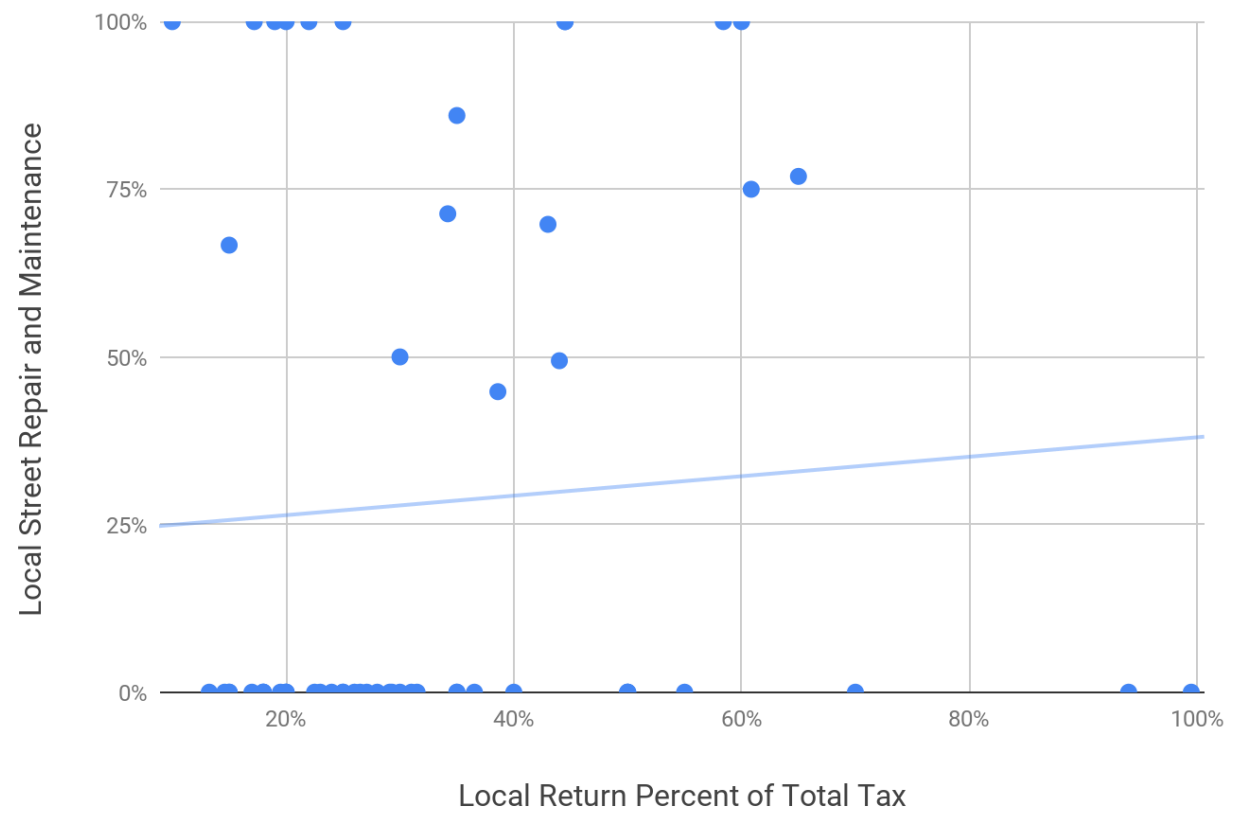


In addition to these kinds of spending restrictions, we found two counties with otherwise unique spending requirements. Cities in San Diego County reported that they maintain an account devoted to spending on projects that meet the requirement that $70 \%$ of this funding be spent to accommodate traffic on the regional arterial system. This program consists of spending on construction of new or expanded facilities, major rehabilitation and reconstruction of roadways, traffic signal coordination and related traffic operations improvements, transportation-related community infrastructure improvements to support smart growth development, capital improvements needed to facilitate transit services and facilities, and operating support for local shuttle and circulator routes and other services.

Finally, Sacramento (Measure A1, 1988) restricted spending on capital road projects for environmental purposes. Similar to meeting PCI requirements to use funding flexibly, the measure states that "No allocation shall be made for a major (i.e. increase the vehicle capacity of the existing facility by $20 \%$ or more) road improvement project unless the recipient Entity certifies that the project conforms to the mandated requirements of any then-applicable locally adopted Air Quality Maintenance Plan."

A few measures do not explicitly limit how funding should be used but describe how cities should prioritize spending decisions. Contra Costa (1988) states "It is the intent of the Authority that local jurisdictions give priority to using these funds for improving major arterial streets." Although flexible, Santa Cruz's Measure J (2004) prioritizes the use of local return funds for capital improvements.

\subsection{How Local Return Restrictions and Requirements Encourage Cities to Meet Complete Streets Goals}

Both prerequisites for receiving local return funds and requirements limiting spending of local return can encourage localities to further county-level planning goals. In some cases, counties employ combinations of these tools to meet a single goal. A clear example of this are stipulations on local return funding to encourage complete streets planning. In this study, a measure is defined as having complete streets policies if it uses the term complete streets specifically or references design for all users, and closely parallels the text in the California complete streets bill. Ten measures in this study include complete streets requirements, with three measures requiring complete streets planning as a prerequisite for receiving funds and nine measures requiring that spending comply with complete streets guidelines (two measures, Ventura Measure AA [2016] and Santa Clara Measure B [2016], require both).

California passed the California Complete Streets Act of 2008 in the same year (taking effect in 2011), requiring that cities and counties meet "the needs of all users of streets, roads, and highways, defined to include motorists, pedestrians, bicyclists, children, persons with disabilities, seniors, movers of commercial goods, and users of public transportation" whenever there is "substantive 
revision of the circulation element of the general plan." ${ }^{54}$ This enacts a requirement, but does not provide funding to meet it.

Since the passage of this law, compliance with complete streets or the adoption of complete streets policies has increasingly become a requirement in local return policy. Marin County Measure A (2004) included complete streets language before the California bill was enacted as a requirement governing the use of funds. Measures in Alameda (2000) and Santa Barbara (2008) were amended to meet complete streets state requirements. Figure 11 shows that complete streets policies first appeared in 2000.

Figure 11. Frequency of Complete Streets Requirements by Year

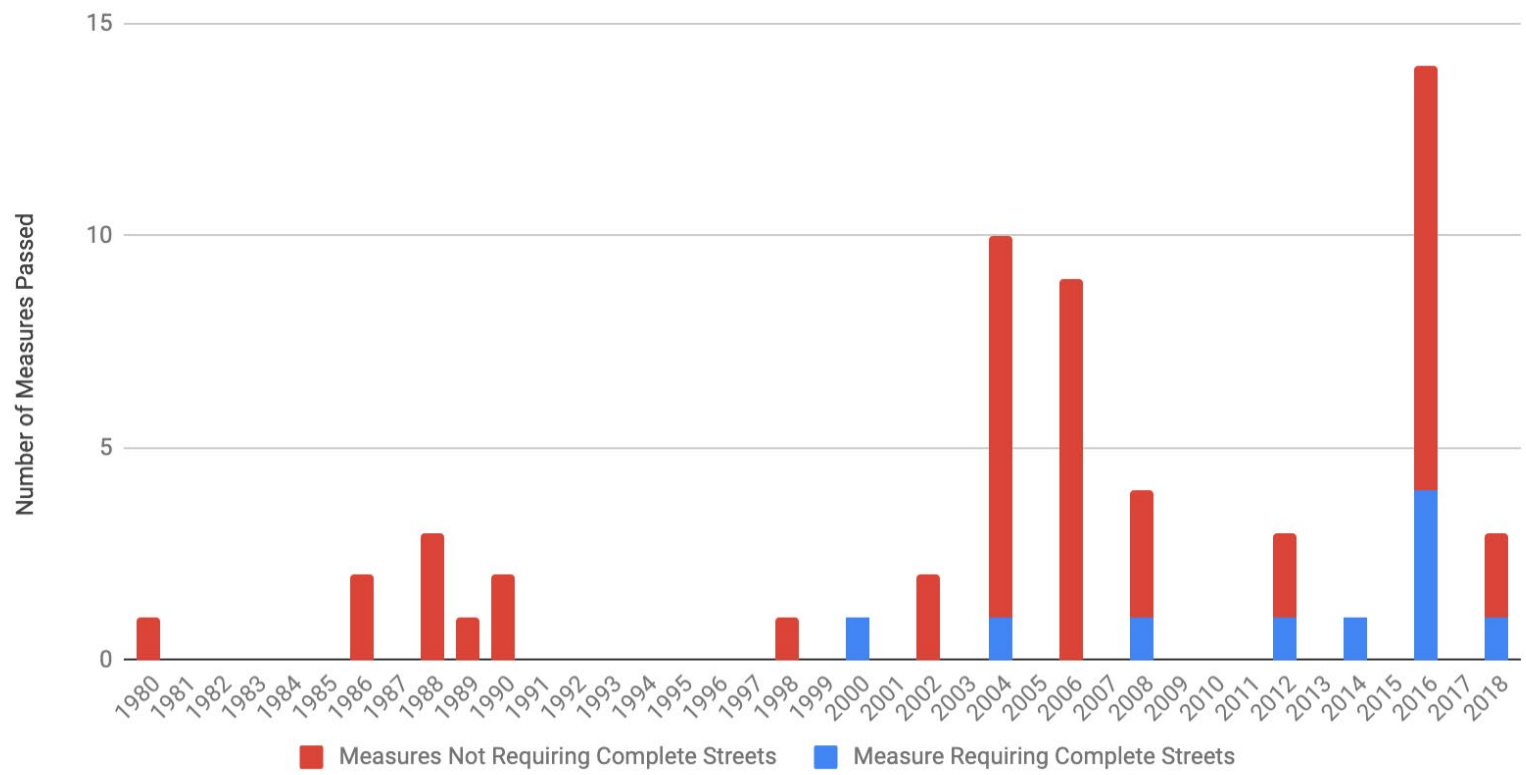

Note: The number of measures passed includes both prerequisites and requirements on base funding.

Requirements for complete streets vary in rigor, with some counties requiring jurisdictions to develop and comply with their own complete streets plans, some requiring that projects support a complete streets philosophy, and others stating that projects should consider all users in their designs. All but one of the measures containing complete streets requirements were put on the ballot in or after 2008, when the California Complete Streets Act was passed. The earlier measure did not use the term complete streets, but stated that "All projects will consider all users, including transit riders, bicyclists, pedestrians, and auto drivers” (Marin County Measure A, 2004).

In Alameda County, which requires adherence to a complete streets philosophy and a minimum percentage of funds allocated to pedestrian and cycling projects, the requirements do not result in local resistance or objection to their policy goals according to interviewees. Some cities report that 
they would embrace this approach even in the absence of the LOST provision requiring that they do so.

Figure 12 analyzes average percentage of roads maintained by city, county, and other entities (including federal or state agencies) in counties that included or did not include complete streets requirements. The figure shows that counties with complete streets policies also have a higher percentage of urban roads.

Figure 12. Jurisdictional Control of Maintained Roads for Counties with Complete Streets Policies

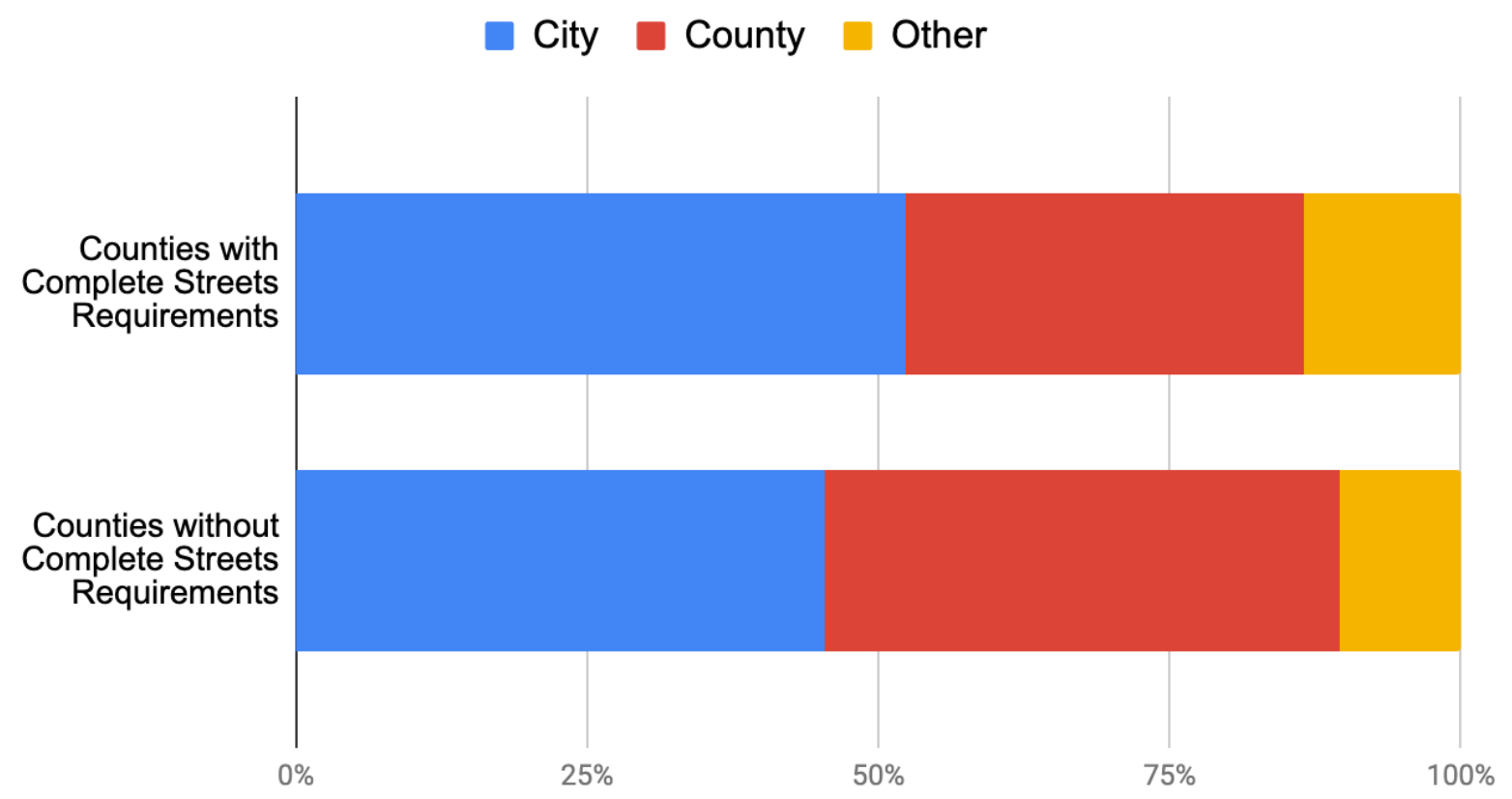

Average Percent of Roads Maintained by Type of Jurisdiction

Source: California Department of Transportation. ${ }^{55}$

Note: All road miles totals are based on 2017 California Public Road Data.

Figure 12 compares the average percentage of roads under jurisdiction control by the city, county, and other entities, for counties with and without complete streets provisions in LOST measures. The measures that include mechanisms to support complete streets are in counties with a slightly higher percentages of city-maintained roads than measures that do not support complete streets planning. Overall, local return programs in counties with larger cities have more recently begun to support complete streets planning through various mechanisms. 


\section{Accountability and Transparency in Local Return Programs}

Local return raises accountability concerns at multiple levels of government. First, the agency that administers the measure is responsible for allocating funds to jurisdictions according to the formulae established in the measure ordinances. Typically, an administering agency publishes an annual report that incorporates an audit of funding distributed to jurisdictions. Second, each jurisdiction in the county is accountable for how it spends the funds it receives. This report first discusses state law requirements to ensure that local jurisdictions use funding received by LOSTs to increase their total spending on transportation, known as maintenance of effort requirements. It then reviews accountability provisions in individual measures to ensure cities meet the prerequisites and spending requirements discussed throughout this report.

\subsection{Maintenance of Effort ${ }^{56}$}

California's 1978 Proposition 13 requires that substantial new tax revenues not be used to replace property taxes that were reduced by Proposition 13. Because of this, measures as early as Alameda Measure B in 1986 include clauses requiring a maintenance of effort (MOE) on behalf of the localities receiving local return funding. The Alameda measure included the following language:

Section 4 of Proposition 13 requires that substantial new tax revenues not replace property taxes cut back because of Proposition 13 ... To that end, prior to the authority allocating funds, each local government shall certify to the authority that the funds will not be substituted for property tax funds which are currently utilized to fund existing local transportation programs. If the local government is unable to segregate property tax revenues from other general fund revenues which cannot be so distinguished, substitution of funds from the authority for general funds is also prohibited. ${ }^{57}$

By 1987, this requirement was codified in the California Public Utilities Code (PUC) as part of the authorizing legislation for LOSTs. ${ }^{56}$ In particular, Division 19 applied this requirement to most LOSTs by including the phrase, "The Legislature, by the enactment of this division, intends that the additional funds provided governmental agencies by this chapter shall supplement existing local revenues being used for public transportation purposes and that local governments maintain their existing commitment of local funds for transportation purposes." ${ }^{58}$ As a result, all measures passed since 1987 require that localities maintain the previous level of spending on local transportation in addition to funds received from LOSTs. However, methods of verification for this requirement are not defined by the state and are regulated by the county ordinance. 
Mechanisms for reporting spending and enforcing MOE requirements vary among measures. Of the measures included in this study, 45 include language requiring maintenance of local spending effort. ${ }^{59}$ Many of these cite the PUC, such as Los Angeles Measure R (2008), which states:

It is the intent of the Legislature, as stated in Public Utilities Code proposed amended Section 130350.5(e), and Metro, that revenues provided from this Ordinance to local jurisdictions in Los Angeles County under the projects and programs described in Attachment A as "Local Return" be used to augment, not supplant, existing local revenues being used for transportation purposes.

Many others use parallel language to the PUC, such as Ventura Measure AA (2016), which states: "It is the intent of the Legislature and the Authority that proceeds from the transactions and use tax be used to supplement, not replace, existing funds being used for transportation improvements and services."

Of the measures with a clear MOE clause, 21 include language suggesting that the county agency implementing the measure would enforce the $\mathrm{MOE}$, although not all of these measures enumerate specific enforcement mechanisms. Measures in six counties specifically cited data reported to the state controller as part of the Annual Report of Financial Transactions for Streets and Roads as acceptable evidence of satisfaction of this requirement. Because the localities already report this data, it would likely result in less paperwork for the localities involved. Other measures either specify that this requirement be monitored through audits or are unclear as to the method of enforcement.

In practice, $\mathrm{MOE}$ is usually defined as the local transportation spending that took place in a base year. This is sometimes a stated year, but some measures specify that this amount can be adjusted regularly; for example, using an average over the previous three years (see San Diego, 2004). Some measures offer flexibility in meeting MOE requirements, including provisions that allow localities to defer payment in the case of an "economic emergency" (see Tulare, 2006) or adjustments in the MOE formula for extraordinary expenditures in the chosen year of analysis. For example, in San Diego, the MOE formula is adjusted every three years but "shall not exceed the growth rate in the local jurisdiction's General Fund revenues over the same time period" (San Diego Measure A, 2016). It also does not include any expenditures from banked savings or non-transportation-related expenditures, and local agencies can request up to three years deferment in special circumstances.

Counties audit the expenditures of jurisdictions to verify that localities are meeting their MOE requirements. Thus, the MOE requirement creates a base level of accountability for local-level spending for many LOST measures. Measure ordinances often include reporting or verification requirements to ensure that localities are meeting the MOE. However, the accountability measures to enforce these requirements vary across ordinances. Some do not mention any kind of stated reporting or verification provision that would increase local accountability (for example, Alameda 
2012), whereas some measures include meeting the MOE requirement as a prerequisite to receiving local return funds and direct the withholding of funds until this prerequisite is met.

Because enforcement requirements are unclear and vary from county to county, the robustness of accountability provisions in localities is dependent on county enforcement measures. Still, MOE requirements, as stated in state law, provide a basic level of local accountability to ensure that local return funding is used to increase the total local investment in transportation.

\subsection{Accountability Mechanisms and Reporting Requirements}

Many measures include explicit reporting requirements on how local jurisdictions spend their allocated funding, in some cases requiring continued reporting before funds are distributed. Seventeen measures from 12 counties require that jurisdictions develop a short-range planning list of projects to be funded by measure revenues (such as a POP, expenditure plan, or CIP) before receiving funds. In a minority of cases, the county agency must substantively approve project lists as conforming to the spending requirements of the expenditure plan. The reporting and approval requirements discussed in this chapter are distinct from those required by MOE clauses or those administrated through compliance with specific regional programs discussed in Chapter IV. Appendix D details the language used by these measures to create these requirements. All but one of the measures listed specify that funding would be withheld if requirements were not met. Alameda Measure B (2000) does not list specific consequences for noncompliance.

\section{Reporting That Requires Approval for Consistency with Ordinance}

Of the 17 measures that require approval of the project list by the county, three state that the list will be approved as long as it conforms to the measure ordinance and expenditure plan. These three measures require county authorities to review and approve a list of projects from localities. The remaining 14 measures require that cities and other localities develop a list of intended projects, such as a CIP or POP, but don't specify the conditions under which that list would be approved. These reporting requirements rely on documentation more than active supervision (discussed below).

Santa Barbara Measure A (2008) requires that local jurisdictions submit a POP with a "detailed description of local jurisdiction expenditures of local return funds from the most recently completed fiscal year, including expenditures on alternative mode projects as defined in the Investment Plan." The county transportation authority approves the POP as long as it is "consistent with this ordinance and the attached Investment Plan, and prior to releasing to the local jurisdiction its share of local program funding for the first fiscal year in the POP." Very similar language is included in Santa Barbara Measure D (2006). 
San Diego Measure A (2016) also requires a POP, but biennially. The transportation commission makes a finding of consistency with the measure ordinance and the county regional plan before approving that POP for funding. For Alameda Measure B (2000), localities must receive governing board approval of projects before spending funds on them, and each project must be in a list of projects, master plan with priority projects, CIP, or resolution.

These are examples of levels of accountability to the county which are demanding, and that arise because of the level of specificity required. Few measures require this level of county oversight of local use of funds. In fact, interviews with public officials reveal an element of trust between county and local officials, and conflicts are generally settled, resulting in city participation conforming to measure guidelines.

\section{Reporting Requirements That Do Not Require Approval but Demonstrate Transparency}

Thirteen measures require that cities and other localities develop lists of intended projects, such as a CIP or POP, but don't specifically require that list to be approved. City project lists are typically approved by the city council in a public meeting at which citizens can comment, and this provides some transparency of spending measure revenues. Reporting requirements rely more on documentation than supervision to provide accountability protections. Reporting is one of the most frequent prerequisites to receiving funding.

Requirements can specify transparency to either the public or the county authority. For example, Santa Clara Measure B (2016) uniquely requires that local jurisdictions submit regular project updates, which are reported on the measure's public website. The Local Streets and Roads Program Guidelines state that "Agencies will submit project updates to VTA [Santa Clara Valley Transportation Authority] on a regular basis. The information will be placed on the 2016 Measure B website to keep the public informed on 2016 Measure B spending. Agencies may also be requested to present updates to the 2016 Measure B Citizen's Oversight Committee." The measure does not, however, specify that project updates must be approved in any way by the county. Los Angeles Proposition C (1990) states that "To maintain eligibility and meet LR Program compliance requirements, Jurisdictions shall submit a Project Description (Form A) as required, an Annual Project Update (Form B) and Annual Expenditure Report (Form C)," but does not specify that any of these reports have to be approved.

Some measures state that the locality must consult with county authorities (see, for example, Placer Measure M, 2016), or "account annually to the (transportation) Commission on the use of such funds" (Los Angeles Proposition A, 1980). Of the measures that require localities to adopt a list of projects, three specify that the list must be approved in the course of a local public process, such as a meeting or hearing. 
The majority of measures require reporting on local return spending by cities, supporting the assertion that there is robust accountability built into the local return system. Other measures are silent with respect to reporting and approval. This does not suggest a comparative lack of accountability in these counties. If such provisions are not spelled out in the ordinance, they may be required by implementation guidelines or implemented in the course of commission business. For example, in Fresno County, cities are not required to present project lists to implementing agencies, but interviewees reported that this created a culture of trust between the county and cities and reduced the administrative burden on smaller cities. Simultaneously, the county facilitates frequent communication with cities about eligible spending, and cities consult with the Citizens Oversight Committee if they have any questions.

According to our interviewees, counties and their subdivisions are allocating LOST local return funds in accordance with the provisions in the ballot measures. We found no evidence of counties withholding or manipulating disbursement of funds as generally called for by legislation and complex formulae laid out in the measure ordinances. 


\section{Determining Allowable Uses of Local Return Funds in Fresno}

According to the measure ordinance, the Fresno County Transportation Authority (FCTA) must "prepare an annual report each year on progress made to achieve the objective of improving transportation conditions related to priority highway operations and local transportation needs." Decisions are monitored by two committees:

- Policy Advisory Committee: composed of one representative of each city in the county and one representative of the county, with each representative on the committee required to be an elected official. ${ }^{60}$

- Citizens Oversight Committee: membership, method of appointment, roles, and responsibilities in accordance with and defined in the initial expenditure plan. ${ }^{60}$

For cities, the FCTA and Fresno Council of Governments (COG) created a Measure $C$ Extension 2007 Local Agency Handbook to provide guidance on implementation of the local return portion of Measure $\mathrm{C}$. The handbook was published after the measure was passed with the plan to be updated annually, but in practice, local return has been governed by a Strategic Implementation Plan (SIP) updated every two years. The SIP updates local return guidance as conflicts arise in spending that warrant clarification.

For example, one community wanted to use flexible funding to put up bollards at local street fairs, but this was deemed by the COG to not be an eligible transportation expense. Another example is an ongoing debate as to whether beautification features can be included in improvements (for example, brick-paved intersections and monument signs). The COG strives to find the right balance in cases like these between helping improve a community and spending money as voters intended. ${ }^{49}$ 


\section{Discussion}

This paper discusses the main themes that emerged from the findings:

- Local return is a crucial part of LOST measures in California, allowing cities to meet local needs ranging from maintenance of local streets to funding for special programs, and it provides access to matching state and federal funding for larger capital investment.

- Local return provisions are carefully crafted to balance the needs of the county across dimensions, including trying to balance resources equitably between urban and rural residents, investing in different transportation modes, and meeting both local and regional policy needs.

- Robust accountability protections ensure that local return funding is distributed and spent as required by the measure.

\subsection{Local Return is a Crucial Part of Measure Expenditure Plans}

Local return is a critical part of LOST measures that enables cities to address their transportation needs, a point on which city officials interviewed for this study unanimously agreed. Most cities allocated local return revenue to maintaining and repairing local streets and roads. Many interviewees commented that without LOST revenues from the county, their cities would have little or no means to meet such needs. That said, some interviewees-those from the most highly and densely populated areas selected for study—also mentioned using local return revenues to address other policy goals, such as congestion management and mitigation of environmental impacts of growth. For example, one interviewee from the city of Alameda emphasized the importance of the funds to the city's transportation policy initiatives. Without this money, "the city would be reduced to filling potholes; with it, the city can work towards more ambitious policy goals, such as lower vehicle miles traveled and reducing vehicle emissions." ${ }^{61}$

Although cities largely rely on these funds to address basic road repair and maintenance needs, even cities that use the funds for policy initiatives more ambitious than street repair may be exploiting their fungibility; for example, a city could use the LOST funds for a congestion management project, allowing it to use other funding sources for routine maintenance and repair. Local return revenue also enables cities to leverage additional funds by selling bonds and matching other state funds and federal grants. For example, Table 11 lists several projects in Alameda County that were leveraged via that LOST provision. Several interviewees report that LOST funding in their counties is structured to help optimize their leveraging capacity. Measures tend to specify dates by which funds must be used to receive new funds, that funds can be saved until enough is available for bigger projects, or that local jurisdictions can borrow or lend funds among one another or with the county. 
Table 11. Projects Leveraged by LOST Funds in Alameda County

\begin{tabular}{|c|c|c|}
\hline Project Sponsor & Project Title & External Grant Program \\
\hline City of Alameda & $\begin{array}{l}\text { Central Avenue Complete Streets } \\
\text { Project }\end{array}$ & $\begin{array}{l}\text { State Active Transportation } \\
\text { Program ATP Cycle } 3\end{array}$ \\
\hline City of Livermore & $\begin{array}{l}\text { Safe Routes to School - Marylin } \\
\text { Avenue Elementary School, Project } \\
\text { No. 2015-29 }\end{array}$ & Safe Routes to School Program \\
\hline City of Oakland & Fruitvale Alive Gap Closure & $\begin{array}{l}\text { State Active Transportation } \\
\text { Program ATP Cycle } 3\end{array}$ \\
\hline City of Union City & $\begin{array}{l}\text { HSIP Cycle } 6 \text { Traffic Signal } \\
\text { Improvements (1404) }\end{array}$ & $\begin{array}{l}\text { Highway Safety Improvement } \\
\text { Program (HSIP) }\end{array}$ \\
\hline
\end{tabular}

Source: Email communication from John Nguyen, Alameda County Transportation Commission, August 1, 2019.

Interviews with local officials indicated that during recent decades, several cities did not receive LOST funding primarily because they opted out of compliance with county funding requirements. The authors lack sufficient data to generalize about the causes of these decisions by city officials, but most cities (if not all) eventually chose to meet requirements to receive funding. For example, in 2013, the city of Riverside declined to charge a development fee as required by Riverside County's Measure A provisions. Soon after that, however, the city decided to repay the development fee revenues and is currently on track to receive all of its Measure A return funding. Similarly, in 2000, the city of Pittsburg in Contra Costa County decided to unilaterally opt out of the county subregion mitigation program, and its local return funds were withheld. However, within a year or two, the city changed its stance and all of those funds were returned. The authors could not ascertain the reasons that such cities temporarily disqualified themselves, but many interviewees commented on how attractive the funds are in enabling cities to conduct fundamental street and road maintenance operations. Although from time to time, the occasional city government may opt out, in every case identified, these cities ultimately decided to work within their county's guidelines.

\subsection{Local Return Programs Are Tailored to Meet Diverse Local Needs}

Local return funds are intended to give locals the flexibility to direct revenue toward community needs, though LOST measures place many limits on this discretion. The majority of measures studied (30 of 58) have entirely flexible local return funding. The remaining 28 measures restrict the use of some portion of the funding to a specific transportation purpose, and 13 measures include no flexible local return funding.

Local return funds can be subject to complicated spending requirements. The simplest are requirements that a portion of local return funding be dedicated to a specific mode or category of transportation. For example, many of the measures studied restrict usage of local return funding to specific categories of transportation. Examples of these categories include local streets and roads, 
bike and pedestrian infrastructure, transit, ADA and paratransit services, safety and traffic operations improvements, safe routes to schools and colleges, or traffic management.

Urban counties tend to have more complicated spending requirements that incorporate goals beyond repair and rehab of streets and roads, such as addressing congestion and environmental impacts of transportation. According to interviewees, these restrictions that specify spending local return on diverse modal investments were added during the measure development process to meet the demands of diverse interest groups among voters and successfully pass the measure.

Rural areas see the funds primarily as a means to address their street and road repair needs. Local return provides crucial funding for local street and road repair and maintenance, with many interviewees stating that they don't know how they would manage without it. Rural counties dedicate larger portions of measures to local return. Additionally, of the 13 measures that do not provide any flexible funding, ten require that all local return funding be spent on local road maintenance and repair.

Beyond this, some counties studied have variations in spending requirements among cities. Fresno exempts its smallest cities from spending on bike and pedestrian infrastructure and ADA services. Santa Barbara requires different percentages of spending on alternative transportation on a per city basis. One example in multiple counties is local return funding that must be spent on road and street maintenance if a city's PCI score is below a predetermined threshold; otherwise, the funding can be used flexibly to address other local priorities. In this way, each city's unique needs are considered while ensuring that funding is used to meet a countywide priority.

\subsection{Conditions on Local Return Funding Can Be Used to Meet Regional Policy Goals}

Conditioning local return funding on compliance with regional programs shows how local return funding can be used as a lever to achieve regional policy goals. Often this takes the form of requiring that local jurisdictions meet the requirements of a regional program to receive local return funding. The most common example of this requires that cities implement development impact fees, often to support the construction and maintenance of regional arterials. These requirements reflect the desire that new development shoulder its fair share of funding infrastructure and the recognition that investment funded by local return enables development that puts pressure on the entire transportation system.

San Diego requires cities to spend local return on regional arterials. Cities in San Diego County reported that they maintain an account devoted to spending on projects that meet the requirement that $70 \%$ of this funding be spent to accommodate traffic on the regional arterial system. This program consists of spending on construction of new or expanded facilities, major rehabilitation and reconstruction of roadways, traffic signal coordination and related traffic operations 
improvements, transportation-related community infrastructure improvements to support smart growth development, capital improvements needed to facilitate transit services and facilities, and operating support for local shuttle and circulator routes and other services.

Multiple measures include participation in regional growth management programs as a condition of receiving local return funding. Contra Costa employs the most stringent of the requirements, linking local return funding to urban growth boundaries established under another countywide measure. Western Riverside and Sacramento counties also include similar restrictions regarding regional environmental plans for conservation and air quality management, respectively.

Many counties report early resistance to this type of prerequisite among some cities, but few compliance issues. This could be interpreted as underscoring the overriding need for local return funding among cities studied. Many are willing to enact policies they would not otherwise support to gain access to desperately needed funding, providing evidence that LOSTs can be vehicles for regional coordination, collaboration, and compromise.

\subsection{Local Return is a Tool to Address Equity Issues}

Counties use many different methods to tailor local return funding to local concerns. There is no simple formula for achieving equity in local return funding distribution, but because measures require a supermajority of voter approval to be enacted, requirements and allocation reflect local geographic and political divisions. County officials who are elected by geographical districts are particularly concerned about the regional distribution of funds and whether localities are receiving their fair share.

Efforts to achieve geographic equity are illustrated by the observed association between a county's population density (represented in this study by the RUCC) and the percentage of funds dedicated to local returns. Counties with a higher RUCC score, indicating that they are more rural, are more likely to have a higher percentage of total tax revenue dedicated to local return. This could indicate a concern that rural populations will not be adequately served by these taxes without a formulaic distribution of funds, and therefore rural voters would not otherwise support the measure. By dedicating a larger portion of the tax to local return and including road miles in allocation formulas, counties are ensuring a certain return on investment for more rural areas.

Counties purposefully tailor the funding distribution formulas in LOST ordinances to local conditions to ensure that all cities receive a reasonable portion of the revenue. The first way to accomplish this is by deciding which variables to consider for allocating local return and how those variables are defined. However, there seems to be a general consensus that the distribution formula should consider both road miles and population. Most measures use population as the primary way to determine allocation, which ensures that all taxpayers benefit to some extent from the measure. This variable tends to benefit urban centers with larger populations, which also leads to concerns 
that cities with a large amount of infrastructure will absorb most of the tax benefits. This effect is tempered, however, by the frequent use of base allocations (city minimums) or the inclusion of a road mile variable. A base allocation ensures that every locality that contributes to the tax receives a certain benefit, including very small cities.

The use of road miles as a variable is particularly relevant to questions of geographic equity because it both benefits rural communities with many roads but few people and helps maintain the road system throughout the county. Using road miles as an allocation variable also links funding to need, particularly if the local return is earmarked for local street and road maintenance or repair. As previously discussed, however, this impact changes based on how the term road miles is defined.

Interviews with local officials suggest that they are content with existing formulae for allocating LOST funds in their counties. In fact, no local official interviewed for this study had a specific concern about the allocation formula used in a given official's county. That being said, county officials are aware of the potential for discord stemming from allocation procedures. Several counties schedule regular reviews of allocation formulae and procedures in part to forestall such an outcome. Alameda County, for example, reviews its allocation (including its subgovernment scheme) every five years. ${ }^{62}$

Some counties use local return to ensure investment that meets diverse modal interests, ensuring investment in non-automobile transportation. A total of 13 measures include categorical requirements outside of local street and road funding or flexible spending, averaging $16.4 \%$ of the local return for these measures. Most frequently, this increases spending on bicycle and pedestrian infrastructure, but three measures use it to require ADA or paratransit funding, or both. LOSTs also dedicated funding to local transit agencies, but this fell outside of the scope of this report, which studied only funding not allocated to jurisdictions.

\subsection{Local Return Programs Have Successful Accountability Provisions}

County agencies that administer measures are subject to robust accounting requirements to show that they have timely distributed local return funding to member jurisdictions. To this end, county agencies almost unanimously publish annual reports tracking their funding disbursements (and spending on other regional projects). Accountability for county agencies is largely a financial question, and county agencies often perform and make public the results of independent thirdparty audits. Ultimately, counties and the cities in them have nothing to gain from failing to properly disburse local return funding, and maintaining local support for these measures is crucial.

County staffs seem to work well with their counterparts in cities to ensure that cities are successful in seeking and obtaining their LOST revenues. For their part, county officials seem to approve all proposed uses of the funds that meet the requirements and rules set forth by their legislation. 
Minor quibbles exist, and perhaps more lie beneath the surface, but the need for the funds seems to trump any significant dissatisfaction among city officials. 


\section{Conclusion and Policy Recommendations}

\subsection{Summary of Findings}

Local return provisions comprise a crucial part of transportation tax measure expenditure plans. Although they vary considerably in various important ways, collectively, return funds enable cities to address their own transportation needs with relatively little conflict or implementation issues. City governments use LOST funds for various needs and purposes, including maintaining and repairing local streets and roads, addressing policy goals such as congestion management and mitigation of environmental impacts of growth and development, and leveraging additional funding in the form of locally issued bonds and state and federal grants.

Tax measures are typically drafted that call for geographic equity provisions in the distribution and return funds, nearly always using variables such as population and road mileage in funding allocation formulae. These equity concerns are also visible in the spending requirements attached to local return funds, which can be used to ensure spending on specific transportation modes and purposes. Our study found little or no discontent among city officials regarding these allocation schemes. Although counties vary considerably in how they attach both prerequisites for receiving funds and requirements for remaining eligible for them, this study identified little evidence that such provisions create either significant conflict or unmanageable burdens for city governments. This is in part because counties develop measures through collaboration with local governments and tend to balance reinforcement of both regional and local priorities with their return fund rules, smoothing their acceptability for city governments.

Return provisions examined in this study generally exhibit a great deal of transparency and accountability. Essentially, counties provide local return funding to city governments consistent with the measure ordinances. Counties employ accountability measures to ensure that local jurisdictions are spending funds as required, including mandatory reporting and auditing. However, some counties and cities do a significantly better job of making that clear to the public by making relevant data available in a readily digestible form.

\subsection{Policy Implications}

The study findings suggest ways that counties should design successful local return provisions in future LOST ballot measures:

- Counties weighing passage of a new transportation tax measure or renewing an expiring one should consider a local return provision. In doing so, they should investigate the range of options for funding allocation and use discussed in this study. Counties with existing return provisions should also review these options as they plan for future revisions and 
consider adapting requirements to meet current and future needs. Counties should consider ways of enabling these various potential benefits of LOST provisions that are tailored to the needs of their city governments and constituents.

- Counties should consider the range of possible allocation strategies discussed in this study to help maximize the fairness and rationality of how return funds are distributed. As many counties already do, they should revisit and update these formulae regularly to ensure their ongoing fairness and relevance to actual needs. To avoid potential problems, however, counties should proceed with caution and care when considering possible rules concerning eligibility for return funds. In interviews, several city officials mentioned that they were consulted as county tax measures were crafted; such collaboration between regional and local officials might help ensure that return rules match local needs and capacity for implementation.

- Counties should consider verifying to the public that they are following their measures' stipulations for allocating and spending local return funds by posting relevant information regularly on their transportation agency websites. However, any reporting requirements must be balanced with placing an undue administrative burden on cities. Counties could also assist their city governments in posting information so on a local level, preferably in a manner standardized across local jurisdictions, to increase public awareness and understanding of projects and services funded by local return.

\subsection{Study Limitations and Recommendations for Future Research}

One caveat of this research is that the authors only conducted interviews with representatives in counties that are successfully implementing LOST measures. Further research in this area should explore the political process by which local return provisions are established and could include measures with contentious local return provisions that have failed at the ballot box.

Other areas for future research include an analysis of what types of projects and services cities spend flexible funding on. For example, is flexible funding spent mostly on streets and roads maintenance, or is it used to fund alternative modes? Further, research could explore how such spending may vary to meet the needs of diverse geographies and demographics.

The scope of this study did not enable clear answers to interesting and important questions. For example, what aspects of local return do measures include because doing so increases the likelihood that they will be approved by the two-thirds majority needed? On a related note, do local governments want local return funds so much that they are willing to accept spending money on county-wide projects as a condition for getting money for their own projects? Why are there greater restrictions on amending the local return formulas than on other aspects of the measures? Although 
the periphery of existing research may hold some clues to answering these questions, we leave more definitive answers to future investigation. 


\section{Appendix A: Case Study Backgrounds}

This appendix describes the ballot measures selected for more detailed study, including interviews with officials from Alameda, Contra Costa, Imperial, Fresno, Riverside, and San Diego counties. For each measure, the appendix provides a brief background on the county and local return provisions in the ballot measures. It then describes the policy goals underlying local return allocation formula and spending restrictions. It then briefly describes how these provisions have worked in practice during measure implementation and how cities have reacted. Last, it reviews the success of accountability and transparency mechanisms included in the measures.

\section{A. Alameda County}

Figure 13. Alameda County Regions and Transportation Projects (2016)

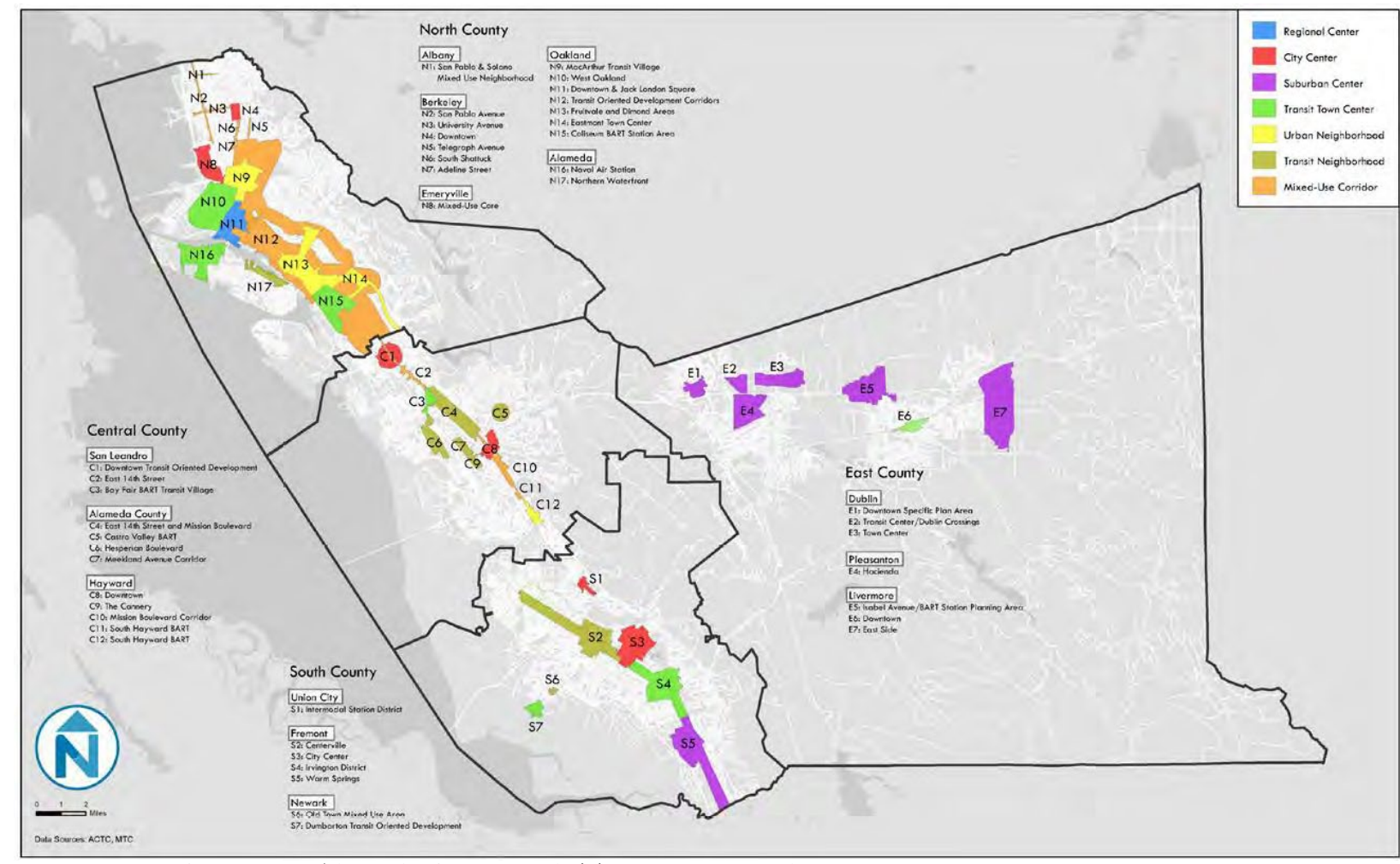

Source: Image from 2016 Alameda Countywide Transportation Plan.

\section{i. Introduction}

This county was selected for further study and interviews because it exemplifies a large, urban county with a LOST provision that requires cities to fund multimodal projects (bicycle, pedestrian, etc.) that help achieve county policy objectives. The LOST provision also requires that cities adopt a "complete streets philosophy." 


\section{ii. Description of County}

Alameda County extends from the highly populated urban core of the region to its rural periphery, including 14 cities and six unincorporated communities. The county seat is the city of Oakland. It borders Contra Costa, San Joaquin, and Santa Clara counties and is connected to San Francisco and San Mateo counties via bridge. Alameda has six interstate freeways, ten state routes, and three major bridges; the county has $40 \%$ of the region's congestion and six of the ten most congested freeways. Alameda County is expected to be home to nearly two million residents (30\% increase) and one million jobs (36\% growth) by 2040 (Countywide Transportation Plan, 2016).

All funding in Alameda LOST measures is allocated first to subregions within the county, including:

- North County-including the cities of Albany, Alameda, Berkeley, Emeryville, Oakland, and Piedmont.

- Central County-including the cities of Hayward and San Leandro, and unincorporated areas.

- South County - including the cities of Fremont, Union City, and Newark, and Union City Transit.

- East County-including the cities of Livermore, Dublin, Pleasanton, unincorporated areas, and the Livermore Amador Valley Transit Authority.

Table 12. Largest Cities in Alameda County

iii. Earlier Measures

\begin{tabular}{|c|c|c|}
\hline & City & Population \\
\hline 1 & Oakland* $^{*}$ & 390,724 \\
\hline 2 & Fremont* $^{*}$ & 214,089 \\
\hline 3 & Hayward* $^{*}$ & 144,186 \\
\hline 4 & Berkeley* $^{*}$ & 112,580 \\
\hline 5 & San Leandro & 84,950 \\
\hline 6 & Livermore & 80,968 \\
\hline 7 & Alameda* & 73,812 \\
\hline 8 & Pleasanton & 70,285 \\
\hline 9 & Union City & 69,516 \\
\hline${ }^{*}$ Cities where officials were \\
interviewed.
\end{tabular}

Alameda County passed Measure B in 1986, which was part of the first run of local return measures implemented after the passage of Senate Bill $878 .{ }^{63}$ Local return funds began at $17.78 \%$ and then 
increased to $18.9 \%$ after the first five years. Funds were allocated annually to subareas of the county, then allocated to local jurisdictions, based $50 \%$ on population and $50 \%$ on road miles.

iv. Current Measure B 2000 for 2002-2022

The 2000 Measure B reauthorized the 1986 measure and expenditure plan. It passed in 2000 with 81.5\% of the vote. According to the 2013-14 Strategic Plan, this measure was the result of an outreach campaign after the failure of the 1998 attempt to renew Measure B, and per these changes "received overwhelming support" (Alameda CTC Strategic Plan FY 2013-2014). It also extended the tax for 20 years, rather than 15.

\section{Funding Specifics}

Local return accounts for $22.34 \%$ of the tax for "any local transportation need based on local priorities, including streets and roads projects, local transit projects, bicycle and pedestrian projects and other transportation uses." Funds are first allocated to geographic subareas in the county, then distributed within those subareas to jurisdictions with a formula weighted $50 \%$ by population and $50 \%$ by road miles. The guidelines also establish the possibility of requesting advanced funds from the Alameda County Transportation Commission (ACTC) to advance improvements in the near term.

The expenditure plan states that these formulas may change based on population and road miles in each city. For example, Alameda County's (central) allocation is reduced by $0.39 \%$ of total revenues to "reflect a transit funding increase" according to the expenditure plan.

These variables are updated annually, and funds are distributed monthly, according to the implementation guidelines. There is no concrete explanation of how funds are distributed to subareas before distribution to local jurisdictions, except that funding is "intended to reflect geographic equity based on the population projections for the County in 2005" (Measure B Expenditure Plan 2000).

Additional funding outside of local returns is available from the following programs:

- $10.45 \%$ of revenues to special transportation for seniors and people with disabilities is distributed to cities and the county based on a formula developed by the Alameda County Paratransit Coordinating Council (PAPCO).

- $5 \%$ to bike and pedestrian safety: $75 \%$ distributed based on population and the rest from $0.19 \%$ of total revenues available on a grant basis to cities and the county for transit center development funds. 
To receive Measure B funds, local jurisdictions must have an adopted complete streets policy and be in compliance with the California Complete Streets Act of 2008. They must also annually report on the citywide PCI, and if the index falls below an average of 60, they must state in the Annual Program Compliance report what they need to increase that index.

\section{Oversight and Reporting}

The 2000 reauthorization of Measure B significantly elaborated on the oversight requirements from the original measure, which largely relied on the authorizing legislation for regulation. The reauthorization created the Citizen's Watchdog Committee to review tax fund expenditures and report to the public. It also required localities to submit to an annual audit of the use of sales tax funds and get local governing board approval for all projects and programs before spending Measure B funds.

\section{Amendments}

The procedure and requirements for local returns are only loosely described in the expenditure plan, and as such, many aspects of local returns are regulated by the Implementation Guidelines adopted in 2011 and "incorporated by reference in the Master Program Funding Agreements." The guidelines contain the measure's only description of a requirement for compliance with complete streets, PCI reporting, and local governing board approval for possible advancement of funds from the ACTC. It is also the only document that describes that the distribution formula should be updated annually.

According to the guidelines,

Implementation Guidelines are adopted by the Alameda CTC on an as-needed basis. Changes to Implementation Guidelines will be brought through the Alameda CTC's Technical Advisory Committee for review and comment, as well as any other Alameda CTC committees as necessary, before changes are adopted by the Alameda CTC Commission.

\section{v. Recent Extension: Measure BB 2014 for 2022-2045}

This measure extended the 2000 Measure B until 2045 and increased the tax to one cent, effective immediately after the measure was passed; the ordinance states that it "shall be imposed beginning at the close of polls on the day of the election at which the measure is adopted by two-thirds vote of the electors voting on the measure or as soon thereafter as the tax may be lawfully imposed until March 31, 2045, for a total tax of one percent." 


\section{Funding Specifics}

Measure BB lowered the local return allocation to 20\% and distribution continues to be based 50\% on population and $50 \%$ on road miles. Funds are distributed monthly and proportional shares are updated annually according to the Implementation Plan. Jurisdictions may request advance funds at the discretion of the ACTC. Requirements include:

- $15 \%$ of funds must go to projects benefiting bicyclists and pedestrians.

- Street projects must support a complete streets philosophy, considering all types of transportation users.

- Funds cannot be used for indirect costs, unless controlled through an approved allocation plan.

- Jurisdictions must report on their PCI, and if it falls below 60, they must specify in the annual Compliance Report what is needed to increase their PCI.

Jurisdictions may request advance funds at the discretion of the ACTC. Outside of local returns, jurisdictions can also receive funds from:

- “Affordable Transit for Seniors and People with Disabilities" funds, allocated based on percentage of population aged 70 or older and PAPCO's formula

- "Freight and Economic Development Program" grant funds

- "Investments in New Technology, Innovation and Development" grant funds

\section{Amendments}

A two-thirds weighted vote of commission members is required to approve an amendment to the expenditure plan (ACTC 2015 Administrative Code), after which all jurisdictions have 45 days to comment. Funding formulae for all programs are to be "revisited within the first five years of the Plan implementation to ensure overall geographic equity based on population and/or other equity factors."

\section{Oversight and Reporting}

Recipients must submit annual audited financial statements and compliance reports to the ACTC. The compliance reports include detailed reports on the recipient's use of funds and reporting deliverables (2018 Compliance Summary Report). They must also sign a Master Funding Agreement, which outlines roles and responsibilities regarding expenditure of the funds and 
includes local hiring requirements. The Implementation Guidelines state that projects and programs that use these funds must receive approval from the local governing board to allow for public input. This involves listing the projects and programs in a project list, master plan, CIP, or resolution.

vi. Transparency to Public

The ACTC provides a comprehensive report on Measure B expenditures and compliance among cities that receive LOST funding on its website. ${ }^{64}$

vii. Alameda County and City Officials Interviewed for This Study

Alameda County Transportation Commission: Tess Lengyel, Deputy Director (June 10, 2019)

Fremont: Michelle Silva-Salinas, Business Manager, Public Works (August 1, 2019)

Oakland: Bruce Williams, Funding Project Manager, Department of Transportation (August 4, 2019)

Alameda: Gail Payne, Senior Transportation Coordinator (August 7, 2019)

Berkeley: Farid Javandel, Transportation Manager (August 14, 2019)

Hayward: Fred Kelly, Transportation Division Manager (August 13, 2019) 


\section{B. Contra Costa}

Figure 14. Map of Contra Costa County, Including Transportation Subregions

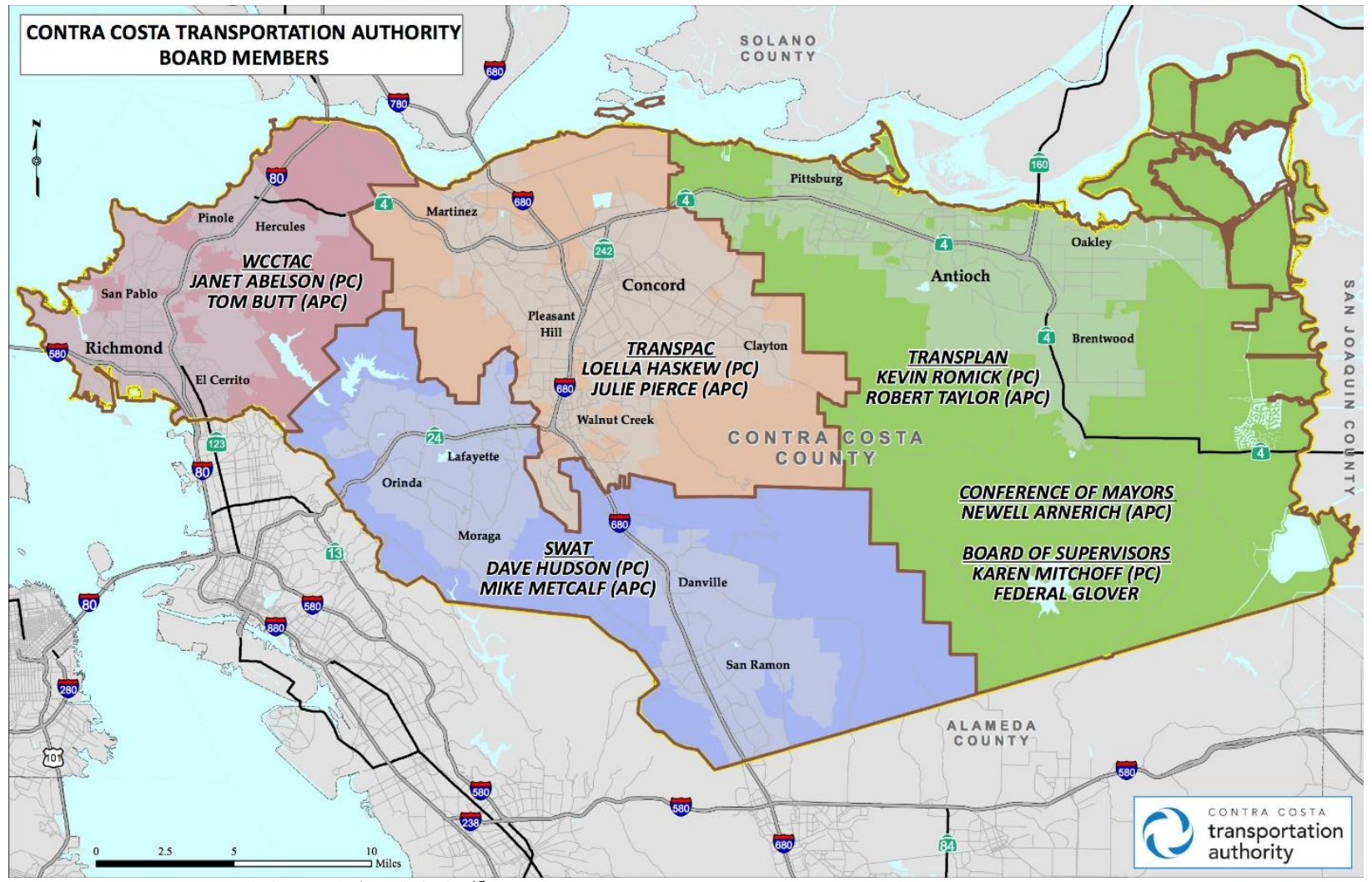

Source: Map retrieved from CALCOG ${ }^{65}$

\section{i. Introduction}

This county was selected for further study and interviews because it exemplifies a largely suburban county with a LOST provision that requires cities to adopt an ULL and a Growth Management Program (GMP).

\section{ii. Description of County}

Contra Costa is a primarily urban and suburban county of approximately 1,123,000 residents. Geographically, the county extends from the northern part of the San Francisco Bay to San Joaquin County in the east and Alameda County in the south. It includes eight cities with a population of more than 40,000, which are listed in Table 13. The county's transportation agency is the Contra Costa Transportation Authority (CCTA), which was formed by voters in a 1988 LOST election to manage the county's transportation sales tax program. The CCTA also serves as the county's designated Congestion Management Agency. ${ }^{66}$ 
Table 13. Largest Cities in Contra Costa County

\begin{tabular}{|l|c|c|}
\hline & City & Population \\
\hline 1 & Concord & 122,067 \\
\hline 2 & Richmond & 103,701 \\
\hline 3 & Antioch* & 102,372 \\
\hline 4 & San Ramon & 72,148 \\
\hline 5 & Walnut Creek & 64,173 \\
\hline 6 & Pittsburg & 63,264 \\
\hline 7 & Brentwood* & 51,481 \\
\hline 8 & Danville & 42,039 \\
\hline 9 & El Cerrito* $^{*}$ & 23,549 \\
\hline
\end{tabular}

${ }^{*}$ City where local official was interviewed.

\section{iii. Earlier Measures}

Measure A was passed in 1998; it stipulated an 18\% local return, which was allotted by means of a base of $\$ 100,000$ per city and a formula of $50 \%$ relative population and $50 \%$ road miles.

iv. Current Measure J (2004)

Current transportation funding for the CCTA comes primarily from Measure J, passed in 2004, which extended Measure A. It stipulates the same local return (18\%) and allocation formula. Most notably, Measure J entails a GMP that is designed to help Contra Costa County plan for and accommodate the continued increases in population, households, and jobs that are expected to occur through 2035. The goal of the GMP is to "achieve a cooperative process for Growth Management on a countywide basis, while maintaining local authority over land use decisions and the establishment of performance standards."

According to the CCTA, ${ }^{67}$ the GMP helps achieve the following:

- Gives local jurisdictions several new forums in which they cooperate to address transportation land use issues and develop joint objectives and plans to achieve them.

- Creates a regional mitigation program that through the imposition of new transportation fees, has generated almost $\$ 250$ million to fund improvements needed to meet the demands resulting from growth.

- Subjects local land use decisions and actions on jobs and housing to increased scrutiny by the public and adjoining jurisdictions. The GMP implementation guide sets forth the procedures for review of general plan amendments and development projection accordance with the cooperative planning requirements of Measure J. 
- Provides a consistent set of tools and performance standards for streets and public services under which projects and changes to general plans are thoroughly evaluated.

\section{Funding Specifics}

Funds are allocated first to four subregions (see map in Figure 14), which then pass them to eligible cities. The county features four subregions: Central, West, Southwest, and East, each represented by a regional transportation planning committee. Central County (the TRANSPAC subregion) includes Clayton, Concord, Martinez, Pleasant Hill, Walnut Creek, and unincorporated areas. West County (the WCCTAC subregion) includes El Cerrito, Hercules, Pinole, Richmond, San Pablo, and unincorporated areas. Southwest County (the SWAT subregion) includes Danville, Lafayette, Moraga, Orinda, San Ramon, and unincorporated areas. East County (the TRANSPLAN subregion) includes Antioch, Brentwood, Oakley, Pittsburg, and unincorporated areas.

To receive its share of Local Transportation Maintenance and Improvement funds and to be eligible for Contra Costa Transportation for Livable Communities funds, each jurisdiction must:

- Adopt a growth management element;

- Adopt a development mitigation program;

- Participate in an ongoing cooperative, multijurisdictional planning process;

- Develop a five-year CIP;

- Adopt a transportation systems management ordinance or resolution;

- Address housing options; and

- Adopt an ULL.

Additionally, the expenditure plan states that "Pedestrian and bicycle facilities are an important part of the regional transportation system. Moreover, as appropriate, components for routine accommodation of bicycle and pedestrian travel shall be incorporated as part of construction projects." It does not, however, state anywhere that funds must be used in this category. According to one interviewee, "no jurisdiction has been denied funds yet, the review process has become more rigorous"

Additional funding is allocated to jurisdictions in three of the subregions: Central County (\$20 million), West County (\$11 million), and Southwest County (\$10.8 million), for additional local streets maintenance and improvement (including funding for major streets, such as: traffic flow, 
safety and capacity improvements, and subregional transportation needs). This additional funding is in the "subregional projects and programs" category and is $2.1 \%$ of the total. The description is "These funds will be used to supplement the annual allocation of the 18\% "Local Streets Maintenance \& Improvements' program funds for jurisdictions in Central County.”

\section{Amendments}

The law (Measure J) provides for amendments that do not have to be approved by the voters. These entail a majority vote of the board and ratification by the cities. This has been done several times, essentially because the law needed to be adjusted for technical issues. One notable example of such an amendment occurred when the ULL boundaries had to be amended because several cities couldn't agree on the lines.

\section{Oversight and Reporting}

The compliance checklist is the primary means of ensuring that cities comply with the funding requirements. Each year, a jurisdiction must demonstrate its compliance with all components of the GMP via a completed compliance checklist. The checklist includes components that comprise the previous requirements. CCTA reviews the checklist and makes findings regarding the jurisdiction's compliance with the requirements of the GMP, consistent with the adopted policies and procedures. If CCTA determines that the jurisdiction does not comply with the GMP requirements, it withholds funds and may also find that the jurisdiction shall not be eligible to receive Contra Costa Transportation for Livable Communities until the Authority determines the jurisdiction has achieved compliance. The Authority's findings of noncompliance may set deadlines and conditions for achieving compliance.

\section{Transparency to the Public}

Many details regarding compliance requirements and expenditure plans are published in an annual expenditure plan report. ${ }^{68}$ The CCTA doesn't maintain a full repository of the cities' GMP checklists and local street maintenance expenditures on its website, but they are posted there as part of the agenda packets when they are being reviewed and approved by relevant committees (i.e., the Citizens Advisory Committee and the Planning Committee) and the Authority's board. They are also made available to the public upon request.

v. Contra Costa County and City Officials Interviewed for This Study

County: Randy Iwasaki, Executive Director, CCTA (June 17, 2019)

County: Martin Engleman, Deputy Executive Director of Planning, CCTA (June 18, 2019) 
Brentwood: Steven Kersevan, Engineering Manager (August 1, 2019)

Antioch: Tracy Shearer, Assistant Engineer (August 5, 2019)

El Cerrito: Christine Radcliffe, Public Works Director and City Engineer (August 5, 2019)

C. Fresno

i. Introduction

This county was selected for further study and interviews because it exemplifies a largely rural county with a significant urban area with LOST provisions that require spending on bicycle and pedestrian infrastructure.

\section{ii. Description of County}

Fresno County is in the San Joaquin Valley in Central California. The county encompasses approximately 6,000 square miles, and the eastern portion of the county includes portions of the foothills of the Sierra Nevada mountain range. More than $60 \%$ of the county's population resides in the Fresno and Clovis metropolitan area. The remainder of the county is largely rural with a significant agricultural economy. 
Figure 15. Fresno County Transportation Network

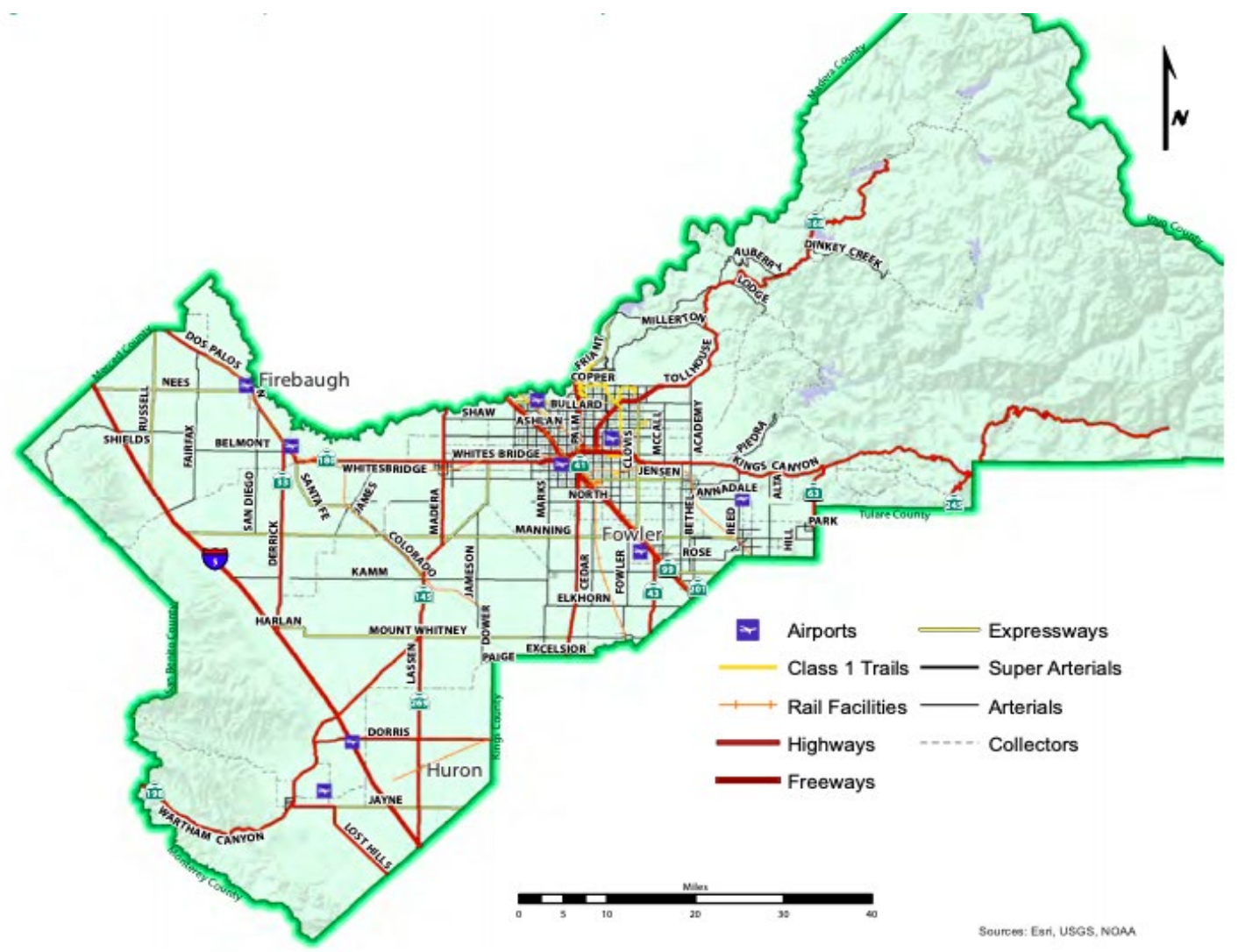

Source: Fresno 2018 RTP/SCS, pages 4-5. ${ }^{69}$

Table 14. Largest Cities in Fresno County

\begin{tabular}{|l|c|c|}
\hline & City & Population \\
\hline 1 & Fresno & 530,093 \\
\hline 2 & Clovis & 112,022 \\
\hline 3 & Reedley & 25,579 \\
\hline 4 & Sanger & 25,313 \\
\hline 5 & Selma & 24,807 \\
\hline 6 & Coalinga & 16,534 \\
\hline 7 & Parlier & 15,286 \\
\hline 8 & Kerman & 15,037 \\
\hline 9 & Kingsburg & 12,041 \\
\hline
\end{tabular}

Source: American Community Survey 2018, U.S. Census

Note: Unincorporated areas have the second largest population share following the city of Fresno.

i. Measure C (1986)

In November 1986, Fresno County voters passed a half-cent sales tax increase (Measure C) for 20 years titled "Improving Roads and Transportation in Fresno County." Measure C's enabling legislation also created the Fresno County Transportation Authority (FCTA) to implement the 
sales tax. The collection of the tax began on July $1,1987 .{ }^{70}$ The measure stressed the construction of highways in anticipation of regional growth. Under the expenditure plan, $75 \%$ of measure revenues funded regional highway construction programs and $25 \%$ of the funds were returned to cities for local transportation purposes.

ii. Measure C Extension (2006)

In 2006, the county voted to extend Measure C for an additional 20 years, from 2007-2027.

The Fresno Council of Governments (FCOG) established the Measure C Reauthorization Steering Committee, ${ }^{71}$ including local officials and other stakeholder groups, which spent close to a year crafting the 2006 Measure C Extension Expenditure Plan. ${ }^{72}$ Fresno County population was projected to grow $44 \%$ during this period, and the "vision of the plan [was] to provide mobility options for all of Fresno County's residents, helping to maintain Fresno County's quality-of-life in its amenities and transportation options." ${ }^{72}$

The FCTA and FCOG share implementation duties under the 2006 measure. The FCTA officially administers the sales tax under the enabling legislation for the original Measure C. As the Metropolitan Planning Organization, FCOG is responsible for long-range planning and programming. Local cities are represented on the FCOG board, which led the development of the measure expenditure plan. The FCTA is responsible for the day-to-day implementation of the sales tax, including the collection of revenues, financing of projects, and distribution of local passthrough funding. ${ }^{42}$

Under the expenditure plan, the regional program (which excludes local return and transit agency funding) focuses on geographic equity by dividing expenditures to mirror the population distribution in the county. An estimated $67.5 \%$ of Measure $\mathrm{C}$ proceeds are spent in urban areas of the county and the remaining $32.5 \%$ are allocated to rural areas. These estimated percentages are consistent with the percentage of Fresno County population in urban (71\%) and rural (29\%) areas at the time of the measure. ${ }^{73}$

\section{iii. Local Return}

The Local Transportation Program returns $34.6 \%$ of all measure revenue directly to agencies and jurisdictions, referred to as pass-through funding under Measure C. ${ }^{74}$ The Local Transportation Program includes three distinct funding programs: (a) the Local Allocation Program (30.6\% of measure revenues), (b) Pedestrian/Trails Program (3.1\% of measure revenues), and (c) Bicycle Facilities Program (0.9\% of measure revenues).

When composing the expenditure plan during the first attempt at measure renewal in 2002, the FCTA proposed expenditures that mirrored the original Measure $\mathrm{C}$ in focusing on highways and 
arterials. According to interviewees, the 2002 measure failed largely due to a coalition of interests that formed against a measure that dedicated such a large portion of revenues to highway projects.

The FCTA revised the expenditure plan for the 2006 measure through an iterative process, composing a measure draft with a large committee of stakeholders and polling constituents. According to interviewees, local return funding was a crucial element for measure support. The first measure largely built the transportation system, but the public wanted to address wear and tear on roads built with revenues from the first measure. Local return funding flexibility also helped garner support among environmental interests by providing funding for programs that would improve air quality, including school transportation, transportation-oriented development, and carpool and vanpool incentives.

The Local Allocation Program is the substantial local return program under the measure. Each incorporated city and Fresno County receives a minimum of $\$ 100,000$ per year, and then an annual allocation based on a $75 \%$ population and $25 \%$ road mile formula. Funding under this program is further divided into three subprograms that place requirements on local agency spending.

- Street Maintenance: $15.30 \%$ of measure revenues.

- ADA Compliance Program: 0.5\% of measure revenues. Only cities that receive more than $\$ 200,000$ of pass-through funding are required to meet ADA spending requirements. As of publication, only one city was subject to this exception.

- Flexible Funding: $14.80 \%$ of measure revenues. This funding can be used for any transportation project at the discretion of the jurisdiction (for example, transit operations, pothole repair, matching for federal or state programs). The measure states that cities "know what their needs are and how best to address those needs."

As previously described, flexible funding helped the measure gain the support of environmental interest groups. According to interviewees, flexible funding allows the measure to conform to the recognition that transportation is multimodal, as opposed to the streets-and-roads approach of the original 1986 measure. It has allowed cities to spend on more modern mobility issues that meet their needs. Flexible funding also has advantages over more categorical funding requirements because it reduces administrative burden in general and allows cities to change spending habits as transportation systems evolve without a formal amendment of the measure.

The measure also includes two programs that distribute funding to jurisdictions: the Pedestrian/Trails Program (3.1\% of measure revenues) and the Bicycle Facilities Program (0.9\% of measure revenues). The Pedestrian/Trails program is further broken down so that $2.15 \%$ of measure revenues in this category are allocated to urban areas and $0.95 \%$ are allocated to rural areas, a funding split that does not reflect population. 
According to an interviewee, the intent for these programs is for the Pedestrian/Trails Program to provide safe recreation and walkability and the Bicycle Facilities Program to support bike commuting corridors and regional connectivity. One interviewee noted that during the development of the measure expenditure plan, spending transportation funding on bicycle and pedestrian infrastructure was not a popular idea and considered more of an amenity than a transportation usage; bike and pedestrian infrastructure was more common in the larger cities in the counties, and some constituents supported this investment as a way to increase property value.

Cities with populations under 25,000 are exempt from both programs and instead can use the funding flexibly. Cities with a population between 25,000 and 75,000 can combine the funding they receive for both programs to spend for any purpose qualified under either of the programs. Cities with a population above 75,000 must meet the requirements of both programs. If cities do not meet the percentage spending requirements, an equal amount of flexible funding is withheld the following year.

According to interviewees, the specificity of these two programs has at times been confusing, and plan amendments and revisions to local return guidance documents were required to clarify and meet city needs. In practice, although funding for the programs is distinct, they are both focused on expanding transportation infrastructure, and implementation is discussed together in the ordinance. To receive funding under either of these programs, jurisdictions were required to adopt, by 2012, a "Master Plan for Trail, Bicycle and Pedestrian Facilities that promotes connectivity within all of Fresno County and its urban areas." Funded projects were then required to be consistent with the developed and approved master plan. Most of the smaller rural cities did not have such a plan and used their measure funding to develop one, and additional funding under the program accumulated until the plan was approved. According to interviewees, all jurisdictions had approved plans within the first five years of the measure.

Overall, the bike and pedestrian programs have been mildly contentious, although all jurisdictions have complied. Smaller jurisdictions that had opposed the requirements used the funding to develop bike and pedestrian master plans. Fresno and Clovis, the largest cities in the county, had bike and pedestrian plans in place before the measure and were required to use the funding to build projects. An interviewee from the city of Fresno noted that the city had pushed for bike, pedestrian, and transit programs to be included in the measures. Fresno had completed significant bike infrastructure before the measure, and according to the interviewee, has already addressed all the "low-hanging fruit." As a result, it has faced significant local resistance to more significant projects such as road diets.

\section{iv. Regional Transportation Mitigation Fee}

To receive measure funding, the county and each city must establish a Regional Transportation Mitigation Fee (RTMF) program that requires new growth and development to contribute to 
regional street and highway project costs. The rationale behind the RTMF is that the measure money shouldn't fund development. ${ }^{49,50}$ The measure estimated that the RTMF program will provide an anticipated $20 \%$ of the funds needed to deliver regional projects during the life of the measure. ${ }^{75}$ According to interviewees, cities and the development community accepted that the RTMF was essential to fund necessary infrastructure. Although everyone benefits from investment in regional infrastructure, there can be mild contention that the revenues are not geographically equitable. For example, the city of Mendota does not have any regional projects in the expenditure plan, yet it instituted the RTMF to receive local return funding.

\section{v. Reporting}

According to the measure ordinance, the FCTA must "prepare an annual report each year on progress made to achieve the objective of improving transportation conditions related to priority highway operations and local transportation needs." Two committees monitor decisions:

- Policy Advisory Committee: composed of one representative of each city in the county and one representative of the county, with each representative on the committee required to be an elected official. ${ }^{60}$

- Citizens Oversight Committee: membership, method of appointment, roles, and responsibilities in accordance with and defined in the initial expenditure plan. ${ }^{60}$

The measure requires that local agencies and jurisdictions account for all funds received under the measure. ${ }^{76}$ The measure requires records be retained based on "generally accepted accounting principles." If the audit cannot be substantiated, funding allocations will be withheld from the city until discrepancies are resolved. If funds were used improperly, cities must repay the funds to the FCTA. ${ }^{77}$

Cities do not need approval before spending local return funding but are expected to follow existing guidelines. In practice, the FCTA audits city spending through a spot-check approach and does not do a project-level audit. Interviewees stated that a project-level audit would bear too high of an administrative burden, but also that spending under local return provisions is a matter of trusting cities to follow the law. Additionally, withholding future money if a city violates the measure provisions has proven an effective enforcement mechanism.

Every five years, jurisdictions must show compliance with spending requirements as outlined by the measure. Jurisdictions have the flexibility to accumulate funding for up to a five years if a larger amount of funding is needed for a specific project, which is then accounted for in the compliance audit. If spending is not compliant, the FCTA may withhold funds until a city comes into compliance, and it has the ability to reallocate the funds for other purposes. ${ }^{78}$ 
The Citizens Oversight Committee is frequently more involved with project-specific decisions, as opposed to the FCTA. County supervisors appoint committee members to represent constituents' interests, reflecting the geography of the county. The committee works in an advisory role and often helps smaller cities with frequent staff turnover conform to both substantive and procedural measure requirements. Local officials often work with the committee to gain support for specific projects before going to the FCTA and claiming eligible expenses. ${ }^{79}$

\section{vi. Implementation}

To provide guidance on implementation of the local return portion of the measure, the FCTA and FCOG created a Measure C Extension 2007 Local Agency Handbook. The handbook was published after the measure passed with the plan to be updated annually, but in practice, local return has been governed by a Strategic Implementation Plan that updates local return guidance as conflicts arise in spending that warrant clarification.

According to interviewees, such occasions arise about once every six months. For example, one community wanted to use flexible funding to put up bollards at local street fairs, but this was deemed by the COG as an ineligible transportation expense. Another example is an ongoing debate regarding whether beautification features can be included in improvements (for example, brick-paved intersections and monument signs). The COG strives to find the right balance in cases like these between helping improve a community and spending money as voters intended.

vii. Fresno County and City Officials Interviewed for This Study

Fresno Council of Governments: Tony Boren, Executive Director, June 19, 2019

Fresno County Transportation Authority: Mike Leonardo, Executive Director, June 6, 2019

Fresno County Measure C Citizens Oversight Committee: Lee Dulap, Member, July 15, 2019

Fresno: Scott Mozier, Public Works Director, July 17, 2019

\section{Imperial County}

i. Introduction

This county was selected for further study and interviews because it a rural county that dedicates more than $90 \%$ of LOST measure revenues to local return. 


\section{ii. Description of County}

Imperial County is a primarily rural area in the southeastern corner of California, forming the state's southernmost border with Arizona. The county's population is approximately 180,000, clustered primarily in the cities listed in Table $15 .{ }^{80}$ Its primary industry is agriculture.

Table 15. Largest Cities in Imperial County

\begin{tabular}{|l|c|}
\hline \multicolumn{1}{|c|}{ City } & Population \\
\hline Brawley & 25,000 \\
\hline Calexico & 40,000 \\
\hline Calipatria & 4,000 \\
\hline E1 Centro & 45,000 \\
\hline Holtville & 6,000 \\
\hline Imperial & 15,000 \\
\hline Westmoreland & 2,000 \\
\hline
\end{tabular}

Note: Calipatria's figure excludes approximately 3,000 prison inmates.

\section{Transportation Sales Tax}

Measure D, a half-cent sales tax addition, originally passed in 1989. It was renewed in 2008 for the 40-year period of 2010 to 2050 with an 83\% majority vote. Most (92\%) Measure D funds are passed to localities, with the remainder reserved for transit, regional highways, and administration. Funds are allocated annually based on the following formula: $80 \%$ population and 20\% maintained street and road mileage.

\section{Funding Prerequisites}

Measure D recipients must maintain a level of effort equal to that provided for by the Measure. "Each Local Agency receiving revenues ... shall annually maintain as a minimum the same level of local discretionary funds expended for street and road purposes as was reported in the State Controller's Annual Report of Financial Transactions for Streets and Roads." Failure to meet this standard results in a penalty of the shortfall between the required expenditure and the annual allocation. In practice, however, each city has reportedly met this requirement each year.

\section{Funding Requirements}

Beginning in 2007, detailed financial statements and project lists from each city are required and were included in county reports. Starting in 2013, each city has a separate report. Funds are required to be spent "in accordance with the following priorities":

1. To repair and rehabilitate existing roadways, 
2. To reduce congestion and improve safety, and

3. To provide for the construction of needed facilities.

Essentially, there are therefore relatively few limitations on how Measure D funds can be used, as long as they are used in the stated ways. In practice, localities report that they use the funds almost exclusively for road repairs and maintenance. To get the funds, cities must submit a list of projects (along with auditing documentation).

\section{Amendments}

According to the measure, local expenditure plans may be amended "by ordinance or resolution, passed by roll call vote entered in the minutes, with two-thirds of the Authority concurring." In practice, this step has not been necessary, given that the original expenditure plans tend to cast a wide net—cities list all of their streets and roads as potential projects in their annual lists.

\section{Oversight and Reporting}

Each city must submit an annual report that includes a detailed description and the amount of sales tax receipts spent on each project. Each city's expenditures are also audited annually. Additionally, Measure D-backed bond expenditures must be reported on a quarterly basis.

\section{Transparency to the Public}

Projects are supposed to be listed on the Imperial County Transportation Commission website, although that does not necessarily provide an accounting of where funds for a given city have been used. In practice, however, locating the relevant documentation for a given city is not a straightforward task. Some cities report that their projects are included in city council meeting minutes.

iii. Imperial County and City Officials Interviewed for This Study

County: Mark Baza, Executive Director, Imperial County Transportation Commission (July 29, 2019)

Calexico: Lillan Falomir, Public Works Manager (August 21, 2019)

Calpitria: Rom Medina, City Manager (August 21, 2019) 


\section{E. Riverside County}

\section{i. Introduction}

This county was selected for further study and interviews because local return allocation differs among regions in the county and the LOST requires adherence to regional planning programs as a condition for receiving local return funding.

\section{ii. Background}

Riverside County has passed two sales tax measures. Measure A, a half-cent sales tax, was passed in 1988 and ran for 20 years. ${ }^{81}$ In 2002, voters approved an extension of Measure A, taking effect in 2009 at the expiration of the original measure and extending the sales tax through 2039.

Table 16. Largest Cities in Riverside County

\begin{tabular}{|c|c|c|c|c|c|}
\hline & City & Population & \multirow{5}{*}{$\begin{array}{l}6 \\
7 \\
8 \\
9\end{array}$} & City & Population \\
\hline 1 & Riverside & 330,063 & & Jurupa Valley & 108,393 \\
\hline 2 & Moreno Valley & 209,050 & & Menifee & 92,595 \\
\hline 3 & Corona & 168,819 & & Indio & 91,240 \\
\hline 4 & Murrieta & 114,985 & & Hemet & 85,275 \\
\hline 5 & Temecula & 114,742 & & & \\
\hline
\end{tabular}

iii. Transportation Sales Tax

Riverside Measure A (2002) is unique in its distinction between subregional programs. Sales tax revenues raised in each subregion are returned to that subregion, which then allocates a percentage of revenues to local return as determined by local needs. Riverside County refers to its local return program as "return to source" funding. The more densely populated Western County (governed by the Western Riverside Council of Governments [WRCOG]) and the Coachella Valley (governed by the Coachella Valley Association of Governments) dedicate 29\% and 35\% of revenues to local return, respectively. Palo Verde Valley, in the extreme eastern portion of the county on the border of Arizona, contains only one incorporated city (Blythe) and allocated all revenues to the city and this portion of the county through its local streets and road programs. 
Figure 16. Subregional Distribution of Local Return Funding in Riverside County
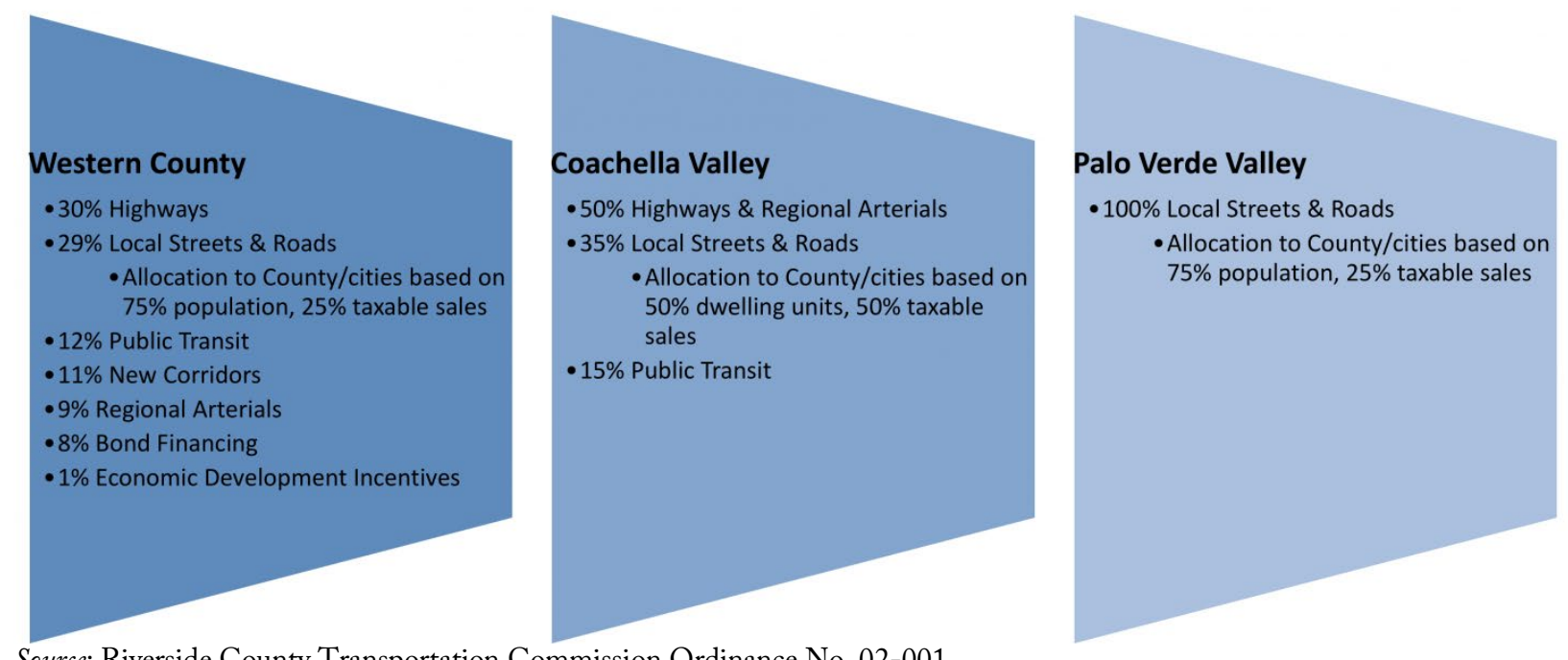

The measure stresses equity in the allocation of funding, with the county Transportation Improvement Plan stating the measure will:

Provide for equity in the distribution of measure "A" revenues. Return funds to the Western County, Coachella Valley and Palo Verde Valley proportionate to the funds generated in those areas. Adopt a Transportation Improvement Plan, which address the unique needs of each of the areas of the county. Provide a reasonable balance between competing highway, commuter rail, transit, and local streets and roads needs.

The measure first allocates measure revenues among the three subregions proportionate to sales tax revenues raised in each region. Then the COG for that subregion (or the county for Palo Verde Valley) allocates funding to jurisdictions in the subregion.

iv. Funding Allocations and Prerequisites (by Subregion)

\section{Western Riverside}

Local return revenue in the western portion of the county is distributed to cities and the county by a formula of $75 \%$ proportionate population and $25 \%$ revenues generated by Measure A.

To be eligible for these funds, each jurisdiction is required to:

1. File a 5-year capital improvement program, updated annually, with the commission; 
2. Participate in a TUMF program to be developed and administered by the commission or the WRCOG; and,

3. Participate in the Multi-Species Habitat Conservation Plan (MSHCP) currently under development by in western Riverside county by endorsing the permit application and signing the implementation agreement.

\section{Coachella Valley}

Thirty-five percent of Measure A revenues are returned to the cities and the county in the Coachella Valley for local return. Funds are allocated based on a formula of 50\% proportionate dwelling units and $50 \%$ sales tax revenues generated in each jurisdiction.

To be eligible for these funds, each jurisdiction is required to:

1. Prepare and annually update a 5-year capital improvement program, and

2. Participate in the TUMF program to assist in the financing of the priority regional arterial system.

If a city or the county chooses not to levy the TUMF, local return funding is withheld and reallocated to the Measure A funds for the Regional Arterial Program.

\section{Palo Verde Valley}

The Palo Verde Valley area is in the far eastern part of Riverside County. The area is not forecasted to have significant growth during the life of the measure, and thus all of the local return is to be used for local streets and roads. Funds are distributed to the city of Blythe and the county of Riverside by a formula of $75 \%$ proportionate population and $25 \%$ sales tax revenues generated in each area.

v. Funding Requirements

Receiving Measure. A funds require meeting a maintenance of effort requirement, which states:

The local cities and the County shall annually submit to the Commission a list of the proposed uses for these funds and a certification that the maintenance of effort requirement is being met. If in any fiscal year the maintenance of effort requirement is not met, the agency shall not be eligible for any Measure A funds in the following fiscal year. Such funds shall be distributed to the remaining local governments using the formula for the area. 


\section{vi. Oversight and Reporting}

The Riverside County Transportation Commission (RCTC) is required by the ordinance to conduct an independent fiscal audit of the expenditure of all sales tax funds raised by this measure. This audit ensures that jurisdictions expend funds in accordance with the measure expenditure plan, meet maintenance of effort requirements, and participate in the TUMF and MSHCP as applicable. Participation in the TUMF program is certified by the relevant COG.

vii. Transparency to the Public

All audits and annual reports are part of the public record, with much of the relevant financial information available in the RCTC annual financial report. ${ }^{82}$ However, detailed Measure A project- and city-level data are not readily available on the RCTC website.

viii. Riverside County and City Officials Interviewed for This Study

RCTC: Theresia Trevino, Chief Financial Officer (June 21, 2019)

RCTC: John Standiford, Deputy Executive Director (June 21, 2019)

La Quinta: Karla Romero, Finance Director and City Treasurer (August 28, 2019)

\section{F. San Diego TransNet}

\section{i. Introduction}

This county was selected for further study and interviews because it is an urban county with LOST provisions that require jurisdictions to implement a development impact fee before receiving funding and provisions that dictate on what local return funding can be spent.

\section{ii. Background}

San Diego County approved its first LOST, known as TransNet, in 1987. The half-cent sales tax was levied starting in 1988, was in place for 20 years, and expired in 2008.

In 2004, anticipating the coming expiration of TransNet, voters approved a measure that extended the half-cent sales tax through 2048. The extension measure was formally listed on the ballot as Proposition A, but in the local media, the 2004 measure continues to be commonly referred to as TransNet Extension or even more simply, by the name given to the original measure, TransNet. When the measure is explained in the media in general but imprecise terms, it is often stated that over 60 years, the funds raised are intended to be programmed so that roughly one third will be spent on highways, one third on transit, and the remaining third on local streets and roads. 
More precisely, the 2004 TransNet Extension created rules and procedures by which it funds a mix of highway, transit, bike and pedestrian, and local road projects and dedicates funding to environmental conservation and measures to mitigate the environmental impacts of projects.

A noteworthy feature of the 2004 extension is that to be eligible to receive local return funds generated by the sales tax, each of the 18 municipalities in the county are required to have in place a program to collect $\$ 2,000$ per new dwelling unit constructed and contribute revenues from local exactions to match the programs funded by the TransNet Extension. The required development fees have escalated annually since they were initially set at $\$ 2,000$ to reflect steady growth in the costs of alleviating congestion. TransNet rules allow municipalities to collect the fee at different times or in different ways in the development process, but new dwelling units are defined in county-wide measures that, for example, allow cities to enact exclusions from fee payment for very few forms of residences, such as board-and-care facilities housing older and disabled citizens. Interviews with San Diego Association of Governments (SANDAG) and municipal officials confirmed that all municipalities in San Diego County have programs in place to collect the required exactions, and that many cities levy several exactions on new residential development that exceed TransNet requirements and, for example, also produce revenue for public safety programs.

In November 2016, another ballot measure, also known Measure A, was placed before the voters. If successful, it would have raised the transportation sales tax by another $0.5 \%$. The measure was favored by $58.4 \%$ of those voting but required a two-thirds majority to be enacted and thus, it failed. In general, support for the measure was stronger in urban and politically liberal areas and weaker in rural, suburban, and more conservative parts of the county. The 2004 measure remains in place and provides San Diego County with a substantial proportion of the transportation revenue available to programs in the region. News media and several interviewees reported that discussions are underway regarding the possibility of including another transportation sales tax on the ballot during the 2020 presidential election, but that the potential measure under discussion would most likely raise money only for capital investments and operating subsidies for the two public transit operators in the county-North County Transit and the San Diego Metropolitan Transit System. Plans for such a measure remain preliminary, and it is not yet determined who would administer the funds if such a measure were to be enacted.

The 2004 measure (TransNet Extension), which raises more than a quarter billion dollars per year, is managed by SANDAG, which is one of only two county transportation and land use agencies in California that serves at once as a Regional Transportation Planning Agency (RTPA) under California law, a Metropolitan Planning Organization under federal law, and a Congestion Management Agency (CMA) under state law. This means that SANDAG has the responsibility to prepare and regularly update the regional long-range (30-year) transportation plan required by federal and state law, and that it also prepares and manages the flow of funds to the list of current projects that comprise the county's short-term (5-year) Transportation Improvement Program. 
Because it has these multiple powers and responsibilities, the SANDAG Board of Directors is also the San Diego Transportation Commission.

Its multiple roles make SANDAG the focus of transportation policy in the San Diego region, and tensions arise constantly regarding the use of TransNet Extension funds. TransNet was planned to be consistent with the Regional Transportation Plan, and there is a broad consensus that it should be periodically amended to remain consistent. The money managed by SANDAG under the measure is critically important to the region and is the source of many policy debates, even though other direct expenditures by Caltrans, cities in the county, and transit agencies constitute a majority of county transportation spending. For the current 5 -year budget period that began in 2017 , TransNet is estimated to provide more than $\$ 2.5$ billion, about a third of the county's transportation funding, with the federal share being 35\%, the state contributing $16 \%$, and local government sources contributing another $16 \%{ }^{83}$

Under its new director, Hasan Ikhrata, SANDAG is discussing whether to undertake major revisions in the near future to reduce greenhouse gas emissions far more aggressively from transportation. Potential revisions being widely discussed, which are currently very controversial, would reduce future spending on highway projects, including reducing commitments made in the past to highways not yet widened or built, while increasing investment in public transit, pedestrian, and cycling programs.

iii. Expenditure Plan

Under the original expenditure plan, presented in Table 17, most (97\%) sales tax revenue produced by the measure is dedicated to funding what is known as the Congestion Relief Program, which is largely a capital investment program. ${ }^{84}$ This program is divided into three categories: Major Transportation Corridor Improvements (48.9\% of measure revenues), Transit System Improvements (16\% of measure revenues), and Local System Improvements (32\% of measure revenues). 
Table 17. TransNet Extension Expenditure Plan

\begin{tabular}{|c|c|c|c|c|}
\hline \# & Expenditure Plan Component & \begin{tabular}{|r|} 
Total TransNet \\
Requirement \\
(40-year Total) \\
\end{tabular} & $\begin{array}{c}\text { Percent } \\
\text { of Net }\end{array}$ & $\begin{array}{l}\text { Percent } \\
\text { of Total }\end{array}$ \\
\hline 1 & Congestion Relief Program & & & \\
\hline 2 & Major Transportation Corridor Improvements: & $\$ 6,850$ & $50.5 \%$ & $48.9 \%$ \\
\hline 3 & Freeway, Highway, \& Transit Capital Projects & $\$ 5,150$ & $38.0 \%$ & $36.8 \%$ \\
\hline 4 & Project Specific Transit Operations & $\$ 1,100$ & $8.1 \%$ & $7.9 \%$ \\
\hline 5 & Freeway, Highway, \& Transit Project Environmental Mitigation & $\$ 600$ & $4.4 \%$ & $4.3 \%$ \\
\hline 6 & Local System Improvements & $\$ 4,480$ & $33.0 \%$ & $32.0 \%$ \\
\hline 7 & Local Street \& Road Projects & $\$ 3,950$ & $29.1 \%$ & $28.2 \%$ \\
\hline 8 & Local Street \& Road Project Environmental Mitigation & $\$ 250$ & $1.8 \%$ & $1.8 \%$ \\
\hline 9 & Smart Growth Incentive Competitive Grant Program & $\$ 280$ & $2.1 \%$ & $2.0 \%$ \\
\hline $\begin{array}{l}10 \\
11 \\
12\end{array}$ & $\begin{array}{l}\text { Transit System Improvements - } \\
\text { Continuing Bus/Rail Support and Improvements, including Senior/ } \\
\text { Disabled/Youth Transit Passes and Specialized Senior/Disabled } \\
\text { Transportation Services }\end{array}$ & $\$ 2,240$ & $16.5 \%$ & $16.0 \%$ \\
\hline 13 & Sub-Total & $\$ 13,570$ & $100.0 \%$ & N/A \\
\hline 14 & Bicycle, Pedestrian \& Neighborhood Safety Grant Program & $\$ 280$ & & $2.0 \%$ \\
\hline 15 & Administration & $\$ 140$ & & $1.0 \%$ \\
\hline 16 & Oversight Committee & $\$ 10$ & & $0.1 \%$ \\
\hline 17 & TOTAL TransNet Funding Requirement & $\$ 14,000$ & & $100.0 \%$ \\
\hline 18 & $\begin{array}{l}\text { TOTAL TransNet Funds Available } \\
\text { " These categories deducted "off the top" prior to other allocations. }\end{array}$ & $\$ 14,000$ & & $100.0 \%$ \\
\hline
\end{tabular}

Source: California Department of Transportation.

iv. Local Return Funds

Most sales tax revenues fund region-serving transportation system capital improvements, and the Local Street and Road Program returns 28.2\% of measure revenues directly to the 18 cities and unincorporated areas of the county for local street and road improvements. Under the local program, each jurisdiction receives an annual minimum base sum of $\$ 50,000$. The remaining revenues are allocated based on a formula that weights the jurisdiction's population by two thirds and its maintained roadway miles by one third. Roads on private land that are the responsibility of the landowners and not maintained by the county are excluded from the calculations.

Local return funds are available to cities and unincorporated areas on the condition that they be used to expand local programs rather than replace other local funds spent on maintenance and operations from sources that predate the enactment of TransNet. Recipient jurisdictions must demonstrate maintenance of effort (MOE) by reporting their continuing expenditure of other local funds and showing that funding from local sources has kept up over time with the declining value 
of money due to inflation. MOE is reported as part of the audit of local transportation spending required by TransNet as implemented by the Independent Taxpayer Oversight Committee (ITOC).

Cities in San Diego County reported that they maintain three accounts for their use of TransNet local funds. One is to be used for projects that meet the requirement that $70 \%$ of this funding be spent to accommodate traffic on the regional arterial system. This program consists of spending on:

Construction of new or expanded facilities, major rehabilitation and reconstruction of roadways, traffic signal coordination and related traffic operations improvements, transportation-related community infrastructure improvements to support smart growth development, capital improvements needed to facilitate transit services and facilities, and operating support for local shuttle and circulator routes and other services.

Another 30\% is managed in a separate account designated for street maintenance and repair. A list of allowable expenditures under the categories of construction and expansion versus operations and maintenance is intended to prevent cities from categorizing their expenditures differently from one another. ${ }^{83}$

If a city wishes to exceed the $30 \%$ limit on maintenance projects, it may submit a request to do so to the SANDAG board, explaining its rationale for the request as part of its biennial project list submittal. This option has rarely been used. More commonly, cities have set aside in a separate account $1 \%$ of their maintenance funds to provide for administrative expenses associated with projects funded by their jurisdiction. Cities also report having separate accounts in which they deposit the proceeds of the exactions charged of residential real estate developers. While keeping funds from different sources in separate accounts, cities also report that they frequently fund improvements using multiple sources of money. An intersection upgrade or bridge replacement project might typically be funded by a project budget that includes TransNet funds, developer exactions, general funds, California gasoline tax disbursements, and other funds. Small jurisdictions reported that to afford projects of significant scale and cost, they frequently bank their annual TransNet revenue until they have adequate funds to cover the cost of a planned project.

Most cities have processes by which they identify and prioritize projects to be funded by TransNet disbursements. Typical processes include surveying members of the city council and staff members of planning and engineering departments and systems of scoring projects based on their urgency or consistency with stated goals. Projects identified by these processes but not able to be funded with available resources are often held over for a later year.

In addition to the funds disbursed to local jurisdictions according to formula, a small proportion of the local return funds in San Diego County are used to create competitive grants programs for 
safety enhancement and for "active transportation and smart growth." Applications for awards in these programs are made and awardees selected by the SANDAG board for projects addressing safety, bicycling, pedestrian movement, and city redesign to fulfill the objectives of "smart growth." Cities have used the competitive grants programs for low-cost improvement projects such as new audible traffic signals, countdown traffic signals, and bike racks.

v. Local Spending Oversight

Every year, each jurisdiction must update a five-year list of projects to be funded by local return revenues. Each jurisdiction must hold a public hearing on the project list and then submit the final list to the commission to verify consistency with the ordinance and the Regional Transportation Plan. The project list is additionally reviewed by the ITOC.

The ordinance specifies that highest priority shall be given to funding "improvements to regional arterials, grade separation projects, and related facilities contributing to congestion relief." It does not provide further details of which types of projects are included or how they should be prioritized.

vi. San Diego County and City Officials Interviewed for This Study

SANDAG: José A. Nuncio, P.E., TransNet Department Director (September 11, 2019)

ITOC: Stewart Halpern, Member (August 21, 2019)

ITOC: Tracy Drager, Assistant Auditor and Controller, San Diego County, Nonvoting Ex Officio Member (September 12, 2019)

San Diego: Benjamin Battaglia, Administrative Services and Fiscal Manager, Transportation and Storm Water Department (September 18, 2019)

San Marcos: Ed Deane, Deputy City Engineer (September 20, 2019)

Chula Vista: Frank Rivera, Principal Civil Engineer, Engineering \& Capital Projects Department (September 24, 2019) 


\section{Appendix B: Interview Guide}

\section{Questions for County Transportation Agencies}

Introductory/background questions

1. What is your job title and major area(s) of responsibility?

2. How long have you worked at your agency?

3. Describe your familiarity with the local return provisions of your LOST tax measure.

\section{Return basic facts and history}

1. Briefly describe the process used to determine local return percentage

a. How important was the local return provision to the success of the measure?

b. Were there other considerations, such as regional divisions (e[.]g. North/South)?

2. Describe the involvement of city officials in crafting the measure expenditure plan.

a. Were city officials who were not on the agency board part of the process?

3. Allocation

a. Do you think that the method of funding allocation among jurisdictions is fair?

4. [If applicable:] Next[,] I have some questions about the prerequisites cities must meet to be eligible for funding

a. What was the rationale for creating these funding prerequisites?

b. What kind of opposition, if any, did cities have to these prerequisites? cities?

c. How does [County $\mathrm{X}]$ monitor if a city has met the prerequisite?

d. What has been the impact of funding prerequisites, if any?

i. Have you withheld any funding from a city for not meeting a prerequisite?

5. [If applicable] Next[,] I have some questions about the rules that guide how cities may spend the local-return funding. 
a. What regional policy goals are intended to be served by these requirements?

b. Can you describe the process and rationale for establishing requirements for how cities spend local return funding?

i. Which stakeholders were involved in determining them?

c. What kind of opposition, if any, did cities have to these spending restrictions?

d. To what extent do cities have flexibility in how they meet these spending requirements?

6. Next[,] I have some questions about monitoring and oversight of the funds

a. How does [County $\mathrm{X}]$ monitor if a city meets spending requirements? (if applicable).

b. If cities must present a list of projects for approval, what is the process for approval?

i. In what ways has this process worked either well or poorly?

c. What is the process if a city wants to change expenditures after a plan is approved?

i. And has this ever occurred?

d. What penalties are established if a municipality does not meet expenditure requirements? Have they ever been imposed?

e. Has funding ever been withheld from a municipality for any reason we have not discussed?

7. Next[,] I have some questions about the overall effectiveness of the local return provisions.

1. How effective has the return provision been with respect to helping to meet the policy goals of the tax initiative?

2. Has implementation of the return provision matched the promises made during the tax campaign and/or the statutory requirements?

Is there anything else you'd like to add that might help me understand the challenges or successes of the local return provision in the ballot measure?

Can you recommend anyone else who might have a perspective on the return provision and its implementation? Was any other agency or group active in creating, supporting, or opposing it? 


\section{Question[s] for city officials and planning departments}

\section{Introductory/background questions}

1. What is your job title and major area(s) of responsibility?

2. How long have you worked in your present position with the city?

3. Describe your familiarity with the local return provisions of your tax measure.

General

1. What was the city's involvement in crafting the measure's local return provision?

Next[,] I have some question[s] about funding allocation among cities.

1. Do you receive your allocated funding every year?

2. Has there ever been a delay in receiving funding?

3. Do you think that the method of funding allocation among jurisdictions is fair?

4. Was funding ever withheld because you did not conform with requirements in the measure?

1. If so[,] please explain?

\section{Now I am going to ask some questions on how you determine how measure funding is spent}

1. Can you describe the process for determining what projects the measure will fund?

a. Does the administering agency approve spending of measure revenues? Have they ever disapproved of your spending? If so[,] what was the outcome?

2. What is the process for changing the project list? How has this worked in practice?

3. Do you ever coordinate projects with other municipalities?

4. Do you make public an accounting of what local return funding was spent on?

2. How do you report spending to the measure administering agency?

1. How often? 
2. How detailed are reports to the county? [[Note: ask for access to them if we do not already have]]

\section{Now I am going to ask you some questions about specific stipulations of the measure}

For measures with prerequisites to spending: To what extent was receiving measure funding a factor in developing what was required by the prerequisites?

For measures with spending requirements: The measure ordinance stipulates the $[[\mathrm{xx} \%]]$ of funding must be spent on [[purpose]].

1. Is this requirement enforced annually?

a. If not, how often do you need to account for this percentage?

2. How do you keep track of this?

3. How is this reported to the County?

4. Is there any oversight to ensure that funding is spent as the measure required? Can you describe the oversight process?

5. Do you think that these requirements impact your spending decision?

6. Would you spend less on $[[\mathrm{xx}]]$ if it wasn't required?

\section{General evaluation}

1. How effective has the return provision been with respect to helping to meet the policy goals of the city?

2. Has implementation of the return provision matched the promises made during the tax campaign and/or the statutory requirements?

Is there anything else you'd like to add that might help me understand your city's challenges or successes with the local return provision in the ballot measure?

Can you recommend anyone else who might have a perspective on the return provision and its implementation? Was any other agency or group active in creating, supporting, or opposing it? 


\title{
Appendix C: Measure Language Conditioning Local Return on Enacting Development Impact Fees
}

\author{
Table 18. Text of Measures Requiring Development Impact Fees
}

\begin{tabular}{|c|c|c|c|}
\hline County & Measure & Year & Requirement Description \\
\hline Contra Costa & Measure $\mathrm{C}$ & 1988 & $\begin{array}{l}\text { To meet the requirements of this Section, each jurisdiction } \\
\text { shall: ... adopt a development mitigation program to ensure that } \\
\text { development is paying its fair share of the costs associated with } \\
\text { that development. }\end{array}$ \\
\hline Contra Costa & Measure J & 2004 & $\begin{array}{l}\text { To receive its share of local return funds and to be eligible for } \\
\text { Contra Costa Transportation for Livable Communities funds, } \\
\text { each jurisdiction must: ... adopt a development mitigation } \\
\text { program }\end{array}$ \\
\hline Contra Costa & Measure X & 2016 & $\begin{array}{l}\text { To receive its share of the } 2016 \text {... Expenditure Plan funding } \\
\text { from Local Streets ... funding and to be eligible for ... } \\
\text { Expenditure Transportation for Livable Communities funds } \\
\text { and the } 2016 \text {... Community Development Transportation } \\
\text { Program funds each jurisdiction must: ... Adopt a Development } \\
\text { Mitigation Program }\end{array}$ \\
\hline Fresno & Measure $\mathrm{C}$ & 2006 & $\begin{array}{l}\text { If any city or Fresno County should choose to not implement } \\
\text { the [Regional Transportation Mitigation Fee], then that agency } \\
\text { shall forfeit annually from the Local Transportation Program } \\
\text { Street Maintenance / Rehabilitation Category an amount equal } \\
\text { to the amount of RTMF that would otherwise have been paid } \\
\text { for development projects within that jurisdiction during the } \\
\text { year. }\end{array}$ \\
\hline Madera & Measure $\mathrm{T}$ & 2006 & $\begin{array}{l}\text { If a Local Traffic Impact Fee Program is not implemented, } 20 \% \\
\text { of the Flexible funding allocation will be forfeited by the local } \\
\text { agency until such time as the agency implements a Local Traffic } \\
\text { Impact Fee Program. }\end{array}$ \\
\hline Merced & Measure $\mathrm{G}$ & 2006 & $\begin{array}{l}\text { To receive funds from the Local Roads Maintenance and } \\
\text { Improvements program of this plan, a jurisdiction must have a } \\
\text { development mitigation program and be collecting } \\
\text { transportation impact fees, including, but not limited to, the } \\
\text { Regional Transportation Impact Fee, to insure that new growth } \\
\text { pays for its share of the transportation infrastructure costs } \\
\text { associated with that growth. }\end{array}$ \\
\hline Monterey & Measure Z & 2008 & $\begin{array}{l}\text {... cities and the County must meet each of the following } \\
\text { requirements to receive funds ... Adopt the Transportation } \\
\text { Agency for Monterey County's Regional Development Impact } \\
\text { Fee ordinance and impose these fees on new development as } \\
\text { applicable to assure that development pays for its impacts on the } \\
\text { regional transportation system. }\end{array}$ \\
\hline
\end{tabular}




\begin{tabular}{|c|c|c|c|}
\hline County & Measure & Year & Requirement Description \\
\hline Monterey & Measure X & 2016 & $\begin{array}{l}\text { Each city and the County of Monterey shall maintain } \\
\text { participation in the Transportation Agency for Monterey } \\
\text { County's Regional Development Impact Fee program and } \\
\text { impose these fees on new development as applicable to assure } \\
\text { that new development pays for its impacts on the regional } \\
\text { transportation system. }\end{array}$ \\
\hline Placer & Measure M & 2016 & $\begin{array}{l}\text { In order to be eligible for these funds, each jurisdiction shall } \\
\text { satisfy and continue to satisfy the following requirements ... } \\
\text { Adopt and administer a development impact fee program that } \\
\text { requires new development to pay a fair share of necessary } \\
\text { transportation improvements attributable to the new } \\
\text { development. }\end{array}$ \\
\hline Riverside & Measure A2 & 2002 & $\begin{array}{l}\text { the Commission shall not allocate funds to an individual city or } \\
\text { the County ... unless the local agency is certified ... to be a } \\
\text { participant in the Transportation Uniform Mitigation Fee } \\
\text { (TUMF) program necessary for the implementation of the } \\
\text { Regional Arterial Program in their area. }\end{array}$ \\
\hline Sacramento & Measure A1 & 1988 & $\begin{array}{l}\text { The Authority shall not allocate revenues to the cities or County } \\
\text { unless they have a fee or tax on development to fund roads. }\end{array}$ \\
\hline Sacramento & Measure A2 & 2004 & $\begin{array}{l}\text { the County and other Measure A jurisdictions must execute this } \\
\text { agreement (Sacramento County Transportation Mitigation Fee } \\
\text { Program) and implement the Fee Program as a condition of } \\
\text { receiving New Measure A allocations for road maintenance ... } \\
\text { as of April 1, } 2009 \text {. }\end{array}$ \\
\hline Sacramento & Measure B & 2016 & $\begin{array}{l}\text { This Measure B Expenditure Plan does not impose a new } \\
\text { impact fee requirement on property development. No revenue } \\
\text { generated from the tax, however, shall be used to supplant } \\
\text { transportation mitigation fees currently imposed on new } \\
\text { property development in Sacramento County. The County and } \\
\text { each incorporated city must continue to impose transportation } \\
\text { impact fee programs as required in Ordinance No. STA-04-01 } \\
\text { as a condition for receiving Measure B funds }\end{array}$ \\
\hline San Benito & Measure $\mathrm{G}$ & 2018 & $\begin{array}{l}\text { Each city and the county shall maintain participation in the } \\
\text { Regional Traffic Impact Mitigation Fee program and shall } \\
\text { impose the adopted fees on new development as applicable, to } \\
\text { ensure new development pays for its impacts on the regional } \\
\text { transportation system }\end{array}$ \\
\hline San Diego & $\begin{array}{l}\text { Proposition } \\
\text { A }\end{array}$ & 2004 & $\begin{array}{l}\text {... each local agency in the San Diego region shall contribute } \\
\$ 2,000 \text { in exactions from the private sector, for each newly } \\
\text { constructed residential housing unit in that jurisdiction to the } \\
\text { [Regional Transportation Congestion Improvement Program } \\
\text { Fees]." or they will not be eligible for local returns }\end{array}$ \\
\hline
\end{tabular}




\begin{tabular}{|c|c|c|c|}
\hline County & Measure & Year & Requirement Description \\
\hline San Joaquin & Measure K & 2006 & $\begin{array}{l}\text { All communities in San Joaquin County must have adopted } \\
\text { both a local development fee program for traffic mitigation and } \\
\text { the Regional Transportation Impact Fee. Should a jurisdiction } \\
\text { not have a local traffic impact mitigation fee and the Regional } \\
\text { Transportation Impact Fee in place by the last day of the fiscal } \\
\text { year, then all revenue apportioned to that community under the } \\
\text { Local Street Repair Program will be reapportioned for the } \\
\text { following fiscal year among all the eligible jurisdictions based on } \\
\text { the adopted formula. }\end{array}$ \\
\hline
\end{tabular}

Note: Santa Barbara (Measure A, 2008) also includes a more equivocal statement; "Where appropriate, traffic impact fees collected from new development served by a regional project will provide a fair share contribution to the cost of the project," but does not stipulate that the fee was a prerequisite for funding. 


\section{Appendix D: Text of Measures with Reporting Requirements}

Table 19. Text of Measures with Reporting Requirements

\begin{tabular}{|c|c|c|c|c|}
\hline County & Measure & Year & $\begin{array}{c}\text { Type of } \\
\text { Requirement }\end{array}$ & Text \\
\hline Alameda & $\begin{array}{c}\text { Measure } \\
\text { B }\end{array}$ & 2000 & $\begin{array}{l}\text { Approval of } \\
\text { project list } \\
\text { through public } \\
\text { process }\end{array}$ & $\begin{array}{l}\text { All projects and programs must receive governing } \\
\text { board approval prior to the jurisdiction expending } \\
\text { the DLD funding. This approval allows the } \\
\text { opportunity for the public to provide input on } \\
\text { planning for local streets and roads projects. } \\
\text { These projects and programs must be included in } \\
\text { any of the following, as long as they have been } \\
\text { adopted by the jurisdiction's governing board: } 1 \text { ) } \\
\text { List of projects on which to specifically spend } \\
\text { Measure B funds 2) Local Streets and Roads } \\
\text { Master Plan with priority projects 3) Capital } \\
\text { Improvement Program 4) A resolution, such as to } \\
\text { submit a grant application } 2016 \text { guidelines. }\end{array}$ \\
\hline $\begin{array}{l}\text { Los } \\
\text { Angeles }\end{array}$ & $\begin{array}{c}\text { Propositi } \\
\text { on A }\end{array}$ & 1980 & $\begin{array}{l}\text { Reporting for } \\
\text { Approval for } \\
\text { consistency } \\
\text { with measure }\end{array}$ & $\begin{array}{l}\text { Allocation of funds to local jurisdictions shall be } \\
\text { subject to the following conditions: (1) } \\
\text { Submission to the Commission of a description } \\
\text { of intended use of the funds, in order to establish } \\
\text { legal eligibility. Such use shall not duplicate or } \\
\text { compete with existing transit service. (2) The } \\
\text { Commission may impose regulations to ensure } \\
\text { the timely use of local transit funds. (3) } \\
\text { Recipients shall account annually to the } \\
\text { Commission on the use of such funds. }\end{array}$ \\
\hline Monterey & $\begin{array}{c}\text { Measure } \\
\text { Z }\end{array}$ & 2008 & Reporting & $\begin{array}{l}\ldots \text { cities and the County must meet each of the } \\
\text { following requirements to receive funds: ... } 5 . \\
\text { Submit a written request to the Transportation } \\
\text { Agency for Monterey County for its approval } \\
\text { identifying the transportation project(s) proposed } \\
\text { to utilize the funding, identifying the project } \\
\text { name, the general scope of work, the amount } \\
\text { requested, and the anticipated year the project } \\
\text { will start. }\end{array}$ \\
\hline
\end{tabular}




\begin{tabular}{|c|c|c|c|c|}
\hline County & Measure & Year & $\begin{array}{c}\text { Type of } \\
\text { Requirement }\end{array}$ & Text \\
\hline Orange & $\begin{array}{c}\text { Measure } \\
\text { M2 }\end{array}$ & 2006 & $\begin{array}{l}\text { Reporting/ } \\
\text { make CIP }\end{array}$ & $\begin{array}{l}\text { Local agencies must conform to annual eligibility } \\
\text { requirements in order to receive fair share } \\
\text { funding and participate in the CTFP funding } \\
\text { process. Key requirements include: Timely use of } \\
\text { funds (expend within three years of receipt); } \\
\text { MOE; Use of funding on transportation activities } \\
\text { consistent with Article XIX of State } \\
\text { Constitution; Include project in 7-year CIP; } \\
\text { Consistency with MPAH (Master Plan of } \\
\text { Arterial Highways), Pavement Management } \\
\text { Program, and Signal Synchronization Master } \\
\text { Plan }\end{array}$ \\
\hline Placer & $\begin{array}{c}\text { Measure } \\
\mathrm{M}\end{array}$ & 2016 & $\begin{array}{l}\text { Reporting/ } \\
\text { make CIP }\end{array}$ & $\begin{array}{l}\text { The County shall consult with each (Municipal } \\
\text { Advisory Council) at least once annually as part } \\
\text { of the development of the MAC's 5-Year CIP to } \\
\text { identify local priorities for resurfacing, pothole } \\
\text { repair, and other road maintenance and repair. }\end{array}$ \\
\hline Sacramento & $\begin{array}{c}\text { Measure } \\
\text { A1 }\end{array}$ & 1988 & $\begin{array}{l}\text { Reporting/ } \\
\text { make project } \\
\text { list }\end{array}$ & $\begin{array}{l}\text {... no allocation shall be made to a recipient } \\
\text { Entity for an expenditure that is not included } \\
\text { within that Entity's Entity Annual Expenditure } \\
\text { Plan; nor shall any allocation be made to the } \\
\text { County, District, a City or CTSA that has not } \\
\text { filed an Entity Annual Expenditure Plan in } \\
\text { compliance with regulations adopted by the } \\
\text { Authority; }\end{array}$ \\
\hline $\begin{array}{l}\text { San } \\
\text { Bernardino }\end{array}$ & $\begin{array}{c}\text { Measure } \\
\text { I2 }\end{array}$ & 2004 & Make CIP & $\begin{array}{l}\text { Local Street Project funds shall be disbursed to } \\
\text { local jurisdictions upon receipt of the annually } \\
\text { adopted Five Year Plan. The locally adopted Five } \\
\text { Year Plans shall be consistent with other local, } \\
\text { regional, and state transportation plans }\end{array}$ \\
\hline San Diego & $\begin{array}{c}\text { Measure } \\
\text { A }\end{array}$ & 2016 & $\begin{array}{l}\text { Transportation } \\
\text { authority } \\
\text { approval for } \\
\text { consistency } \\
\text { with measure. }\end{array}$ & $\begin{array}{l}\text { Each Local Agency and transit operator shall } \\
\text { biennially approve a 5-year project list and a } \\
\text { biennial program of projects (POP) it plans to } \\
\text { fund during the succeeding two fiscal years with } \\
\text { local return. The Commission shall review each } \\
\text { Local Agency's and Transit Operator's POP } \\
\text { submittal and make a finding of consistency with } \\
\text { the provisions of this Ordinance and with the } \\
\text { Regional Plan before approving the Local } \\
\text { Agency's POP for funding. All (local } \\
\text { infrastructure) projects (and priorities and } \\
\text { phasing in the plan) in local return ... must be } \\
\text { consistent with the Regional Plan. All } \\
\text { transportation projects in the POP must be } \\
\text { included in the RTIP. }\end{array}$ \\
\hline
\end{tabular}




\begin{tabular}{|c|c|c|c|c|}
\hline County & Measure & Year & $\begin{array}{c}\text { Type of } \\
\text { Requirement }\end{array}$ & Text \\
\hline $\begin{array}{l}\text { Santa } \\
\text { Barbara }\end{array}$ & $\begin{array}{c}\text { Measure } \\
\text { D }\end{array}$ & 2006 & $\begin{array}{l}\text { Public hearing } \\
\text { and approval } \\
\text { for consistency } \\
\text { with ordinance }\end{array}$ & $\begin{array}{l}\text { A public hearing shall be conducted by the local } \\
\text { jurisdiction regarding the proposed program of } \\
\text { projects before adopting and submitting the } \\
\text { project list to the Authority for approval. After a } \\
\text { noticed public hearing, the Authority shall adopt } \\
\text { the program of projects provided that it is } \\
\text { consistent with this ordinance and the } \\
\text { expenditure plan, and prior to releasing to the } \\
\text { local jurisdiction its share of local program } \\
\text { funding for the first fiscal year in the program of } \\
\text { projects. Expenditures may be made on projects } \\
\text { using local program funds only if they are } \\
\text { included in the Authority's most recently adopted } \\
\text { program of projects. }\end{array}$ \\
\hline $\begin{array}{l}\text { Santa } \\
\text { Barbara }\end{array}$ & $\begin{array}{c}\text { Measure } \\
\mathrm{A}\end{array}$ & 2008 & $\begin{array}{l}\text { Public hearing } \\
\text { and approval } \\
\text { for consistency } \\
\text { with ordinance }\end{array}$ & $\begin{array}{l}\text {... need a 5-year POP including information } \\
\text { about each of the projects to be funded with } \\
\text { Local Street and Transportation Improvement } \\
\text { Program revenues allocated according to the } \\
\text { Investment Plan. Local agencies shall submit } \\
\text { their POP to the Authority for approval. The } \\
\text { POP shall be in a format specified by the } \\
\text { Authority and shall include project location, } \\
\text { scope, schedule, cost[,] and funding sources. The } \\
\text { POP shall also include a detailed description of } \\
\text { local jurisdiction expenditures of local return } \\
\text { funds from the most recently completed fiscal } \\
\text { year, including expenditures on alternative mode } \\
\text { projects as defined in the Investment Plan ... } \\
\text { After a noticed public hearing, the Authority } \\
\text { shall adopt the POP submitted by each local } \\
\text { jurisdiction provided that it is consistent with this } \\
\text { ordinance and the attached Investment Plan, and } \\
\text { prior to releasing to the local jurisdiction its share } \\
\text { of local program funding for the first fiscal year in } \\
\text { the POP. }\end{array}$ \\
\hline Santa Cruz & $\begin{array}{c}\text { Measure } \\
\mathrm{J}\end{array}$ & 2004 & $\begin{array}{l}\text { Public hearing } \\
\text { and approval } \\
\text { for consistency } \\
\text { with ordinance }\end{array}$ & $\begin{array}{l}\text { (In order to be) eligible for these funds, each } \\
\text { agency will be required to adopt a } 5 \text {-Year CIP, } \\
\text { updated annually[,] and adopted following a } \\
\text { public hearing. }\end{array}$ \\
\hline
\end{tabular}




\section{Abbreviations and Acronyms}

\begin{tabular}{ll}
\hline ADA & Americans with Disabilities Act \\
CCTA & Contra Costa Transportation Authority \\
CIP & Capital Improvement Plan \\
COG & Council of Governments \\
FCTA & Fresno County Transportation Authority \\
ITOC & Independent Taxpayer Oversight Committee \\
LOST & Local Option Sales Tax \\
MOE & Maintenance of Effort \\
MPAH & Master Plan of Arterial Highways \\
MSHCP & Multi-Species Habitat Conservation Plan \\
PAPCO & Paratransit Coordinating Council \\
PCI & Pavement Condition Index \\
POP & Program of Projects \\
PUC & Public Utilities Code \\
RCTC & Riverside County Transportation Commission \\
RTMF & Regional Transportation Mitigation Fee \\
RTP & Regional Transportation Plan \\
RUCC & Rural-Urban Continuum Code \\
SANDAG & San Diego Association of Governments \\
SIP & Strategic Implementation Plan \\
TIP & Transportation Improvement Plan \\
TUMF & Transportation Uniform Mitigation Fee \\
ULL & Urban Limit Line \\
\hline
\end{tabular}




\section{Endnotes}

1 "Ballot Box Transportation Finance: November 2016-UCLA Institute of Transportation Studies," Jaimee Lederman and Madeline Brozen, updated August 20, 2019, http://www.its.ucla.edu/2016/11/03/ballot-box-transportation-finance-november-2016/.

2 American Fact Finder. U.S. Census Bureau, 2015. January 12, 2019. https://data.census.gov/cedsci/.

${ }^{3}$ Martin Wachs, "The Future of Transportation Finance: A New Generation of User Fees," The RAND Corporation (blog), May 14, 2010, https://www.rand.org/blog/2010/05/the-future-oftransportation-finance-a-new-generation.html.

${ }^{4}$ This figure is equivalent to $\$ 4.5$ billion in 2017 dollars and is likely higher because new measures have been enacted since 2010, although there is no reliable available figure on current LOST revenues in California.

5 "The Equity Challenges and Outcomes of California County Transportation Sales Taxes," Maxwell Albrecht, Anne Brown, Jaimee Lederman, Brian D. Taylor, and Martin Wachs, accessed July 4, 2019, http://www.its.ucla.edu/publication/equity-challenges-outcomes-california-countytransportation-sales-taxes/.

6 "Beyond the Gas Tax: Funding California Transportation in the 21st Century," F. Noel Perry, Colleen Kredell, Marcia E. Perry, and Stephanie Leonard, July 12, 2019, https://www.next10.org/sites/default/files/transportation-funding-brief-final.pdf.

7 “The California Fuel Tax Swap," Anne Brown, Mark Garett, and Martin Wachs, July 25, 2019, https://next10.org/sites/default/files/transportation-funding-brief-final.pdf.

${ }^{8}$ The California fuel tax swap refers to legislation passed in 2010 that traded the existing fuel sales tax for a variable excise tax with the express purpose of relieving the state's general fund from transportation debt financing.

${ }^{9}$ Robert Hannay and Martin Wachs, "Factors Influencing Support for Local Transportation Sales Tax Measures," Transportation 34 (2007): 17-35. https://doi.org/10.1007/s11116-006-0006-4.

${ }^{10}$ Henry B. R. Beale, Elbert R. Bishop, and William G. Marley, "How to Pass Local Option Taxes to Finance Transportation Projects," Transportation Research Record 1558 (1996): 74-82. https://doi.org/10.1177/0361198196155800111. 
${ }^{11}$ Amber E. Crabbe, Rachel Hiatt, Susan D. Poliwka, and Martin Wachs, "Local Transportation Sales Taxes: California's Experiment in Transportation Finance," Public Budgeting E Finance 25 (2005): 91-121. https://doi.org/10.1111/j.1540-5850.2005.00369.x.

12 Todd Goldman and Martin Wachs, "A Quiet Revolution in Transportation Finance: The Rise of Local Option Transportation Taxes,” Transportation Quarterly 57 (2003): 19-32.

${ }^{13}$ Ashad Hamideh, Jung Eun Oh, Samuel Labi, and Fred Mannering, "Public Acceptance of Local Government Transportation Sales Taxes: A Statistical Assessment," State and Local Government Review 40 (2008): 150-9. https://doi.org/10.1177/0160323X0804000302.

${ }^{14}$ Nico Calavita, "Growth Machines and Ballot Box Planning: The San Diego Case," Journal of Urban Affairs 14 (1992): 1-24. https://doi.org/10.1111/j.1467-9906.1992.tb00272.x.

${ }^{15}$ Kate Lowe, Rolf Pendall, Juliet Gainsborough, and Mai Thi Nguyen, "Ballot Box Planning: Rail Referenda Implementation," Journal of Public Transportation 17 (2014): 75-98. https://doi.org/10.5038/2375-0901.17.1.4.

${ }^{16}$ Jennifer Dill, Todd Goldman, and Martin Wachs, "California Vehicle License Fees: Incidence and Equity," Journal of Transportation and Statistics 2 (1999): 133-47.

17 "Why Campaigns for Local Transportation Funding Initiatives Succeed or Fail: An Analysis of Four Communities and National Data," Peter J. Haas, Kristen Sullivan Massey, Linda O. Valenty, and Richard Werbel, August 2, 2019, https://rosap.ntl.bts.gov/view/dot/5128.

18 Steven Callander and Davin Raiha, "Durable Policy, Political Accountability, and Active Waste," Quarterly Journal of Political Science 12 (2017): 59-97. https://doi.org/10.1561/100.00016120.

${ }^{19}$ Karel Martens and Peter van Weelden, "Decision-Making on Transport Infrastructure and Contested Information: A Critical Analysis of Three Approaches," European Planning Studies 22 (2014): 648-66. https://doi.org/10.1080/09654313.2013.783665.

${ }^{20}$ William Franko, Caroline J. Tolbert, and Christopher Witko, "Inequality, Self-Interest, and Public Support for 'Robin Hood' Tax Policies,” Political Research Quarterly 66 (2013): 923-37. https://doi.org/10.1177/1065912913485441.

${ }^{21}$ Andrew D. Green, Max Neiman, Shel Bockman, and Barbara Sirotnik, "Public Support for Transportation Sales Taxes in California: A Two County Assessment," California Journal of Politics and Policy 5 (2013): 645-70. https://doi.org/10.5070/P2X886. 
22 Vladimir Kogan, Stéphane Lavertu, and Zachary Peskowitz, "Performance Federalism and Local Democracy: Theory and Evidence from School Tax Referenda." American Journal of Political Science 20 (2015): 418-435. https://doi.org/10.1111/ajps.12184.

23 "Federalist No 57: The Alleged Tendency of the New Plan to Elevate the Few at the Expense of the Many Considered in Connection with Representation from the New York Packet," James Madison, July 3, 2019, https://avalon.law.yale.edu/18th_century/fed57.asp.

${ }^{24}$ Juita-Elena (Wie) Yusuf, Meagan M. Jordan, Aimee L. Franklin, and Carol Ebdon, "How Much are Citizen Perceptions of Fiscal Accountability Influenced by Government Transparency, Information Access, and Participation Opportunities?" Public Finance \& Management 17 (2017): 369-93.

${ }^{25}$ Craig M. Burnett and Vladmir Kogan, "The Politics of Potholes: Service Quality and Retrospective Voting in Local Elections.” Journal of Politics 79 (2016): 302-14. https://doi.org/10.1086/688736.

${ }^{26}$ Susan A. Macmanus. "'Bricks and Mortar" Politics: How Infrastructure Decisions Defeat Incumbents," Public Budgeting E Finance 24 (2004): 96-112. https://doi.org/10.1111/j.02751100.2004.02401005.x.

${ }^{27}$ Paul N. Thompson, "Are School Officials Held Accountable for Fiscal Stress? Evidence from School District Financial Intervention Systems," Economics of Education Review 72 (2019): 44-54. https://doi.org/10.1016/j.econedurev.2019.05.005.

${ }^{28}$ David S. Lee, Enrico Moretti, and Matthew J. Butler, "Do Voters Affect or Elect Policies? Evidence from the U. S. House," Quarterly Journal of Economics 119 (2004): 807-59. https://doi.org/10.1162/0033553041502153.

${ }^{29}$ Poul A. Nielsen and Donald P. Moynihan, "How Do Politicians Attribute Bureaucratic Responsibility for Performance? Negativity Bias and Interest Group Advocacy," Journal of Public Administration Research and Theory 27 (2017): 269-83. https://doi.org/10.1093/jopart/muw060.

${ }^{30}$ Michael W. Sances, "Ideology and Vote Choice in U.S. Mayoral Elections: Evidence from Facebook Surveys,” Political Behavior 40 (2018): 737-62. https://doi.org/10.1007/s11109-0179420-x.

${ }^{31}$ Whitney B. Afonso, "State LST Laws: A Comprehensive Analysis of the Laws Governing Local Sales Taxes,” Public Budgeting E Finance 37 (2017): 25-46. https://doi.org/10.1111/pbaf.12171. 
32 Xioahu Wang, "Assessing Administrative Accountability: Results from a National Survey," American Review of Public Administration 32 (2002): 350-70. https://doi.org/10.1177/0275074002032003005.

${ }^{33}$ Wayne Cameron, "Public Accountability: Effectiveness, Equity, Ethics," Australian Journal of Public Administration 63 (2004): 59-67. https://doi.org/10.1111/j.1467-8500.2004.00402.x.

${ }^{34}$ Maria Cucciniello, Gregory A. Porumbescu, and Stephan Grimmelikhuijsen, "25 Years of Transparency Research: Evidence and Future Directions," Public Administration Review 77 (2017): 32-44. https://doi.org/10.1111/puar.12685.

${ }^{35}$ Local return also includes funding distributed to the county for spending on transportation purposes in unincorporated areas.

36 "Highway Performance Monitoring System (HPMS) Data," Caltrans, February 16, 2019, https://dot.ca.gov/programs/research-innovation-system-information/highway-performancemonitoring-system.

${ }^{37}$ Stanislaus' 2016 Measure L includes a base allocation based on a guaranteed $1.25 \%$ of the tax, rather than a fixed quantity, and thus is not included in calculations of maximum and minimum base allocations.

${ }^{38}$ California 2017 Public Road Data: Statistical Information Derived from the Highway Performance Monitoring System.

39 "Master Plan of Arterial Highways (MPAH) Overview," Orange County Transportation Authority, November 20, 2018, https://www.octa.net/Projects-and-Programs/AllProjects/Streets-Projects/Master-Road-Plan/Overview/.

40 "Rural-Urban Continuum Codes," U.S. Department of Agriculture, February 28, 2019, https://www.ers.usda.gov/data-products/rural-urban-continuum-codes/.

${ }^{41}$ Jaimee Lederman, Anne Brown, Brian D. Taylor, and Martin Wachs, "Lessons Learned from 40 Years of Local Option Transportation Sales Taxes in California," Transportation Research Record, 2672(4), (2018): 13-22. https://doi.org/10.1177/0361198118782757.

${ }^{42}$ Tony Boren (Executive Director, Fresno County Council of Governments), interview by Jaimee Lederman, June 19, 2019. 
${ }^{43}$ Cities are also required to comply with any state and federal transportation regulations that apply to any local transportation spending from other sources. For example, projects funded by LOSTs must be included in regional transportation plans and general plans.

${ }^{44}$ Fred Kelly (Transportation Division Manager, city of Hayward), interview by Peter Haas, August 13, 2019.

45 "The cities and the county in the Western County Area must participate in the Multi Species Habitat Conservation Plan (MSHCP) by endorsing the Permit Allocation and executing the Implementation Agreement with the resources agencies in order to be eligible to receive local streets and roads funds."

46 “Orange General Plan: Growth Management," City of Orange, February 12, 2019, https://www.cityoforange.org/DocumentCenter/View/567/General-Plan---GrowthManagement-PDF.

${ }^{47}$ The Growth Management Plan includes the following passage: "To ensure that traffic impacts associated with new development are adequately addressed ... the City will ... ensure that new development pay for or implement its fair share of street improvement costs associated with development, including regional traffic mitigation. The City will not use any new revenues generated from Measure $\mathrm{M}$ to pay for improvements incurred by a private development project. The City will continue to collect transportation impact fees for improvements within its boundaries and will work with adjacent jurisdictions to ensure that an appropriate level of transportation impact fees is maintained within the GMAs."

48 Martin Engleman (Deputy Executive Director, Planning, Contra Costa Transportation Authority), interview by Peter Haas, June 18, 2019.

${ }^{49}$ Mike Leonardo (Executive Director, Fresno County Transportation Authority Deputy), interview by Jaimee Lederman, June 6, 2019.

${ }^{50}$ Scott Mozier (Public Works Director, city of Fresno), interview by Jaimee Lederman, July 17, 2019.

51 "Understanding PCI," Save California Streets, April 23, 2019, http://www.savecaliforniastreets.org/read-the-report/understanding-pci/.

52 "The PCI is a measurement of pavement grade or condition and ranges from 0 to 100 . A newly constructed road will have a PCI of 100, whereas a failed road will have a PCI of 25 or less. The pavement condition is primarily affected by the climate, traffic loads and volumes, construction 
materials, and age. The symptoms manifested by the pavement as it ages or fails are determined by the distress types that are present, such as fatigue or alligator cracking, rutting, etc."

53 "Standard Practice for Roads and Parking Lots Pavement Condition Index Surveys," ASTM International, April 25, 2019, https://www.astm.org/Standards/D6433.htm.

54 “Assembly Bill No. 1358," State of California, December 14, 2019, http://leginfo.legislature.ca.gov/faces/billNavClient.xhtml?bill_id=200720080AB1358.

55 “California Public Road Data," California Department of Transportation, April 14, 2019, https://dot.ca.gov/programs/research-innovation-system-information/highway-performancemonitoring-system.

56 “Prop 13 Sec. 4, PUC Section 180200,” State of California.

57 “1986 Measure B Expenditure Plan,” Alameda County Transportation Commission, November 3, 2018, https://www.alamedactc.org/wpcontent/uploads/2018/12/1986_MeasureB_Expenditure_Plan.pdf.

58 “California Public Utilities Code 180200,” State of California.

59 The other 13 measures included in this sample have ordinances that are silent on MOE, were put in place before the 1987 addition to the PUC, or do not have local return provisions.

60 “Section 142105(d), Division 15, California Public Utilities Code," State of California.

${ }^{61}$ Gail Payne (Senior Transportation Coordinator, city of Alameda), interview by Peter Haas, August 7, 2019.

62 Tess Lengyel (Alameda County Transportation Commission, Deputy Director), interview by Peter Haas, June 10, 2019.

${ }^{63}$ Measure B passed in this election with $57 \%$ of the vote and was the only Alameda ordinance passed with less than two-thirds approval of the voters.

64 "Measure B and Measure BB: Program Compliance Report," Alameda County Transportation Commission, July 2, 2019, https://www.alamedactc.org/wp-content/uploads/2019/06/FY1718_MB-BB_DLD_Compliance_Rpt_20190520.pdf?x33781. 
65 "Member Profile: Contra Costa Transportation Authority," California Association of Councils of Governments, July 10, 2019, https://www.calcog.org/index.php?src=directory\&view=members\&srctype=detail\&back=member s\&refno $=23$.

66 "CALCOG Website," California Association of Councils of Governments, August 12, 2019, https://www.calcog.org/index.php.

67 "Growth Management Program (GMP)," Contra Costa Transportation Authority, October 17, 2018, https://ccta.net/2018/10/17/growth-management-program-gmp/.

68 "A Transformative Plan for Contra Costa's Future: 2020 Transportation Expenditure Plan," Contra Costa Transportation Authority, November 20, 2019, https://ccta.net/wpcontent/uploads/2019/09/CCTA_TEP_Draft24_final_090419_lowres.pdf.

69 “Actions: Assessing Our Transportation Needs," Fresno Council of Governments, August 20, 2019, https://www.fresnocog.org/wp-content/uploads/2017/02/2018-RTP-Final-DraftChapter-4-Action-7_5_18.pdf.

70 "Public Utilities Code, Division 15 Section 142000, Fresno County Transportation Improvement Act 1986," State of California.

${ }^{71}$ Members of the Steering Committee represented the interests of: ADA and seniors, agriculture, building industry, business (chambers of commerce), cities of Clovis and Fresno, Coalition for Livable Communities, County of Fresno, eastside Fresno County cities, Environmental Justice Task Force, faith-based organizations, Fresno Area Residents for Rail Consolidation, Fresno Business Council, Fresno County Transportation Authority, labor, League of Women Voters of Fresno, medical, Sierra Club-Tehipite Chapter, Southwest Transportation Agency, Taxpayers Association, trails and education, trucking, and westside Fresno County cities.

72 “Continuing Measure C," Fresno Council of Governments, February 2, 2019, https://www.fresnocog.org/continuing-measure-c/.

73 “2006 Measure C Extension Expenditure Plan," Council of Fresno County Governments, February 2, 2019, http://measurec.com/wpcontent/uploads/2018/05/2006MeasureCExpenditurePlan.pdf.

${ }^{74}$ Other pass-through funding includes a portion of funding for the regional public transit program that is allocated to transit agencies (19.66\% of measure revenues) and funding for improvements to regional airports (1\% of measure revenues). 
${ }^{75}$ Specific Regional Transportation Program highlights and implementing guidelines are described in Appendix D of the measure expenditure plan.

76 “California Public Utilities Code Section 142257,” State of California.

77 "FCTA 2007 Administrative Code," Fresno County Transportation Authority, February 2, 2019, http://measurec.com/download/fcta-2007-administrative-code/.

${ }^{78}$ Expenditure plan Appendix C.

${ }^{79}$ Measure B passed in this election with $57 \%$ of the vote and was the only Alameda ordinance passed with less than two-thirds approval of the voters.

80 “Imperial County Website,” Imperial County, July 14, 2019, https:/www.co.imperial.ca.us/.

${ }^{81}$ Ordinance No. 88-1.

82 "Comprehensive Annual Financial Report," Riverside County Transportation Commission, February 10， 2019， https://www.rctc.org/wp-content/uploads/2018/12/RCTC_FY18CAFR.pdf.

83 "TransNet Ordinance and Expenditure Plan Rules," San Diego Association of Governments, February 20, 2019, https://www.sandag.org/uploads/projectid/projectid_341_15158.pdf.

${ }^{84}$ TransNet Extension, Ordinance and Expenditure Plan, Commission Ordinance 04-01. 


\section{Bibliography}

Afonso, Whitney B. "State LST Laws: A Comprehensive Analysis of the Laws Governing Local Sales Taxes.” Public Budgeting \& Finance 37 (2017): 25-46. https://doi.org/10.1111/pbaf.12171.

Alameda County Transportation Commission. “1986 Measure B Expenditure Plan.” November 3, $2018.2 \quad$ https://www.alamedactc.org/wpcontent/uploads/2018/12/1986_MeasureB_Expenditure_Plan.pdf.

Alameda County Transportation Commission. "Measure B and Measure BB: Program Compliance Report.” July 2, 2019. https://www.alamedactc.org/wpcontent/uploads/2019/06/FY17-18_MBBB_DLD_Compliance_Rpt_20190520.pdf?x33781.

Albrecht, Maxwell, Anne Brown, Jaimee Lederman, Brian D. Taylor, and Martin Wachs. "The Equity Challenges and Outcomes of California County Transportation Sales Taxes." July 4, 2019. http://www.its.ucla.edu/publication/equity-challenges-outcomes-californiacounty-transportation-sales-taxes/.

American Fact Finder. U.S. Census Bureau, 2015. January 12, 2019.

ASTM International. "Standard Practice for Roads and Parking Lots Pavement Condition Index Surveys.” April 25, 2019. https://www.astm.org/Standards/D6433.htm.

Beale, Henry B. R., Elbert R. Bishop, and William G. Marley. "How to Pass Local Option Taxes to Finance Transportation Projects." Transportation Research Record 1558 (1996): 74-82. https://doi.org/10.1177/0361198196155800111.

Burnett, Craig M., and Vladmir Kogan. "The Politics of Potholes: Service Quality and Retrospective Voting in Local Elections." Journal of Politics 79 (2016): 302-14. https://doi.org/10.1086/688736.

Calavita, Nico. "Growth Machines and Ballot Box Planning: The San Diego Case." Journal of Urban Affairs 14 (1992): 1-24. https://doi.org/10.1111/j.1467-9906.1992.tb00272.x.

California Association of Councils of Governments. "CALCOG Website." May 05, 2019. https://www.calcog.org/index.php. 
California Association of Councils of Governments. "Member Profile: Contra Costa Transportation Authority." July 2019. https://www.calcog.org/index.php?src=directory\&view=members\&srctype=detail\&back= members\&refno $=23$.

California Department of Transportation. "California Public Road Data.” April 14, 2019. https://dot.ca.gov/programs/research-innovation-system-information/highwayperformance-monitoring-system.

Callander, Steven, and Davin Raiha. "Durable Policy, Political Accountability, and Active Waste." Quarterly Journal of Political Science 12 (2017): 59-97. https://doi.org/10.1561/100.00016120.

Caltrans. "Highway Performance Monitoring System (HPMS) Data." February 16, 2019. https://dot.ca.gov/programs/research-innovation-system-information/highwayperformance-monitoring-system.

Cameron, Wayne. "Public Accountability: Effectiveness, Equity, Ethics." Australian Journal of Public Administration 63 (2004): 59-67. https://doi.org/10.1111/j.14678500.2004.00402.x.

City of Orange. “Orange General Plan: Growth Management.” February 12, 2019. https://www.cityoforange.org/DocumentCenter/View/567/General-Plan---GrowthManagement-PDF.

Contra Costa Transportation Authority. "A Transformative Plan for Contra Costa's Future: 2020 Transportation Expenditure Plan.” November 20, 2019. https://ccta.net/wpcontent/uploads/2019/09/CCTA_TEP_Draft24_final_090419_lowres.pdf.

Contra Costa Transportation Authority. "Growth Management Program (GMP)." October 17, 2018. https://ccta.net/2018/10/17/growth-management-program-gmp/.

Council of Fresno County Governments. "2006 Measure C Extension Expenditure Plan." February 2, 2019. http://measurec.com/wpcontent/uploads/2018/05/2006MeasureCExpenditurePlan.pdf.

Crabbe, Amber E., Rachel Hiatt, Susan D. Poliwka, and Martin Wachs. "Local Transportation Sales Taxes: California's Experiment in Transportation Finance." Public Budgeting \& Finance 25 (2005): 91-121. https://doi.org/10.1111/j.1540-5850.2005.00369.x. 
Cucciniello, Maria, Gregory A. Porumbescu, and Stephan Grimmelikhuijsen. "25 Years of Transparency Research: Evidence and Future Directions." Public Administration Review 77 (2017): 32-44. https://doi.org/10.1111/puar.12685.

Dill, Jennifer, Todd Goldman, and Martin Wachs. "California Vehicle License Fees: Incidence and Equity." Journal of Transportation and Statistics 2 (1999): 133-47.

Franko, William, Caroline J. Tolbert, and Christopher Witko. "Inequality, Self-Interest, and Public Support for 'Robin Hood' Tax Policies.” Political Research Quarterly 66 (2013): 92337. https://doi.org/10.1177/1065912913485441.

Fresno Council of Governments. "Actions: Assessing Our Transportation Needs.” August 20, 2019. https://www.fresnocog.org/wp-content/uploads/2017/02/2018-RTP-Final-DraftChapter-4-Action-7_5_18.pdf.

Fresno Council of Governments. "Continuing Measure C." February 2, 2019. https://www.fresnocog.org/continuing-measure-c/.

Fresno County Transportation Authority. "FCTA 2007 Administrative Code." February 2, 2019. http://measurec.com/download/fcta-2007-administrative-code/.

Goldman, Todd, and Martin Wachs. "A Quiet Revolution in Transportation Finance: The Rise of Local Option Transportation Taxes.” Transportation Quarterly 57 (2003): 19-32.

Green, Andrew D., Max Neiman, Shel Bockman, and Barbara Sirotnik. "Public Support for Transportation Sales Taxes in California: A Two County Assessment." California Journal of Politics and Policy 5 (2013): 645-70. https://doi.org/10.5070/P2X886.

Haas, Peter J., Kristen Sullivan Massey, Linda O. Valenty, and Richard Werbel. "Why Campaigns for Local Transportation Funding Initiatives Succeed or Fail: An Analysis of Four Communities and National Data." August 2, 2019. https://rosap.ntl.bts.gov/view/dot/5128.

Hamideh, Ashad, Jung Eun Oh, Samuel Labi, and Fred Mannering. "Public Acceptance of Local Government Transportation Sales Taxes: A Statistical Assessment." State and Local Government Review 40 (2008): 150-9. https://doi.org/10.1177/0160323X0804000302.

Hannay, Robert, and Martin Wachs. "Factors Influencing Support for Local Transportation Sales Tax Measures.” Transportation 34 (2007): 17-35. https://doi.org/10.1007/s11116-0060006-4. 
Imperial County. “Imperial County Website.” July 14, 2019. https://www.co.imperial.ca.us/.

Kogan, Lavertu, \& Peskowitz, "Performance Federalism and Local Democracy: Theory and Evidence from School Tax Referenda." American Journal of Political Science 20 (2015): 4184356 https://doi.org/10.1111/ajps.12184.

Lederman, Jaimee, and Madeline Brozen. "Ballot Box Transportation Finance: November 2016UCLA Institute of Transportation Studies.” August 20, 2019. http://www.its.ucla.edu/2016/11/03/ballot-box-transportation-finance-november-2016/.

Lederman, Jaimee, Anne Brown, Brian D. Taylor, and Martin Wachs. "Lessons Learned from 40 Years of Local Option Transportation Sales Taxes in California." Transportation Research Record 2672, no. 4 (December 2018): 13-22. https://doi.org/10.1177/0361198118782757.

Lee, David S., Enrico Moretti, and Matthew J. Butler. "Do Voters Affect or Elect Policies? Evidence from the U. S. House." Quarterly Journal of Economics 119 (2004): 807-59. https://doi.org/10.1162/0033553041502153.

Lowe, Kate, Rolf Pendall, Juliet Gainsborough, and Mai Thi Nguyen. "Ballot Box Planning: Rail Referenda Implementation.” Journal of Public Transportation 17 (2014): 75-98. https://doi.org/10.5038/2375-0901.17.1.4.

Macmanus, Susan A. "“Bricks and Mortar" Politics: How Infrastructure Decisions Defeat Incumbents.” Public Budgeting \& Finance 24 (2004): 96-112. https://doi.org/10.1111/j.0275-1100.2004.02401005.x.

Madison, James. "Federalist No 57: The Alleged Tendency of the New Plan to Elevate the Few at the Expense of the Many Considered in Connection with Representation from the New York Packet." July 3, 2019. https://avalon.law.yale.edu/18th_century/fed57.asp.

Martens, Karel, and Peter van Weelden. "Decision-Making on Transport Infrastructure and Contested Information: A Critical Analysis of Three Approaches." European Planning Studies 22 (2014): 648-66. https://doi.org/10.1080/09654313.2013.783665.

Nielsen, Poul A., and Donald P. Moynihan. "How Do Politicians Attribute Bureaucratic Responsibility for Performance? Negativity Bias and Interest Group Advocacy." Journal of Public Administration Research and Theory 27 (2017): 269-83. https://doi.org/10.1093/jopart/muw060. 
Orange County Transportation Authority. "Master Plan of Arterial Highways (MPAH) Overview.” November 20, 2018. https://www.octa.net/Projects-and-Programs/AllProjects/Streets-Projects/Master-Road-Plan/Overview/.

Perry, F. Noel, Colleen Kredell, Marcia E. Perry, and Stephanie Leonard. "Beyond the Gas Tax: Funding California Transportation in the 21st Century." July 12, 2019. https://www.next10.org/sites/default/files/transportation-funding-brief-final.pdf.

Riverside County Transportation Commission. "Comprehensive Annual Financial Report." February 10, 2019. https://www.rctc.org/wp-content/uploads/2018/12/RCTC_FY18CAFR.pdf.

San Diego Association of Governments. "TransNet Ordinance and Expenditure Plan Rules." February 20, 2019. https:/www.sandag.org/uploads/projectid/projectid_341_15158.pdf.

Sances, Michael W. "Ideology and Vote Choice in U.S. Mayoral Elections: Evidence from Facebook Surveys." Political Behavior 40 (2018): 737-62. https://doi.org/10.1007/s11109017-9420-x.

Save California Streets. "Understanding PCI." April 23, 2019. http://www.savecaliforniastreets.org/read-the-report/understanding-pci/.

State of California. “Assembly Bill No. 1358." December 14, 2019. http://leginfo.legislature.ca.gov/faces/billNavClient.xhtml?bill_id=200720080AB1358.

State of California. "Public Utilities Code, Division 15 Section 142000, Fresno County Transportation Improvement Act 1986.”

State of California. "California Public Utilities Code Section 142257."

State of California. "California Public Utilities Code 180200."

State of California. "Prop 13 Sec. 4, PUC Section 180200, California Public Utilities Code 180001(e),”

State of California. "Section 142105(d), Division 15, California Public Utilities Code.”

Thompson, Paul N. "Are School Officials Held Accountable for Fiscal Stress? Evidence from School District Financial Intervention Systems." Economics of Education Review 72 (2019): 44-54. https://doi.org/10.1016/j.econedurev.2019.05.005. 
U.S. Department of Agriculture. "Rural-Urban Continuum Codes." February 28, 2019. https://www.ers.usda.gov/data-products/rural-urban-continuum-codes/.

Wachs, Martin. "The Future of Transportation Finance: A New Generation of User Fees." The RAND Corporation (blog), May 14, 2010. https://www.rand.org/blog/2010/05/the-futureof-transportation-finance-a-new-generation.html.

Wachs, Martin, Mark Garett, and Anne Brown. “The California Fuel Tax Swap.” July 25, 2019. https://next10.org/sites/default/files/transportation-funding-brief-final.pdf.

Wang, Xiaohu. "Assessing Administrative Accountability: Results from a National Survey." American Review of Public Administration 32 (2002): 350-70. https://doi.org/10.1177/0275074002032003005.

Yusuf, Juita-Elena (Wie), Meagan M. Jordan, Aimee L. Franklin, and Carol Ebdon. "How Much are Citizen Perceptions of Fiscal Accountability Influenced by Government Transparency, Information Access, and Participation Opportunities?" Public Finance and Management 17 (2017): 369-93. 


\section{About the Authors}

\section{Jaimee Lederman, PhD}

Jaimee Lederman earned her $\mathrm{PhD}$ in Urban Planning at University of California, Los Angeles (UCLA), concentrating in transportation planning and policy. She most recently worked as a Senior Public Administration Analyst at the Institute of Transportation Studies at UCLA. Before coming to UCLA, she received a JD and a Master of Arts in Economics from NYU, and she is a member of the New York State and District of Columbia Bar Associations.

\section{Stephanie Kellogg, MURP}

Stephanie Kellogg completed her Master of Urban and Regional Planning at UCLA with a focus in regional economic development. Her interests involve land use policy and political economy.

\section{Peter J. Haas, PhD}

Peter J. Haas is Professor Emeritus at San José State University. He is the author of numerous articles and research monographs on transportation policy as well as the coauthor of the second edition of a text on policy research, Applied Policy Research: Concepts and Cases.

\section{Martin Wachs, PhD}

Martin Wachs is Distinguished Professor Emeritus of Civil \& Environmental Engineering and City \& Regional Planning at the University of California, Berkeley, where he directed the Institute of Transportation Studies and the University of California Transportation Center. He earlier spent 25 years at UCLA, where he was Chairman of the Department of Urban Planning for 11 years. After retiring from the university, Wachs became the Director of Transportation, Space, and Technology Program at the RAND Corporation. He now teaches and conducts research at UCLA in transportation policy.

\section{Asha Weinstein Agrawal, PhD}

Dr. Agrawal is the Director of the MTI National Transportation Finance Center and Professor of Urban and Regional Planning at San José State University. Her research and teaching interests in transportation policy and planning include transportation finance, bicycle and pedestrian planning, and travel survey methods. Agrawal also works in the area of transportation history. She has a BA from Harvard University in Folklore and Mythology, an MSc from the London School of Economics and Political Science in Urban and Regional Planning, and a $\mathrm{PhD}$ from the University of California, Berkeley, in City and Regional Planning. 


\section{Hon. Norman Y. Mineta}

\section{MTI BOARD OF TRUSTEES}

Founder, Honorable Norman

Mineta*

Secretary (ret.),

US Department of Transportation

Chair,

Abbas Mohaddes

President \& COO

Econolite Group Inc.

Vice Chair,

Will Kempton

Retired

Executive Director,

Karen Philbrick, PhD*

Mineta Transportation Institute San José State University

Winsome Bowen

Chief Regional Transportation

Strategy

Facebook

David Castagnetti

Co-Founder

Mehlman Castagnetti

Rosen \&Thomas

Maria Cino

Vice President

America \& U.S. Government

Relations Hewlett-Packard

Enterprise

\author{
Grace Crunican** \\ Owner \\ Crunican LLC
}

Donna DeMartino

Managing Director

Los Angeles-San Diego-San Luis

Obispo Rail Corridor Agency

\section{John Flaherty}

Senior Fellow

Silicon Valley American

Leadership Form

William Flynn *

President \& CEO

Amtrak

\section{Rose Guilbault}

Board Member

Peninsula Corridor

Joint Powers Board

Ian Jefferies*

President \& CEO

Association of American

Railroads
Diane Woodend Jones

Principal \& Chair of Board

Lea + Elliott, Inc.

David S. Kim*

Secretary

California State Transportation

Agency (CALSTA)

Therese McMillan

Executive Director Metropolitan

Transportation Commission

(MTC)

Jeff Morales

Managing Principal

InfraStrategies, LLC

Dan Moshavi, PhD*

Dean, Lucas College and Graduate

School of Business

San José State University

Toks Omishakin*

Director

California Department of

Transportation (Caltrans)
Takayoshi Oshima

Chairman \& CEO

Allied Telesis, Inc.

Paul Skoutelas*

President \& CEO

American Public Transportation

Association (APTA)

Beverley Swaim-Staley

President

Union Station Redevelopment

Corporation

Jim Tymon*

Executive Director

American Association of State

Highway and Transportation

Officials

(AASHTO)

$*$ = Ex-Officio

** = Past Chair, Board of Trustees

\section{Directors}

Karen Philbrick, PhD

Executive Director

Hilary Nixon, PhD

Deputy Executive Director

Asha Weinstein Agrawal, PhD

Education Director

National Transportation Finance

Center Director

\section{Brian Michael Jenkins}

National Transportation Security

Center Director

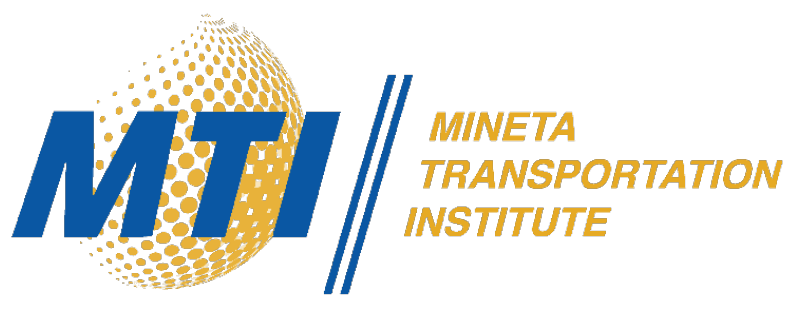

